\title{
The Effect of Allopurinol and Inosine Administration on Xanthine Oxidoreductase Gene Expression, Mitochondrial Respiration, and Inflammation in Broiler Chickens
}

Tabatha Settle

West Virginia University

Follow this and additional works at: https://researchrepository.wvu.edu/etd

\footnotetext{
Recommended Citation

Settle, Tabatha, "The Effect of Allopurinol and Inosine Administration on Xanthine Oxidoreductase Gene Expression, Mitochondrial Respiration, and Inflammation in Broiler Chickens" (2014). Graduate Theses, Dissertations, and Problem Reports. 516.

https://researchrepository.wvu.edu/etd/516

This Dissertation is protected by copyright and/or related rights. It has been brought to you by the The Research Repository @ WVU with permission from the rights-holder(s). You are free to use this Dissertation in any way that is permitted by the copyright and related rights legislation that applies to your use. For other uses you must obtain permission from the rights-holder(s) directly, unless additional rights are indicated by a Creative Commons license in the record and/ or on the work itself. This Dissertation has been accepted for inclusion in WVU Graduate Theses, Dissertations, and Problem Reports collection by an authorized administrator of The Research Repository @ WVU. For more information, please contact researchrepository@mail.wvu.edu.
} 


\title{
The Effect of Allopurinol and Inosine Administration on Xanthine Oxidoreductase Gene Expression, Mitochondrial Respiration, and Inflammation in Broiler Chickens.
}

\author{
Dissertation submitted to the \\ Davis College of Agriculture, Forestry, and Consumer Sciences \\ At West Virginia University \\ In partial fulfillment of the requirements for the degree of \\ Doctor of Philosophy \\ in \\ Animal and Food Science \\ Dr. Hillar Klandorf, PhD., Chair \\ Dr. Kenneth Blemings, Ph.D. \\ Dr. Janet Tou, Ph.D. \\ Dr. Knox VanDyke, Ph.D \\ Dr. Melissa Marra, Ph.D
}

Division of Animal and Nutritional Sciences

Morgantown, WV

2014

Keywords: oxidative stress, allopurinol, inosine, xanthine oxidoreductase, inflammation, mitochondrial respiration, uric acid

Copyright 2014 [Tabatha Settle] 


\section{ABSTRACT \\ The Effect of Allopurinol and Inosine Administration on Xanthine Oxidoreductase Gene Expression, Mitochondrial Respiration, and Inflammation in Broiler Chickens.}

\section{Tabatha Settle}

Birds have a remarkable longevity for their body size despite an increased body temperature, higher metabolic rate, and increased blood glucose concentrations. Theoretically, birds should sustain a much higher degree of oxidative damage yet do not, in part due to the powerful antioxidant, uric acid. As the end-product of purine degradation, uric acid is generated in the xanthine/hypoxanthine reactions catalyzed by xanthine oxiodreductase (XOR). In the first study, inosine, a purine precursor, was fed to 3 groups of 5 birds: Group 1 was fed 0 (control), Group 2, 0.6 mols inosine $/ \mathrm{kg}$ feed (INO) and Group 3, INO treatment plus $50 \mathrm{mg}$ allopurinol $/ \mathrm{kg}$ BM (INOAL). Allopurinol is a known inhibitor of XOR and thereby reduces uric acid (UA). INOAL birds showed lower total liver XOR activity $(\mathrm{p}=0.005)$ but kidney XOR activity was not affected. Both INO and INOAL birds had higher plasma and kidney UA concentrations than controls. Liver uric acid (LUA) was significantly reduced in INOAL birds when compared to other treatments. XOR gene expression was increased $(\mathrm{p}=0.007)$ in the liver tissue of INOAL birds when compared to CON and INO birds. However, there were no significant changes in XOR gene expression in the kidney tissue. To our knowledge, this is the first report of XOR gene expression measured under these conditions. The results suggest that regulation of UA production is tissue dependent. The results also indicate a compensatory effect of allopurinol on XOR gene expression which can be linked to a decrease in antioxidant protection from UA.

In the second study, Cobb $x$ Cobb broilers ( $n=12 ; 4$ weeks old) were separated into two treatments $(\mathrm{n}=6)$; control $(\mathrm{CON})$ and $\mathrm{AL}$ (allopurinol $35 \mathrm{mg} / \mathrm{kg} \mathrm{BW}$ ). The purpose of this study was to assess mitochondrial function in broiler chickens in response to potential oxidative stress generated from the administration of allopurinol. Mitochondria were freshly isolated from liver tissue and assessed for State III and State IV respiration using polarography. There was a significant reduction in State III respiration $(\mathrm{p}=0.01)$ and State IV respiration $(\mathrm{p}=0.007)$ in allopurinol-treated birds compared to the controls. The purpose of the third study was to assess the effect of allopurinol on gene expression of inflammatory cytokines IFN- $\gamma$, IL-1 $\beta$, IL-6 and IL-12p35 as well as iNOS and XOR in liver tissue. Cobb x Cobb broilers were separated into two groups at 4 weeks of age $(\mathrm{n}=10)$; control $(\mathrm{CON})$ and ALLO (allopurinol $35 \mathrm{mg} / \mathrm{kg} \mathrm{BW}$ ). After one week of allopurinol treatment, half of the birds in each group (CON 1 and ALLO 1) were euthanized with the remaining continued with allopurinol treatment for an additional week (CON 2 and ALLO 2). Results demonstrated a significant increase in gene expression of XOR, IFN- $\gamma$, IL-1 $\beta$, and IL-12p35 in ALLO 2 birds as compared to birds in CON 2. iNOS was numerically increased in ALLO 2 birds though this was not significant $(\mathrm{p}=0.076)$. Liver uric acid content was significantly decreased in both ALLO 1 $(\mathrm{p}=0.003)$ and ALLO $2(\mathrm{p}=0.012)$ birds when compared to CON1 and CON 2 respectively. No differences in body weight (BW) were measured from 0-7 days of age in any of the groups. However there was a significant decrease in BW of AL2 birds when compared to CON 2 birds at $10(\mathrm{p}=0.011)$ and 14 days $(\mathrm{p}=0.012)$ of treatment. The reduced uric acid concentration in the liver suggests that allopurinol treatment leads to a lowered antioxidant activity in this tissue which increases inflammation and oxidative stress and results in mitochondrial dysfunction. 


\section{DEDICATION}

This dissertation is dedicated to my future husband, Ryan Barber, for all of his love and support throughout my degree. I would also like to dedicate this work to my mother, Janice White for her love throughout this journey. Thank you and I love you both. Also, to my four-

legged companions, Darwin, Phoebe, and Kili who have provided furry therapy for the past four years even though they had no idea what I was talking about, only that I had food. 


\section{ACKNOWLEDGEMENTS}

I would like to thank Dr. Hillar Klandorf, my committee chair, for his guidance throughout my graduate career at WVU, his enthusiasm for research, and for giving me a chance to prove myself as a student. Thank you to my other committee members, Dr. VanDyke, Dr. Tou, Dr. Marra and Dr. Blemings for their help and willingness to answer questions and use of their laboratory facilities. I would also like to thank the faculty of the Davis College for all of their support and eagerness to take time to teach, specifically, Dr. Ma and Dr. Bowdridge for all of their help with PCR analysis. Finally, I would like to thank our lab technician, Elizabeth Falkenstein, for all of her work and help with the projects, our farm technicians, Fred Rowe and Rick Wood for their help with the birds and feed. Also, I would like to thank my fellow graduate students, Kaitlin Maditz and Crissa Cooey for all of their support and the occasional shoulder to lean on. 


\section{TABLE OF CONTENTS}

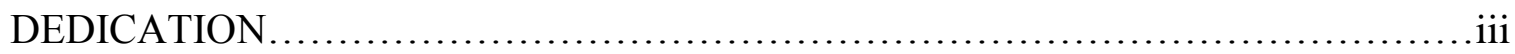

ACKNOWLEDGMENTS.....................................................iv

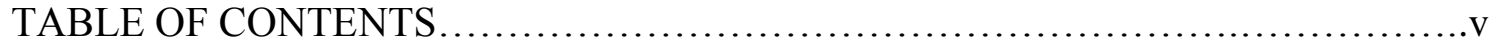

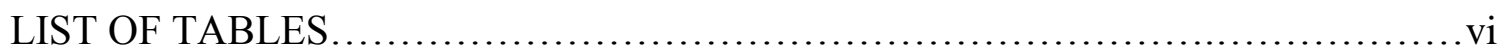

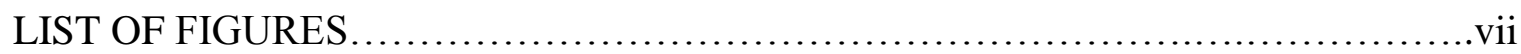

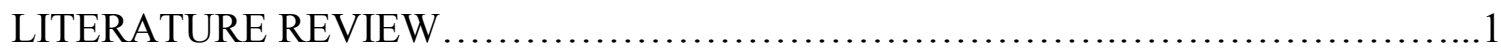

Reactive Oxygen Species.........................................................

Avian Mitochondria: Structure and ROS Production.................................

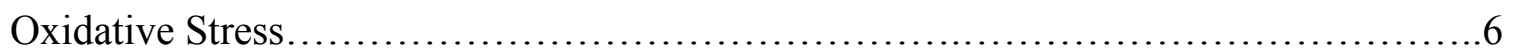

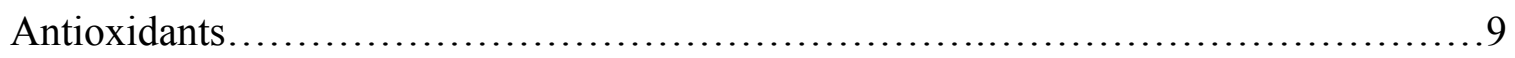

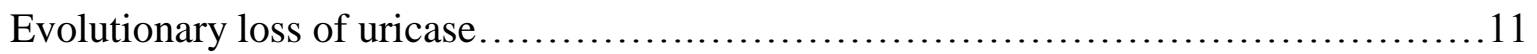

Xanthine Oxidoreductase........................................................

Uric acid in the antioxidant defense system.................................. 19

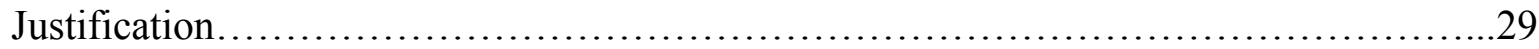

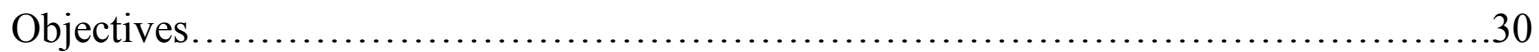

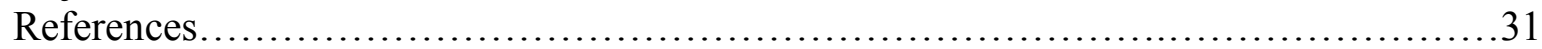

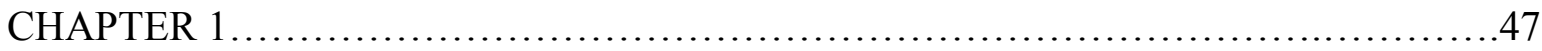

Abstract....................................................................... 48

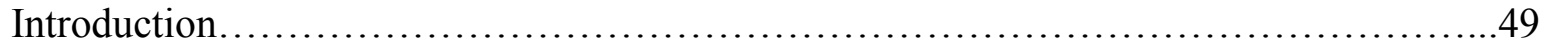

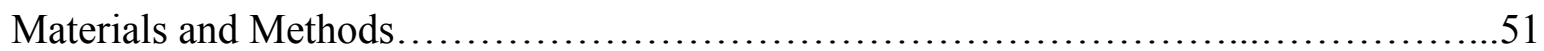

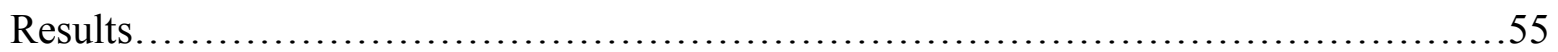

Discussion............................................................. 57

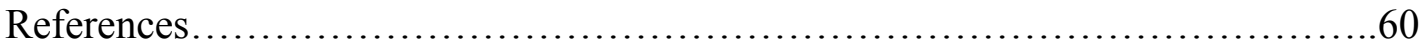

Tables and Figures....................................................... 64

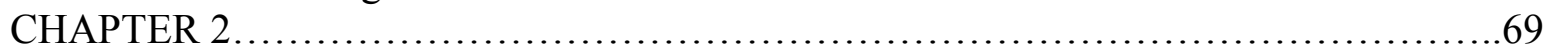

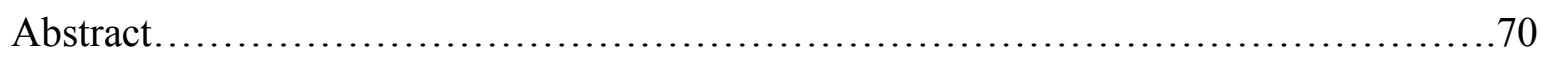

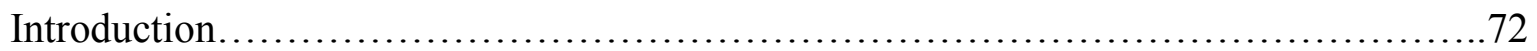

Materials and Methods...............................................................

Results and Discussion........................................................ 80

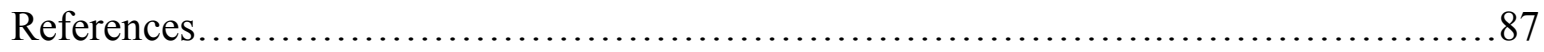

Tables and Figures................................................................ 90

Conclusions and Future Studies............................................. 104

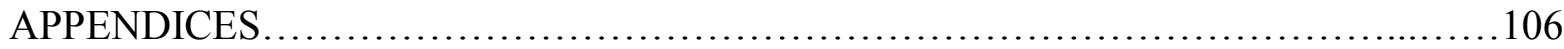

Appendix 1: Role of Uric acid as An Antioxidant..............................106

Appendix 2: Starter Diet Composition..................................... 92

Appendix 3: Grower Diet Composition...................................93 


\section{LIST OF TABLES}

CHAPTER ONE

Table 1. Body Mass and Plasma Uric Acid...........66

Table 2. Liver XOR and Liver Uric Acid.............67

Table 3. Kidney XOR and Kidney Uric Acid...........68

CHAPTER TWO

Table 1. Study 1A Body Weight, Relative Liver Weight, and Relative Heart Weight .....993

Table 2. Heart RCR, Liver RCR, and Cytsolic Uric Acid of Heart and Liver................94

Table 3. Primer Sets for Genes.....................................................95

Table 4. Study 2B Body Weight............................................... 96

Table 5. Relative Liver Weight and Liver Uric Acid................................97 


\section{LIST OF FIGURES}

Literature Review

Figure 1.Schematic of Mitochondrial ROS, Oxidative Stress, and Antioxdants..........45

Figure 2. Purine Degradation Pathway........................................46

Chapter One

Figure 1. XOR Gene Expression in the Liver.....................................64

Figure 2. XOR Gene Expression in the Kidney...................................65

\section{Chapter 2}

Figure 1. State 3 and State 4 Mitochondrial Respiration in Heart and Liver Tissue......91

Figure 2. IFN- $\gamma$ Gene Expression................................................ 98

Figure 3. IL-1 $\beta$ Gene Expression................................................... 99

Figure 4. IL-6 Gene Expression............................................. 100

Figure 5. IL-12p35 Gene Expression......................................... 101

Figure 6. iNOS Gene Expression.......................................... 102

Figure 7. XOR Gene Expression............................................ 103 


\section{Literature Review}

\section{Reactive Oxygen Species}

Reactive oxygen species (ROS) are molecules and free radicals derived from molecular oxygen. Oxygen is required for the generation of all ROS and reactive nitrogen species (RNS) as well as reactive chlorine species (Fang et.al., 2002). Ground state oxygen, also referred to as the triplet state, is considered to be a bi-radical, meaning that it contains two unpaired electrons in the outer shell. The two electrons exhibit the same spin which enables the oxygen molecule to react with one electron at a time. In a chemical bond, oxygen is not particularly reactive with the two electrons. However, if one of the unpaired electrons becomes excited it can alter its spin pattern which results in a singlet oxygen species. The singlet oxygen can react with other pairs of electrons, especially those involved in double bonds, and can become a powerful oxidant (Halliwell and Gutteridge, 1999).

The most commonly known ROS produced in biological systems are the hydroxyl $(\cdot \mathrm{OH})$ radicals, the superoxide radicals $\left(\mathrm{O}_{2}^{-} \cdot\right)$, nitric oxide $(\mathrm{NO} \cdot)$, peroxynitrite $\left(\mathrm{ONOO}^{-}\right)$, and hydrogen peroxide $\left(\mathrm{H}_{2} \mathrm{O}_{2}\right)$. Free radicals and other ROS are constantly formed in the body and have been implicated in pathogenic states and oxidative stress (Aruoma, 1998). Of these ROS, superoxide and hydrogen peroxide radicals are of the most importance in reduction-oxidation reactions as well as substrates in the formation of other ROS, particularly the highly toxic hydroxyl radical (Halliwell and Gutteridge, 1999).

Hydroxyl radicals are considered to be amongst one of the more toxic ROS. This is due to evidence that $\mathrm{OH} \cdot$ attacks all proteins, DNA, PUFA in cell membranes, and a variety of other molecules (Aruoma, 1998). Hydroxyl radicals can be generated by Fenton chemistry 
$\left(\mathrm{Fe}^{2+}+\mathrm{H}_{2} \mathrm{O}_{2} \rightarrow \mathrm{Fe}^{3+}+{ }^{-} \mathrm{OH}+{ }^{-} \mathrm{OH}\right)$, which are catalyzed by transition metals. Fenton reaction generation of $\mathrm{OH} \cdot$ radicals is known to occur in submitochondrial particles under oxidative stress (Thomas et.al., 2009) as well as during a number of toxicological states (Hara et.al., 2009). Exposure to radiation can cause homolytic fission of water molecules, resulting in the production of hydroxyl radicals as well (Halliwell and Gutteridge, 1999). Reduction-oxidation reactions with superoxide, hydrogen peroxide, and hypochlorous acid also generate hydroxyl radicals in vivo (Rosen et.al., 1995).

Superoxide radicals are normally generated in the body via respiratory burst during phagocytosis in immunological defense and from the leakage of electrons from the mitochondrial electron transport chain. Superoxide is an oxygen-centered radical and can have selective reactivity to a variety of tissue types, proteins, DNA, etc. (Aruoma, 1998). In addition to superoxide radicals, hydrogen peroxide can be produced during mitochondrial respiration and during the xanthine/hypoxanthine reaction during purine degradation (Terada et.al., 1990). $\mathrm{H}_{2} \mathrm{O}_{2}$ can also be formed when superoxide is dismutated (a reaction involving a single substance that produces two products), by the enzyme, superoxide dismutase and is comparatively weakly reactive (Aruoma, 1998). However, $\mathrm{H}_{2} \mathrm{O}_{2}$ can act as a substrate for hydroxyl radical production as well as generation of other ROS.

Accumulated damage by ROS contributes to many pathogenic states as well as nonpathogenic states and is due to the highly unstable nature of the ROS. Strand breakage, base modification, and DNA-protein crosslinks can be linked to ROS mediated damage (Halliwell and Gutteridge, 1999). Accumulation of damage by ROS can result in a condition known as oxidative stress. 
Mitochondria are responsible for the leakage of high energy electrons via the electron transport chain in a normal metabolic state. Complex III is the principal site for production of ROS as the ROS products are directed away from the matrix antioxidants; whereas, ROS products in complex I are released in proximity to antioxidants (Chen et al., 2003). Complex II and complex IV are also implicated in ROS production, specifically concerning the superoxide anion and has been reviewed extensively by Turrens (2003).

\section{Avian Mitochondria: Structure and ROS production}

\section{Structure of Avian Mitochondria}

The mitochondrion has been described as the "powerhouse" of the cell. This is due to the electron transport chain that results in the release of energy and the proton pumps that result in energy conservation through oxidative phosphorylation. The mithochondria is composed of an outer membrane, the inner membrane, cristae, and matrix. The inner membrane is folded into cristae, which markedly increases the surface area. It is within the inner membrane that the enzyme complexes for electron transport and oxidative phosphorylation reside as well as other transfer systems and various dehydrogenase enzymes. The matrix contains enzymes for fatty acid oxidation, urea synthesis, prophoryin synthesis, and the tricarboxylic acid cycle (TCA) in addition to other processes. The mitochondrial DNA (mtDNA), ribosomes, and the proteins necessary for transcription of mtDNA and translation of mRNA are also found within the matrix. These basic structures and functions are found throughout the animal kingdom for those animals relying on oxygen as the final electron acceptor.

Birds, while sharing the same basic mitochondrial structure with mammalian and reptilian species, also exhibit some unique differences. Slautterback (1965) first noted a 
difference in avian mitochondrial structure. In this study, mitochondria were isolated from the cardiac cells of canaries, sparrows, zebra finches, quail, and geese. The birds were selected on the basis of heart rate. For example, canaries, sparrows, and zebra finches have a very fast heart rate whereas the quail and goose have an intermediate and slower heart rate, respectively (Slautterback, 1965). Surprisingly, mitochondria from the canary cardiac tissue showed two unique structures of cristae, referred to as zigzag and the others as retriform. These names were assigned to each structure based in the appearance of the cristae patterns. Quail cardiac mitochondria also demonstrated numerous and tightly packed interleaved cristae with a much greater length than width. Also present in the quail were whorl patterns of cristae, such that no region of the mitochondria was devoid of a cristal membrane. The goose model, with the lower heart rate, demonstrated fewer and less complex cristae. Because the other bird species did not demonstrate these structures it was concluded that there was a poor correlation between heart rate and the complexity or size of cardiac mithochondria in birds. However, the findings of unique mitochondrial morphologies between the species created a foundation for further research into various tissues with an emphasis on skeletal muscles used for flight.

Research into flight muscles of hummingbirds indicated that the mitochondrial structure may differ from other vertebrates. Hummingbirds are unique in that the respiration rates of muscle in a flying hummingbird range from $7-10 \mathrm{~mL}$ of $\mathrm{O}_{2}$ per $\mathrm{cm}^{3}$ of mitochondria per minute which is nearly twice the capacity of mammals that are moving at a maximum aerobic capacity (Suarez et al., 1991). This is achieved by double packing of mitochondrial cristae (Suarez et al., 1997). It is also remarkable that mitochondria occupy at least $35 \%$ of the fiber volume in hummingbird flight muscles whereas if they were similar to mammals, they would need approximately $70 \%$ mitochondrial content, which would not be sufficient to provide lift due to 
lack of force-generating myofibrils (Rome and Lindstedt, 1998). These structural differences in avian mitochondria give rise to a greater ability to more efficiently utilize oxygen.

\section{Avian Mitochondrial ROS Production}

Given that birds have double-packed cristae and therefore mitochondrial respiration may differ, it is of interest to determine how this affects ROS production (Figure 1). Surprisingly, birds have a lower mitochondrial ROS production rate. Hydrogen peroxide production was lower in brain tissue mitochondria of pigeons than in rats (Barja et al., 1994). Further evidence in the brain nonsynaptic mitochondria of pigeons indicated that ROS production was less in complex I when compared to ROS production in the same tissue of rats (Barja and Herrero, 1998). Further studies with brain mitochondrial complex I in budgerigar and canaries showed similar results with lowered ROS production (Pamplona et al., 2005). Mitochondrial hydrogen peroxide release rate was also lower in the brain, heart, and kidney of pigeons as compared to rats (Barja, 1998).

Recently, Brown et al. (2009) proposed a mechanism responsible for the reduction of ROS production in birds. Mitochondria from the livers of House sparrows (Passer domesticus), the big brown bat (Eptesicus fuscus), and mice (Mus musculus) were isolated for analysis of mitochondrial respiration rates, proton leak kinetics, and hydrogen peroxide release. Basal hydrogen peroxide rates were two-fold higher in the sparrows compared to the mice and that inhibition of the electron transport chain with rotenone and antimycin A increased ROS production rate by 20-27 fold in sparrows (Brown et al., 2009). These results seem to be consistent with the hypothesis of "spare oxidative capacity" put forth by Lane (2005) which predicts that higher substrate oxidation capacity downstream of ROS production sites, relative to upstream capacity, would reduce electron transport chain reduction state, and in doing so, ROS 
release rate. It can thus be concluded that there are distinct mechanisms by which ROS release from the mitochondria is controlled and that these mechanisms are species specific.

\section{Oxidative stress}

The ground state of oxygen is essential to all aerobic organisms. However, oxygen reliance can lead to toxicity and imbalance in the body's physiological processes. Oxidative stress is one such instance in which this toxicity occurs.

Oxidative stress is defined as the imbalance between the oxidants (ROS) in the body and the antioxidants such that the imbalance favors the oxidants (VanDyke, 2002). The ROS imbalance can be caused, in general, by diminished antioxidant concentration and by increased production of ROS (Halliwell and Gutteridge, 1999). This can be caused by endogenous sources such as the leak of electrons from the mitochondria (Cadenas and Davies, 2000) and exogenous sources such as carbon monoxide (Hara et al., 2009), radiation, and other environmental factors. Oxidative stress has a large role in cell and DNA damage, aging, and plays a part in many disease states.

Oxidative stress has been implicated as one of the major contributing factors damage to DNA. DNA damage and repair mechanisms occur in vivo at a continuous rate (Aruoma, 1998). Hydroxyl and superoxide radicals are implicated in the mechanism behind DNA damage. Single strand-breaks of DNA can be inhibited by antioxidant defense systems such as uric acid (Cohen et al., 1984).

Oxidative stress has also been implicated in various disease states such as ischemia and reperfusion, diabetes, and neurodegenerative disease. Ischemia reperfusion occurs during cardiovascular events or damage to the brain in which the tissue is deprived of oxygen (Halliwell 
and Gutteridge, 1999). Also, associated with these events is an increase in ROS in addition to an increase in xanthine oxidase activity is increased which leads to release of superoxide radicals from the reaction with xanthine (Harrison, 2002). It has also been reported that peroxynitrite has a role in CNS inflammation (Hooper et al., 2000) and in multiple sclerosis (Hooper et.al., 1998).

Oxidative stress can contribute to inflammation. Oxidative stress can activate a variety of transcription factors including NF-kB, PPAR $\gamma$, and AP-1 (Reuter et al., 2010). In turn, activation of these transcription factors can lead to the expression of genes coding for inflammatory cytokines and chemokines among other regulatory molecules. ROS are involved in a broad spectrum of diseases associated with chronic inflammation and some cancer mechanisms (Reuter et al., 2010). When the inflammatory response is initiated, mast cells and leukocytes are recruited to the damaged area which leads to "respiratory burst" due to an increase in oxygen uptake and results in an accumulation of ROS (Coussens and Werb, 2002). These inflammatory cells also produce soluble mediators, such as metabolites of arachidonic acid, cytokines (IL-1, IL-6, IL-12, etc.), chemokines (IL-8, CXC's, etc.), which signal for further recruitment of inflammatory cells to a site, thereby increasing ROS production. Induction of these chemokines and cytokines as well as nitric oxide synthase (NOS), the enzyme family responsible for the conversion of Larginine and NADPH to nitric oxide (NO) and L-citrulline, have been reported to have a role in oxidative stress induced inflammation (Hussain and Harris, 2007). Furthermore, inducible nitric oxide synthase (iNOS) is regulated by NF- $\kappa B$ in inflammatory responses (Guzik et al., 2003) and calmodulin (Alderton, et al., 2001). Inflammation, and increase in oxidative stress, and a decrease in NO production has been linked to pulmonary hypertension syndrome in broiler chickens (Chapmen and Wideman, 2006). Additionally, dysfunction of cardiac and lung mitochondria have been linked with inflammation and and a posible underlying factor in 
pulmonary hypertension syndrome in broilers, resulting in an increase in ROS production (Tang et al., 2002; Cawthon et al., 2000; Iqbal et al., 2000).

Lastly, oxidative stress is a factor in the aging process. Over time, oxidative damage has an effect on glycoxidation of proteins, lipids, and DNA. These markers can accumulate over time and have an impact on aging (Martin et.al., 1996). To cope with oxidative stress, the organism typically up-regulates the antioxidant defense systems.

Birds are considered a long-lived species. Given what is known about the decreased endogenous natural ROS production and the indication that there are lowered states of oxidative damage, the correlation between these factors and aging needs to be determined. Based on the Free Radical Theory of Aging, it is stated that senescence is a result of the accumulation of free radical induced oxidative damage over time (Beckman and Ames, 1998). In response, birds have developed an evolutionary means of coping with free radical production by a reduction in mitochondrial ROS production (despite having double-packed cristae) as well as an efficient antioxidant defense system.

Consequently, birds have a lower production of ROS from the mitochondrial electron transport chain and a decrease in oxidative damage. However, there remains the issue of heightened metabolism, elevated plasma glucose, and increased body temperature that are associated with oxidative damage sustained over time. It is essential that a long-lived species have an efficient antioxidant defense system. Birds, like humans, have a high concentration of uric acid circulating in the blood plasma. It has been hypothesized that, with the evolutionary loss of uricase, the enzyme responsible for the conversion of uric acid to allantoin, birds have become equipped with a very potent antioxidant defense. 


\section{Antioxidants}

Organisms balance their redox status by mediation of ROS production by antioxidants. An antioxidant is, broadly, an agent that catalytically removes free radicals and actively scavenges ROS and reactive nitrogen species (RNS) (Halliwell and Gutteridge, 1999). Antioxidants tend to work at low concentrations and are readily oxidized by ROS thereby decreasing the rate at which the ROS can react with the surrounding cells and tissues. It has also been suggested that individual low molecular weight antioxidants participate in a coordinated network with other antioxidants that scavenge radicals (Kagan and Packer, 1994).

Antioxidants and nutrition form an intimate relationship. Exogenous sources of antioxidants can be obtained from the diet. These can include, but are not limited to, Vitamin E (tocopherols), ascorbic acid (Vitamin C), carotenoids and flavenoids.

Vitamin E ( $\alpha$-tocopherol) is a potent membrane-bound, lipid soluble antioxidant that is known to react in a direct manner with singlet oxygen (Machlin and Bendich, 1987). Vitamin E is also known as a scavenger of peroxyl radicals. It is thought that $\alpha$-tocopherol has the most potent antioxidant capabilities as compared to other tocopherols due to the fact that the $\mathrm{H}$ donating ability of different tocols increases in efficiency with greater ring methyl substitution (Traber and Atkinson, 2007). During a deficiency state, it has been reported that low vitamin E status resulted in the depletion of other antioxidants such as ascorbate (Shevdova et.al., 2007). It was also reported that mice with single-walled carbon nanotubes inserted showed induced accumulation of lipid peroxidase products and a more severe oxidative stress state due to deficiency in vitamin $\mathrm{E}$ (Shevdova et. al., 2007). Vitamin $\mathrm{E}$ is decidedly an important antioxidant along with vitamin $\mathrm{C}$. 
Vitamin C (ascorbic acid or ascorbate) is also an exogenous antioxidant that can be obtained from the diet. Vitamin C is known to be an important water-soluble cytosolic antioxidant involved with regeneration of tocopherol from tocopheroxy radicals (Machlin and Bendich, 1987). With the information concerning the regeneration of tocopherol from the tocopheroxy radical, it has been reported that there is a synergistic relationship between vitamin C and vitamin E (Niki, 1991). Vitamin C scavenges superoxide radicals as well as other singlet oxygen species (Machlin and Bendich, 1987).

In addition to dietary antioxidants, endogenous antioxidants also play a vital role in regulating ROS production and can be either enzymatic or non-enzymatic. One of the most well known of these is the enzyme, superoxide dismutase (SOD). SOD is found in the cytosol (CuZn SOD) of cells as well as in the mitochondrial matrix (manganese-SOD) (Turrens, 2003). As SOD scavenges superoxide, it prevents the production of other ROS. In addition to enzymatic endogenous antioxidants, the body also has non-enzymatic antioxidant defense systems. For example, natural estrogen is an antioxidant that is thought to posess 2.5 times greater potency than vitamin E and vitamin C (Ruiz-Larrea et.al., 2000). The antioxidant capability of natural estrogen is reported to be dependent on the hydrophilic or lipophilic nature of the radical species, as well as the catechol or phenol structure of the estrogen (Ruiz-Larrea, 2000). Estrogen is reported to have a role in neuroprotection (Behl et.al., 1997; Moosmann and Behl, 1999) as well as exerting a protective effect in cardiovascular disease (Mendelsohn and Karas, 1999; Dantas et.al., 2002) and modulating enzyme expression of superoxide dismutase (Strehlow et.al., 2003). Additionally, it has been shown that extracellular SOD mRNA was stabilized by estrogen as well as expression and activity of both MnSOD and extracellular SOD was stimulated (Strehlow 
et.al., 2003). In addition to estrogen, uric acid also plays a significant role in the antioxidant defense system of humans, birds, reptiles, and other mammals.

\section{The Evolutionary Loss of Uricase: Implications for Avian Longevity}

Uric acid is the end-product of purine metabolism in humans, reptiles, new world primates, and birds. Unlike most mammals, these species lack uricase or urate oxidase (Uox) which catalyzes the oxidation of uric acid to allantoin. Analysis of the promoter, coding, exonic and intronic regions of human and several primate species determined that the hominoid lineage had eight independent nonsense mutations that resulted in the deactivation of the Uox gene (Oda et al., 2002). Of the eight mutations, six are caused by a change from $\mathrm{C}$ to $\mathrm{T}$ in an arginine codon (CGA). After examination of the prevalence of the arginine codon in the primate species, it was suggested that the increasing occurance of the CGA codon is highly correlated with the loss of urate oxidase (Oda et al., 2002). The authors concluded that this loss was a stepwise event and not a single step over evolutionary time (Oda et al., 2002). Currently, the DNA database does not have a Uox sequence for birds or reptiles and further analysis will be needed to discover the evolutionary loss of Uox in these species. The loss of this enzyme by long-lived species is considered to be linked to the antioxidant properties of uric acid. It is also hypothesized that coevolution occurred between the downregulation of XOR and the increase in uric acid concentrations in species lacking urate oxidase (Oda et al., 2002). The transcription and core promoter activity of human XOR is repressed (Xu et al., 2000), suggesting that there is a regulatory mechanism to prevent the overproduction of uric acid in purine metabolism. It should be determined if such a relationship exists in species other than humans that lack the same Uox activity and whether this is, in fact, a coevolutionary event that can be linked to antioxidant 
defense involving uric acid. A review of the loss of uricase and clinical implications in human pathology has been written by Alvarez-Lario and Macarron-Vicente (2010).

\section{Xanthine Oxidoreductase : The Formation of Uric Acid}

\section{XOR Chemistry and Structure}

The enzyme xanthine oxidoreducatse (XOR) catalyzes the terminal reactions in purine degradation to uric acid (Figure 2). Specifically, XOR catalyzes the formation of uric acid from hypoxanthine and xanthine. This enzyme has been known for over 100 years and studied in detail for approximately 60 years (Harrison, 2002). XOR is a complex and highly conserved molybdoflavoenzyme, most notably found in bovine milk where it forms a major component of the milk fat globule membrane (Harrison, 2002). XOR exists in two interconvertible forms: XD (xanthine dehydrogenase) and XO (xanthine oxidase). XO (EC 1.17.3.2) catalyzes reactions (1) and (2), while XD (EC 1.17.1.4) catalyzes reaction (3) (Terada et al., 1990).

(1) xanthine $+2 \mathrm{O}_{2}+\mathrm{H}_{2} \mathrm{O} \leftrightarrow$ uric acid $+2 \mathrm{O}_{2}{ }^{-}+2 \mathrm{H}^{+}$

(2) xanthine $+\mathrm{O}_{2}+\mathrm{H}_{2} \mathrm{O} \leftrightarrow \quad$ uric acid $+\mathrm{H}_{2} \mathrm{O}_{2}$

(3) $x$ anthine $+\mathrm{NAD}^{+}+\mathrm{H}_{2} \mathrm{O} \leftrightarrow \quad$ uric acid $+\mathrm{NADH}+\mathrm{H}^{+}$

$\mathrm{XOR}$ is a homodimer containing catalytically independent subunits with an approximate molecular mass of 300kDa and containing one molybdenum co-factor (Mo-Co), an FAD group, and two iron-sulfur centers. The protein structure of $\mathrm{XO}$ is comparatively large, having a molecular weight of 275,000 g/mol (Hart et al, 1970) while the protein structure of XD has a molecular weight of 300,000 g/mol (Lyon and Garret, 1978). 
The oxidative hydroxylation of xanthine to uric acid occurs at the molybdenum center (Hille and Nishino, 1995). XO and XD differ in that XD can reduce both molecular oxygen and $\mathrm{NAD}^{+}$but has a greater affinity for the latter, while $\mathrm{XO}$ reacts only with molecular oxygen. Both forms catalyze the reaction which converts hypoxanthine to xanthine and then the further conversion of xanthine to uric acid. A complete understanding of the XOR reaction with xanthine remains uncertain in some aspects. However, there are common features found among them. For example, XOR reaction with xanthine occurs as both a reduction and oxidation reaction (Xia et al., 1999)

The reductive half reaction occurs at the Mo-Co center. XOR accepts two electrons from xanthine which reduces the Mo (VI) to Mo (IV). At the xanthine C8 position, hydrogen is transferred to a sulphido ligand of molybdenum which results in the $\mathrm{M}=\mathrm{S}$ bond becoming an $\mathrm{M}$ SH bond. Simultaneously, there is a nucleophilic attack by a hydroxyl group at C8 which results in the formation of uric acid. The hydroxyl is ultimately derived from water, but it is uncertain if it reacts independently or as a Mo ligand (Murray et al., 1966).

The oxidative half reaction takes place at the FAD portion of the XOR molecule. The intramolecular electron transfer between the Mo-Co and FAD is mediated by the $\mathrm{Fe}_{2}-\mathrm{S}_{2}$ centers (Hille and Anderson, 1991). The $\mathrm{Fe}_{2}-\mathrm{S}_{2}$ centers serve as an electron reservoir to maintain the MoCo as Mo (VI) and flavin as $\mathrm{FADH}_{2}$ for the reaction catalysis (Olson et al., 1974). Electrons are transferred from $\mathrm{FAD}$ to $\mathrm{NAD}^{+}$or $\mathrm{O}_{2}$. In the reoxidation of fully reduced $\mathrm{XO}$, the first two steps involve the transfer of two electrons to $\mathrm{O}_{2}$, which generate hydrogen peroxide (Berry and Hare, 2004; Hille and Massey, 1981). XO transfers its remaining electrons in separate steps which results in the independent reduction of $\mathrm{O}_{2}$ from which superoxides are formed (Berry and Hare, 2004). The overall oxidation reaction of XO yields two superoxide radicals and two peroxides. 
In comparison to $\mathrm{XO}, \mathrm{XD}$ may produce more superoxide radicals in reaction per mole of $\mathrm{O}_{2}$. This occurs as a result of the greater thermodynamic stability of FAD, which is more reactive with oxygen in the $\mathrm{XD}$ form. While $\mathrm{XD}$ may produce more superoxide radicals, $\mathrm{XD}$ reacts more slowly with oxygen: the maximal rate of superoxide production is $25 \%$ less than that of $\mathrm{XO}$ (Saito and Nishino, 1989). This may also be due to the greater affinity of $\mathrm{NAD}^{+}$binding with XD, making $\mathrm{O}_{2}$ a poor competitor (Harris and Massy, 1997). The mechanism of electron transfer from $\mathrm{XD}$ to $\mathrm{NAD}^{+}$is not as well understood as that of oxygen, but it is suggested that $\mathrm{XD}$ cycles between a two and a four electron-reduced states (Harris and Massey, 1997). NAD ${ }^{+}$binds to XD in the reduction of the four electron state and subsequently transfers two electrons to produce NADH (Harris and Massey, 1997). Detailed reviews of this mechanism have been published by Harris (2002) and Hille and Nishino (1995).

XOR has been implicated in various pathological states due to the increased production of ROS (superoxide, hydroxyl, and hydrogen peroxide). The production of these ROS is thought to result in increased oxidative stress within the organism, which increases the instance of disease particularly if the endogenous antioxidant protection is somehow compromised. In the case of XOR, the enzyme is thought to play a role in tissue structural damage and interference of cell signaling (Berry and Hare, 2004).

The gene structure of XOR has been determined in several species including humans, mice, chickens, and insects. The gene loci that code for human and mouse XOR have been elucidated and the associated genes have been assigned to chromosomes 2p22 and 17 (Harrison, 2002; Cazzaniga et al., 1994). Drosophila genes tend to be more compact with only four or five exons (Terao et al.,1997). In mammals the exon-intron structure is highly conserved and contains $>60 \mathrm{~kb}$ and approximately 36 exons (Xu et al.,1996). Mammalian and avian cDNA 
sequences have also been reported. Avians, specifically chickens, have a sequence that corresponds to 1358 amino acids whereas mammalian enzymes have a range from 1330-1335 with 90\% homology (Harrison, 2002). The Mo-Co binding site is the most conserved of the amino acid sequences and has a $94 \%$ homology between human, rat, and mouse XOR (Xu et al.,1995).

Mutations in the XOR gene in humans, more specifically concerning the XD form, have been linked to inheritable xanthinuria. Classic xanthinuria is categorized into two different types: type I xanthinuria is characterized by the lack of XD activity whereas type II is characterized by the lack of both XD and aldehyde oxidase. Several mutations have been found to be responsible for the type I condition (Sakamoto et al., 2001). The mutations associated with type II have been located on the gene for human molybdenum cofactor sulphurase, which is required for XOR activity (Ichida et al., 2001). The majority of patients with xanthinuria present as asymptomatic, while others present with renal failure, xanthine calculi, and excretion of xanthine in the urine.

XOR activity can be inhibited by allopurinol (1,5 dihydro-4-hydroxypyrazolo ( 3,4-d ) pyrimidin-4-one) and oxypurinol (Figure 2). Allopurinol is the structural analog of hypoxanthine, meaning that it is chemically similar; however it has different biochemical properties. More specifically, it interferes with purine catabolism by inhibiting XOR. Allopurinol is rapidly oxidized by XOR in vivo to the active metabolite, oxypurinol (Pacher et al., 2006). Both allopurinol and oxypurinol are isosteres (have the same number of valence electrons) of hypoxanthine and xanthine respectively (Pacher et al., 2006). Allopurinol binds to Mo (VI) and is oxidized while oxypurinol binds to Mo (IV) and is reduced. The reduced XOR-oxypurinol complex rearranges into a tightly bound inhibitory complex (Galbusera et al., 2006). Oxypurinol is a noncompetitive inhibitor of XOR while allopurinol can act as a competitive inhibitor at low 
concentrations and noncompetitive at high concentrations (Pacher et al., 2006). Allopurinol can be administered either orally or by intravenous injection (Pea, 2005). Evidence suggests that allopurinol has a half- life of $2-3 \mathrm{~h}$ and reaches peak plasma concentrations $30-60$ min following oral dosage. Oral bioavailability of allopurinol is suggested to be 67-90\% (Pea, 2005).

Oxypurinol has a lower oral bioavailability than allopurinol with a half life of $14-30 \mathrm{~h}$ which is thought to be due to a reduced renal absorption resulting in peak plasma concentration occurring in 3-5h (Pea, 2005).

\section{Mammalian XOR Tissue Distribution}

XOR activity has been detected in a number of mammalian species as well as bacteria and plants. XOR activity in mammalian species has been found to be highest in the liver and intestine (Harrison, 2002; Parks and Granger, 1986). There is also evidence of enzyme activity in the heart, pancreas, brain, kidney and blood plasma. In reptiles, XOR activity has been reported in the kidney tissue of Dhubb lizards (Al-Seeni, 2009). Histochemical studies have given rise to evidence that the enzyme is present in the endothelial cells of bovine capillary and mammary glands (Jarasch et al., 1981), primarily in the cytosol of these cells. These locations were confirmed in humans (Jarasch et al., 1984). XOR activity in both forms has also been located in epithelia of a variety of rat tissues. Moriwaki and colleagues (1998) measured XOR activity in rat tissues using an immunohistochemical technique developed by Kooij et al. (1991). The findings of this study (Moriwaki et al., 1998) showed comparatively increased enzyme activity in the small intestine and moderate activity in the surface epithelium of the tongue, esophagus, stomach, bronchioles, alveoli, renal tubules, and large intestine. Activity was also moderate to strong in the liver, particularly in the cytoplasm of the hepatic and sinusoidal cells and more marked in the pericentral zone of these cells. A biochemical study by Devenyi et al. (1987) found 
XOR activity, in the XD form, in the pancreatic tissue of control mice as well as XO activity in the pancreatic homogenate, which was contributed to the reversible conversion of XD to XO.

Along with tissue distribution, the subcellular localization of XOR is not yet fully understood in mammalian models. Some studies have suggested that the XOR is found predominately in the cytosol of endothelial cells of bovine tissue and rat hepatocytes (Jarasch et al., 1984; Ischikawa et al.,1992). Other studies have suggested various locations for both forms of XOR, including the peroxisomes of rat hepatocytes (Angermuller et al., 1987), on the cell membrane surface and the cytosol of human endothelial and epithelial cells (Rouquette et al.,1998), and in the pericentral zone of the cytoplasm in hepatic rat cells (Moriwaki et al., 1998). Research to determine the tissue distribution and the location of XOR within the cell environment is thus still needed.

Evidence for an antibody specific to XOR has been discovered in the blood of humans and other mammals. A study by Chen et al. (1996) found that XOR was virtually absent from the plasma of sheep and cattle, but was present in the plasma of buffalo. A study by Benboubetra and colleagues (1997) concluded that there were both IgG and IgM antibodies specific to XOR. A previous study by Bruder et al., (1984) concluded that IgG antibodies were present in rabbit, guinea pig, goat, bovine, mouse, and human sera; however, there is no known immune memory generated over multiple exposure to XOR or immunological tolerance to this protein (Bruder et al, 1984), suggesting that there is no immunity to circulating XOR.

\section{Avian XOR Tissue Distribution}

Similar to mammals, avian XOR is predominately found in the XD form with low, but detectable levels of XO activity. XOR has been studied extensively in the XD form in chickens 
and turkeys. XOR, in the XD form was first described as being non-autoxidizable in birds, which would differ from mammalian XO (Westerfeld and Richert, 1951). Subsequent studies have focused on a variety of variables that could affect XOR activity in birds including nutrition trials with variable protein content, starvation and re-feeding, and embryonic development.

Results from nutrition trials showed that as protein content increases in the diet, XOR activity also increases. Westerfeld et al. (1962) reported that soy and casein diets fed to chicks and poults increased XD activity in liver tissue in a relatively linear relationship with protein content with no significant difference between the sources of protein. Scholz and Featherston (1967) reported that an increase in isolated soybean protein in the diet (25 or $75 \%)$ increased XD activity in the liver of 21-day old chicks and also resulted in an increased enzyme activity after a 24 hour starvation period.

In addition to nutritional studies, XOR activity has also been measured in birds administered allopurinol (Fhaolain and Coughlan, 1978) or inosine (Della-Corte and Stirpe, 1967). Turkey liver samples incubated with allopurinol resulted in progressive loss of XD activity until less than $1 \%$ remained after three minutes (Fhaolain and Coughlan, 1978). Recently, Carro et al, (2009b) found that XOR activity in the liver tissue of broilers administered allopurinol (50 mg/kg body mass) was significantly increased and concluded that this could be a compensatory mechanism to maintain normal uric acid concentrations in the body. Feeding a mixture of allopurinol and inosine (a purine precursor) to chickens for 6 days, caused a significant decrease in liver XOR activity and uric acid concentrations in the liver tissue, indicating that the allopurinol was inhibiting XOR activity regardless of the presence of inosine which is converted into uric acid (Settle et al, 2012). 
XOR activity has also been measured during the development of the embryo and immediately after hatching. It was noted that XD increases significantly in the liver for at least eight days prior to hatching and after hatch (Strittmatter, 1965). Additionally, chick embryos showed detectable amounts of XD at approximately 10 days of development (Strittmatter, 1965). Embryonic leg and breast muscle tissue showed detectable XOR activity at 10 days of development, which peaked in breast muscle at hatch (Garcia-Palmer et al., 1985).

Remy et al. (1951) and Nishino et al. (1989) also reported that XOR was present in chicken liver and kidney tissue although XO was a minor component of the total XOR activity. However, the majority of the earlier studies did not specifically measure XO activity. Recently, Carro et al. (2009a) reported that detectable XO activity was found in the liver, pancreas, kidney, intestine, and breast muscle in 7 and 10-week old broilers while no activity was found either in the plasma or in the heart, brain, or lung tissues. XD activity was predominant in all tissues, but XD was much lower in the breast muscle, brain, heart, and lungs than in the rest of the analyzed tissues (Carro et al, 2009a).

\section{Uric Acid in the Antioxidant Defense System}

Organisms balance their redox status by inactivation of ROS by antioxidants. An antioxidant is, broadly, an agent that catalytically scavenges ROS and reactive RNS (Halliwell and Gutteridge, 1999). Antioxidants tend to work at low concentrations and are readily oxidized by ROS thereby limiting the ability of ROS to react with the surrounding cells and tissues.

Uric acid is known to scavenge singlet oxygen, peroxy radicals, and hydroxyl radicals (Ames et al., 1981). Uric acid interacts with iron ion complexes, in that it exhibits that ability to bind these complexes which could signify additional antioxidant capabilities (Davies et 
al., 1986). Uric acid also has a role in protecting DNA from single-strand breaks caused by free radicals in the body (Cohen et al., 1984) as well as a protective role in neurodegenerative diseases. Uric acid administration improves mitochondrial respiratory activity and function in the livers of ob/ob mice with nonalcoholic steatohepatitis (Garcia Ruiz et al., 2006). Uric acid, as a scavenger of peroxynitrite, has been shown to exhibit protective properties in the inhibition of CNS inflammation and the blood-CNS barrier that has been compromised by peroxynitrite damage (Hooper et al., 2000). In addition to this, uric acid administered as treatment for encephalomyelitis showed a significant reduction in the symptoms and increased survivability in a mouse model (Hooper et al., 1998). In contrast, uric acid has been associated as a complication of cardiovascular disease and is well known as a complication of gout when excretion is impaired (Skinner et al., 1998). As stated by Fang et al (2013) uric acid can act as a stimulator of glutamate transporters in astroglia whereby it protects neurons from glutamate-induced toxicity and exerts protection of the spinal cord in addition to scavenging free radicals.

The brain and central nervous system are exposed to oxidative damage by free radical processes throughout life. It is hypothesized that this assault by ROS on these tissues can greatly contribute to the pathogenesis of certain disease states and exacerbates injury sites. Understanding the antioxidant defense system is critical in identifying markers of disease as well as potential therapeutic treatments. As discussed previously, uric acid can act as a very potent antioxidant. Uric acid has been associated with neuroprotective capabilities in cases of ischemic stroke and hypoxia injuries as well as neurodegenerative disorders.

Hypoxia and ischemic stroke are both conditions during which tissue is deprived of oxygen for a certain amount of time before reperfusion. During this time, cell death and apoptosis are occurring and free radical damage has been linked to many complications after reperfusion of the 
tissue. This has been reviewed extensively by Erecinska and Silver (2001). The role of uric acid in ischemic events is not fully understood. Studies in hippocampal cell culture have found that uric acid protects against metabolic insults and attenuates oxidative damage (Fang et al, 1998). It has also been reported that rats exposed to ischemia and reperfusion during and following treatment with uric acid show reduced injury to the brain as well as amelioration of behavioral and cognitive deficits often associated with these injuries (Fang at al., 1998). Furthermore, the use of uric acid in conjunction with a recombinant tissue plasminogen activator (rt-PA) prevented the early fall of UA associated with a loss of neural protection (Amaro et al., 2007). In addition to ischemic injury, there is evidence supporting the hypothesis of neuroprotective properties of uric acid in neurodegenerative diseases such as Parkinson's and Alzheimer's.

Parkinson's Disease (PD) is a neurodegenerative disease that may in fact be correlated with uric acid concentrations. PD is characterized by degeneration of the pigmented dopaminergic neurons in the substantia nigra pars of the mid brain. Patients will present with bradykinesia, resting tremors, and congnitive impairment among other symptoms. The specific underlying cause of this cell death is not fully understood. It is hypothesized that oxidative stress and mitochondrial dysfunction may play a role in the pathogenesis of PD and this has been reviewed extensively by Hald and Lotharius (2005). The role of uric acid has not been fully elucidated, but evidence suggests that decreased serum uric acid has been linked with PD.

In a population study by Lonneke et al. (2005), 4,695 participants screened for PD and patients with parkisonian or dementia markers at baseline were excluded. There was a correlation between higher serum uric acid concentrations and a reduced incidence of PD over a course of 9.4 years (Lonneke et al., 2005). Additionally, case studies by Davis et al. (1998) and Weisskopf et al (2007) showed similar evidence that higher serum levels of UA are associated with a 
decrease in the development of PD. Cognitive impairment is also associated with PD. In a study by Annanmaki et al. (2007) there was a correlation found between congnitive ability with 40 PD patients with poor cognitive exams associated with reduced plasma uric acid levels. Based on these findings, it has been suggested that uric acid be considered for therapeutic use in patients with PD however, more research is needed in this area to ascertain the dose of UA and how this will ultimately affect overall physiological response with respect to risks associated with increasing uric acid concentrations.

Alzheimer's disease (AD) is also characterized by a loss of cognitive function and neuronal degeneration in patients. $\mathrm{AD}$ is ultimately considered a neuropsychiatric disorder and the etiology of the disease remains largely unknown. Oxidative stress induced damage by enhanced lipid peroxidation in areas of the brain has been implicated as an underlying factor in the progression of the disease (Lovell et al., 1995). Free radical damage may also be a factor in $\beta$-amyloid plaque formation associated with AD (Pappolla et al., 1998). There is an increase of antioxidants such as catalase and SOD in the hippocampus and amygdala during $\mathrm{AD}$ (Zemlan et al., 1989 and Pappella et al., 1992). Similar to PD, uric acid has been shown to be decreased in patients with AD (Hensley et al., 1998 and Kim et al, 2006). Research has suggested that combining uric acid precursors such as inosine with ascorbic acid may have therapeutic affects for AD patients, but dose and duration of treatment have not been determined (Waugh, 2008).

Uric acid is the dominant antioxidant defense system for birds and can be linked to their ability to cope with heightened metabolic ROS production and conditions throughout their lives. The concentration of uric acid in broiler plasma ranges from 0.2 to $0.8 \mathrm{mM}$ (Simoyi et al., 2002). 
A study by Stinefelt et al. (2005) demonstrated the free radical scavenging abilities of uric acid, in doses equal to and exceeding the range found in birds, using electron spin resonance. It was found that uric acid had a concentration-dependent effect on reduction of hydroxyl and superoxide radicals such that increasing the concentration of uric acid will cause an increased scavenging of these radicals (Stinefelt et al, 2005). Further evidence from this study showed a decrease in DNA fragmentation and lipid peroxidation (Stinefelt et al., 2005). These results support the argument that uric acid acts as a scavenger of free radicals and can be considered vital to antioxidant defense.

In addition, there are several studies with chickens that demonstrate a negative correlation between uric acid concentrations and oxidative stress (Carro et al., 2009b; Simoyi et al., 2002). Broilers fed a high protein diet consisting of $45 \%$ casein had a significant increase in plasma uric acid concentrations which was also associated with a decrease in oxidative stress in the fast growing birds suggesting that the protein levels were not detrimental to bird health (Machin et al., 2004). When broilers were fed diets supplemented with either xanthine or hypoxanthine, plasma uric acid was markedly increased as compared to controls and this was associated with a decrease in oxidative stress (Simoyi et al., 2002). On the contrary, birds fed allopurinol (40 or $50 \mathrm{mg} / \mathrm{kg}$ body mass) showed decreased plasma uric acid concentrations associated with a significant increase in oxidative stress at both doses (Simoyi et al., 2002). A similar study with inosine ( $0.6 \mathrm{mols} / \mathrm{kg}$ feed/day) administered to broilers treated with hemin (a prooxidant) showed that inosine elevated plasma uric acid concentrations and reduced hemininduced oxidative stress (Seaman et al., 2008). When a mixture of inosine and allopurinol was fed to broilers, after 3 days, there was a marked decrease in plasma uric acid as compared with 
broilers receving only inosine, which suggests that tissues may be susceptible to oxidative damage (Settle et al, 2012).

Uric acid has also been studied in wild bird populations. Recently, Cohen et al. (2007) measured total antioxidant capacity, uric acid concentrations, and oxidative stress in 92 species of birds. The results from this study indicated that as the birds were held in captivity, oxidative stress increases over time while uric acid concentrations in the blood decreased (Cohen et al., 2007). It was concluded that antioxidant activity decreased over time in response to the stress and was either being consumed or shunted from the bloodstream (Cohen et al., 2007). Conclusions from this study support the inverse relationship between uric acid concentrations and oxidative stress are valid and comparative across species.

Uric acid is suggested to be the most important factor in the amelioration of oxidative burden in birds. Numerous studies have shown a correlation between the increase in plasma uric acid concentrations and the reduction in oxidative stress. In view of the observation, further research is critical for understanding the regulation of uric acid concentrations in health and disease with the view to reduce oxidative burden.

\section{Avian Renal Transport of Uric Acid}

In birds, uric acid is packaged in protein vesicles in the kidney before secretion (Braun and Dantzler, 1997) and the insoluble uric acid crystals excreted along with fecal material from the cloaca (Skinner et al., 2001). Uric acid is secreted from the avian renal proximal tubule epithelium. A micropuncture study with European starlings (Sturnus vulgaris) determined the net flow and transport of urate by the nephron (Laverty and Dantzler, 1983). Net urate secretion has been measured in chicken (Shannon, 1983) and ducks (Stewart et al., 1969) with a measured 
fractional secretion range of 6-16 percent. A fractional secretion rate of 4.72 on average was determined for starlings. This suggests that urate transport may be species specific and that birds have an exceptionally active transport of uric acid across the nephron and glomerulous. A more recent study by Dudas et al. (2005) in chicken renal proximal epithelium cell culture showed a

secretion of $\left(\mathrm{C}^{14}\right)$ urate under control conditions in an Ussing Chamber to be at a ratio of 3:1 in a unidirectional flow. OAT 1, OAT3, MRP4, and MRP2, known transporters of human urate, were identified in the basolateral membrane and the brush border membrane of the renal tissue (Dudas et al., 2005). Further study of MRP4 in chick kidney tissues revealed that the transporter was present in the brush border membrane and that it is required for active urate secretion from the proximal tube epithelium (Bataille et al., 2008).

\section{Uric acid and Inflammation}

Beyond a role in antioxidant defense mechanisms, uric acid has been negatively associated with the inflammatory response in which can lead to a greater incidence of gout and vascular disease pathogenesis. Uric acid has often been thought to exacerbate vascular disease mechanisms under conditions of hyperuricemia. This has been reviewed in detail by Jin et al. (2012). In a study by Martinon et al. (2006) it was noted that monosodium urate may induce the activation of Nucleotide-Binding Oligmerization Domain-like receptor protein 3 (NLRP3) inflammasome which contains proinflammatory capsase- 1 which is the mechanism that is responsible for upregulation of IL-1 $\beta$ and IL-18 inflammatory cytokines (Martinon et al., 2006).

\section{Avian Gout}


While uric acid is a major antioxidant defense for birds, it is also implicated in disease. Birds can suffer from hyperuricemia, a state during which uric acid precipitates in tissues of affected animals. Gout can be caused by several factors such as renal disorders, oversupplementation of protein in the diet, and other causes (Lumeij et al., 1998). Avian gout exists in two forms: articular and visceral. Articular gout occurs when the crystals settle within the joints, comparative to human gout, and is considered to be a chronic condition over time. This causes damage to the joint and thereby difficulty in movement and ultimately can lead to death due to inability to obtain food. Visceral gout is the more acute form in which the crystallized uric acid precipitates into the viscera causing extensive tissue damage that leads to organ failure and eventual death.

Susceptibility to articular gout was identified in a specific strain of New Hampshire chickens with inherited muscular dystrophy when fed a high protein diet (80\%) at 1-2 weeks of age, respectively (Peterson et al., 1971). There were no signs of gout in control birds. Visceral gout was not detected in any of the birds. Of note, XD activity in the liver was significantly increased in gout-susceptible birds as well, which was to be expected as it is one of two forms of the XOR enzyme responsible for uric acid production (Peterson et al., 1971). Another study found that there was a sex-linked heritability to uricemia and gout development in a dwarf white leghorn strain (Cole et al., 1969).

Austic and Cole (1972) determined that the development of articular gout was associated with impaired renal clearance, as there was a decrease in renal tubular uric acid secretion by approximately $40 \%$ in birds with a predisposition to hyperuricemia and gout. Further studies confirmed the mechanism of a defect in renal tubular secretion of uric acid using dwarf white leghorn chickens that were selected for a high incidence of hyperuricaemia and articular gout 
versus birds of the same strain that were not gouty (Zmuda and Quebbemann, 1975). Birds demonstrating a $64 \%$ reduction in tubular excretion ratio developed articular gout (Zmuda and Quebbemann, 1975). Furthermore, the site of this defect was identified in the peritubular membrane.

A study by Guo et al. (2005) confirmed that excess dietary protein and calcium contributes to hyperuricaemia and development of visceral gout and kidney damage in growing laying hens. Additional studies have shown that in cases of hypervitaminosis D, or vitamin D toxicity, visceral gout can occur in macaw chicks (Takeshita et al., 1986). Vitamin D toxicity results in abnormally high calcium blood concentrations and this can be linked to gout conditions (Guo et al., 2005). Hypovitaminosis A can also be linked to gout conditions in birds. Crocodile hatchlings approximately 10 months of age exposed to low vitamin A and high protein in the diet presented hyperuricaemia and severe visceral gout which led to an increase in mortality (Ariel et al., 1997). Comparative studies in birds have yielded similar results.

Lastly, wild bird populations have also been effected by articular and visceral gout due to dietary intake. The Oriental white-backed vulture population has been in serious decline $(<95 \%)$ since the 1990's and has been recently placed on the critically endangered species list (Oaks et al., 2004). A contributing factor to the mortality of the vultures is the consumption of diclofenac, a common antibiotic used in livestock. In a study using contaminated carcass meat, researchers observed a high incidence of visceral gout in the vultures due to adverse effects by the drug on renal function by the drug (Oaks et al., 2004).

Treatments for avian gout include monitoring of dietary calcium, protein, and vitamin supplements. Allopurinol has also been used in cases of hyperuricaemia in Red-tailed Hawks 
(Buteo jamaicensis). However, there is an increase and accumulation of xanthine, a precursor to uric acid, and this has been observed to precipitate in a manner similar to uric acid in the renal tubules, which can lead to nephropathy and possible renal failure (Ling et al., 1991). A study conducted by Lumeij and Redig (1992) found that allpurinol was toxic to red-tailed hawks at doses of 50 and $100 \mathrm{mg} / \mathrm{kg}$ body mass and exacerbated hyperuriceamia in the birds. Allopurinol was observed to cause vomiting and other toxic side effects (Lumeij et al., 1998) A follow-up to this study used a $25 \mathrm{mg} / \mathrm{kg}$ dose of allopurinol and determined that the dose was safe, but there were no changes in plasma uric acid, xanthine, hypoxanthine, allopurinol, and oxypurinol, making this a questionable treatment (Poffers et al., 2002).

Based on the research, several conclusions can be drawn. A healthy bird does not normally contract either form of gout. Under conditions that cause renal tubular secretion of uric acid to decline, there is an increase in the incidence of gout. High doses of allopurinol are likely to increase oxidative stress in treated birds, which increases mortality and therefore alternative treatments to gout should be explored. Studies in humans have suggested that the role of uric acid is not fully elucidated and further research in this area is required to understand the balance of antioxidant protection and disease pathogenesis. 


\section{JUSTIFICATION}

This research will investigate how xanthine oxidoreductase activity and gene expression affects uric acid production in a number of tissues. In birds, uric acid provides a potent antioxidant defense system. However, upregulation of xanthine oxidase can lead to increased production of reactive oxygen species. Decreasing uric acid production by administration of allopurinol has been shown to also increase oxidative stress. The metabolite of allopurinol, oxypurinol, is also known to inhibit the activity of xanthine oxidase. Conversely, administration of inosine has been shown to increase uric acid production and therefore reduce oxidative stress. It is important to understand activity and gene expression of xanthine oxidoreductase in avians as it will allow for a more complete understanding of the role the enzyme has in oxidative stress. Furthermore, administration of allopurinol has demonstrated a residual toxic effect in liver and

kidney tissue even after removal for one week ulitmaltely resulting in a decrease in the health of the birds. It was hypothesized that this effect increases the likelihood of oxidative damage within the tissue. Oxidative damage is often associated with an increase in inflammation and mitochondrial dysfunction. The allopurinol broiler model will be implemented in this research to establish that a reduction in uric acid, a primary antioxidant defense mechanism, will potentially result in inflammation and an alteration of mitochondrial function. 


\section{OBJECTIVES}

1. Xanthine oxidoreductase (XOR) catalyzes the terminal reactions of purine degradation in birds to yield uric acid and can be inhibited by allopurinol. It is hypothesized that reduction of uric acid within tissues will result in a compensatory increase in XOR gene expression in order to restore antioxidant protection to the tissues.

2. Oxidative stress plays an important role in inflammation. It is in the interest of these undertaken studies to determine to what extent inflammation is contributing to poultry when uric acid is reduced. It is known that mitochondrial function can be impaired by inflammatory states induced by oxidative stress such that inducible nitric oxide synthase (iNOS) is increased in inflammation as well as inflammatory cytokines (IL-6, IL-12-P35, IL-1 $\beta$, and IFN- $\gamma$ ) in states of oxidative stress. By reducing uric acid in the liver tissue, it is hypothesized that there will be an upregulation of inflammatory cytokine gene expression, $\mathrm{XOR}$ gene expression, and a decrease in mitochondrial function, measured as State III and State IV respiration, in a compensatory response to the loss of a primary antioxidant. 


\section{REFERENCES}

1. Alderton, W.K., Cooper, C.E., Knowles, R.G. 2001. Nitric oxide synthases : structure, function, and inhibition. Biochem. J. 357 (593-615)

2. Al-Seeni, A.E. (2009). Some biochemical studies on aldehyde oxidase and xanthine oxidase of agamid lizard uromastyx microlepis (Dhubb). World Journal of Chemistry 4(1): 45-51

3. Alverez-Lario, B. and Macarron-Vicente, J. (2010). Uric acid and evolution. Rheumatology. 49: 2010-2015

4. Ames, B., Cathcart, R., Schwiers, E., Hochstein, P. (1981). Uric acid provides an antioxidant defense in humans against oxidant and radical-caused aging and cancer: a hypothesis. Proc. Natl. Acad. Sci. 78(11): 6858-6862

5. Amaro, S., Soy, D., Obach, V., Cervera, A., Planas, A, Chamorro, A. (2007) A pilot study of dual treatment with recombinant tissue plasminogen activator and uric acid in acute ischemic stroke. Stroke 38: 2173-2175

6. Annanmaki, T., Muuronen, A., Murros, K. (2007). Low plasma uric acid level in Parkinson's disease. Movement Disorders 22(8): 1133-1137

7. Angermuller, S., Bruder, G., Volk1, A., Wesch, H., Fahimi, H.D. (1987). Localization of xanthine oxidase in crystalline cores of peroxisomes: a cytochemical and biochemical study. European Journal of Cell Biology. 47: 137-144

8. Ariel, E., Ladds P.W., Buenviaje, G.N. (1997). Concurrent gout and suspected hypovitaminosis A in crocodile hatchlings. Aust. Vet. J 4:247-249

9. Aruoma, O. (1998). Free radicals, oxidative stress, and antioxidants in human health and disease. JAOCS. 75 (2): 199-211

10. Austic, R. E. and Cole, R. K. (1972). Impaired renal clearance of uric acid in chickens having hyperuricemia and articular gout. Am . J. Physiol, 223(3): 525-530 
11. Barja, G. (1998). Mitochondrial free radical production and aging in mammals and birds. Annals of New York Academy of Sciences 854(1): 224-238

12. Barja, G. and Herrero, A. (1998). Localization at complex I and the mechanism of the higher free radical production if brain nonsynaptic mitochondria in the short-lived rat than in the longevous pigeon. Journal of Bioenergetics and Biomembranes 30(3):235-243

13. Barja, G., Cadenas, S., Rojas, C., Perez-Campo, R., Lopez-Torres, M. (1994). Low mitochondrial free radical production per unit $\mathrm{O}_{2}$ consumption can explain simultaneous presence of high longevity and high aerobic metabolic rate in birds. Free Radical Research 21(5) 317-327

14. Bataille, AM., Goldmeyer, J., Renfro, J. L. (2008). Avian renal proximal tubule epithelium urate secretion is mediated by Mrp4. Am J Physiol Integr Comp Physiol 295:2024-2033

15. Beckman, K. and Ames, B. 1998. The free radical theory of aging matures. Physiological Reviews 78(2): 547-581

16. Benboubetra, A., Gleeson, A., Harris, C.P.D., Kahn, J., Arrar, L., Brennand, D., Reid, J., Reckless, J.D., Harrison, R. (1997). Circulating anti-xanthine oxidoreductase antibodies in healthy human adults. European Journal of Clinical Investigation 27: 611-619

17. Berry, C. and Hare, J. (2004). Xanthine oxidoreductase and cardiovascular disease: molecular mechanisms and pathophysiological implications. Journal of Physiology 555 (3): 589-606

18. Braun, E. and W. Dantzler. (1997). Vertebrate renal system. In: Handbook of Physiology.Comparative Physiology. Bethesda, MD: American Physiological Society, sect.13, vol I, chapt. 8, pp 481-576.

19. Braun, E.J. and Dantzler, W.H. (1972). Function of mammalian-type and reptilian-type nephrons in kidney of desert quail. Am J Physiol 222:617-629

20. Brown, J., McClelland, G., Faure, P., Klaiman, J., Staples, J. (2009). Examining the mechanisms responsible for lower ROS rates in liver mitochondria from long-lived house 
sparrow (Passer domesticus), and big brown bat (Eptesicus fuscus) compared to the shortlived mouse (Mus musculus). Mechanisms of Ageing and Development 130: 467-476

21. Bruder, G., Jarasch, E., Heid, H. (1984). High concentrations of antibodies to xanthine oxidase in human and animal sera: molecular characterization. Journal of Clinical Investigation 74: 783-794

22. Cadenas, E. and Davies, K.J.A. (2000). Mitochondrial free radical generation, oxidative stress, and aging. Free Radic. Biol. Med. 29:222-230

23. Carro, M.D, Falkenstein, E., Blemings, K.P., Klandorf, H. (2009a). Determination of xanthine oxidoreductase activity in broilers: effect of $\mathrm{pH}$ and temperature of the assay and distribution in tissues. Poult. Sci. 88:2406-2414

24. Carro, M.D., Falkenstein, E., Radke, W.J., Klandorf, H. (2009b). Effects of allopurinol on uric acid concentrations, xanthine oxidoreductase activity, and oxidative stress in broiler chickens. Comparitive Biochemistry and Physiology, Part C 151: 12-17

25. Cawthon, D., Beers, K., Bottje, W.J. 2001. Electron transport chain defect and inefficient respiration may underlie pulmonary hypertension syndrome (ascites)- associated mitochondrial dysfunction in broilers. Poultry Science 80: 474-484

26. Cazzaniga, G., Terao, M., Lo Schiavo, P., Galbiati, F., Segalla, F., Seldin, M.F., Garattino, E. (1994). Chromosomal mapping, isolation, and characterization of the mouse xanthine dehydrogenase gene. Genomics 23: 390-402

27. Chamorro, A. Plana, A.M., Muner, D.S., Deulofeu, R., (2004). Uric acid administration for neuroprotection in patients with acute brain ischemia. Medical Hypotheses 62: 173-176

28. Chapman, M.E. and Wideman, R.F. 2006. Evaluation of total plasma nitric oxide concentrations in boirlers infused intraveneously with sodium nitrite, lipopolysaccharide, aminoguanidine, and sodium nitroprusside. Poultry Science 85: 312-320

29. Chen, Q., Vazquez, E., Mghaddas, S., Hoppel, C., Lesnefsky, E. (2003). Production of reactive oxygen species by mitochondria: central role of complex III. Journal of Biological Chemistry 278(38): 36027-36031 
30. Chen, X.B., Samaraweera, L., Kyle, D.J., Orskov, E.R., Abeygunawardene, H. (1996). Urinary excretion of purine derivatives and tissue xanthine oxidase (EC 1.2.3.2) activity in buffalos(Bubalis bubalis) with special reference to differences between buffalo and Bos taurus cattle. British Journal of Nutrition 75: 397-407

31. Cohen, A., Aberdroth, R., Hochstein, P. (1984). Inhibition of free radical-induced DNA damage by uric acid. FEBS 174 (1): 147-150

32. Cohen, A., Klasing, K., Ricklefs, R. (2007). Measuring circulating antioxidants in wild birds. Comparitive Biochemistry and Physiology. 147(B): 110-121

33. Cole R.K., Austic, R. E., and Shane, S.M. (1969). Hereditary uricemia and articular gout in chickens. Poultry Sci. 48: 1796

34. Coussens, L.M. and Werb, Z. 2002. Inflammation and cancer. Nature 420: 860-867

35. Davies, K., Sevanian, A., Mukkassah-Kelly, S., Hochstein, P. (1986). Uric acid-iron complexes: a new aspect of the antioxidant functions of uric acid. Biochem.J. 235:747-754

36. Davis, J.W., Grandinetti, A., Waslien, I., Ross, G.W., White, L.R., Morens, D.M. (1996) Observations on serum uric acid levels and the risk of idiopathic parkinson's disease. American Journal of Epidemiology 144(6): 480-484

37. Della-Corte.E. and Stirpe, F. (1967). Regulation of xanthine dehydrogenase in chick liver: further experiments on the effects of inosine, actinomycin D, and other factors. Biochemical J. 102: 520-524

38. De Lau, L., Koudstaal, P., Hofman, A., Breteler, M. (2005). Serum uric acid and the risk of Parkinson disease. Annals of Neurology 58: 797-800

39. Devenyi, Z.J., Orchard, J.L., Powers, R.E. (1987). Xanthine oxidase activity in mouse pancreas: effects of caerulein- induced acute pancreatitis. Biochemical and Biophysical Research Communications 149(3): 841-845

40. Dudas, P.L., Pelis, R.M., Braun, E. J., Renfro, J. L. (2005). Transepithelial urate transport by avian renal proximal tubule epithelium in primary culture. J. Exp. Biol. 208:4305-4315 
41. Erecinska, M., Silver, I. (2001) Tissue oxygen tension and brain sensitivity to hypoxia. Respiration Physiology 128: 263-276

42. Fang, P., Li, X., Luo, J.J., Wang, H., Yang, X. (2013) A double-edged sword: uric acid and neurologigical disorders. Brain Disorders and Therapy Vol 2 issue 2

43. Fang, Y., Yank, S., Wu, G. (2002). Free radicals, antioxidants, and nutrition. Nutrition 18(10): 872-879

44. Fhaolain, I.N. and Coughlan, M.P. (1978). Effects of allopurinol and oxypurinol on turkey liver xanthine dehydrogenase. FEBS Letters 90(2): 305-30

45. Galbusera, C., Orth, P., Fedida, D., Spector, T. (2006). Superoxide radical production by allopurinol and xanthine oxidase. Biochemical Pharmacology 71: 1747-1752

46. Garcia-Palmer, F. J., Pons, A., Alemany, M., Palou, A. (1985). Patterns of amino acid enzyme in domestic fowl breast and leg muscle during development. Comparitive Biochemistry and Physiology 82B:143-146

47. Guo, X., Huang, K., Tang, J. (2005). Clinicopathology of gout in growing layers by high calcium and high protein diets. British Poultry Science 46(5): 641-646

48. Guzik, T.J., Korbut, R., Guzik, A. 2003. Nitric oxide and superoxide in inflammation and immune regulation. Journal of Physiology and Pharmacology 54 (4): 469- 487

49. Hald, A. and Lotharius, J. (2005). Oxidative stress and inflammation in Parkinson's disease: is there a causal link? Experimental Neurology 193: 279-290

50. Halliwell, B. and Gutteridge, J.M.C. (1999). Free Radicals in Biology and Medicine third edition. Oxford University Press.

51. Hara, S., Mizukami, H., Mukai, T., Kurosaki, K., Kuriiwa, F. Endo, T. (2009). Involvement of extracellular ascorbate and iron in hydroxyl radical generation in rat striatum in carbon monoxide poisoning. Toxicology 264: 69-73 
52. Harris, C.M. and Massey V. (1997). The oxidative half-reaction of xanthine dehydrogenase with NAD; reaction kinetics and steady-state mechanism. J. of Biol.Chem. 272: 28335-28341

53. Harrison, R. (2002). Structure and function of xanthine oxidoreductase : where are we now? Free Radical Biology and Medicine 33(6): 774-797

54. Hart, L.I., McGartoll, M.A., Chapman, R., Bray, R.C. (1970). The composition of milk xanthine oxidase. Biochem J. 116(5): 851-864

55. Hensley, K., Maidt, M., Yu, Z., Sang, H., Markesbery, W., Floyd, R. (1998). Electrochemical analysis of protein nitrotyrosine and dityrosine in alzheimer brain indicates region-specific accumulation. Journal of Neuroscience 18(20): 8126-8132

56. Hille, R. and Massey, V. (1981). Studies on the oxidative half- reaction of xanthine oxidase. J. Biol. Chem. 256: 9090-9095

57. Hille, R. and Anderson, R.F. (1991). Electron transfer in milk xanthine oxidase as studied by pulse radiolysis. J. Biol. Chem. 266: 5608-5615

58. Hille, R. and Nishino, T. (1995). Xanthine oxidase and xanthine dehydrogenase. FASEB Journal 9: 995-1003

59. Holmes,D.J. and Austad, S.N. (1995). The evolution of avian senescence patters; implications for understanding primary aging processes. American Zooloogy 35:307-317

60. Hooper, D.C., Scott, G.S., Zborek, A., Miksheeva, T., Kean, R.B., Koprowski, H., Spitsin, S.V. (2000). Uric acid, a peroxynitrite scavenger, inhibits CNS inflammation, blood-CNS barrier permeability changes, and tissue damage in a mouse model of multiple sclerosis. FASEB Journal. 14: 691-698

61. Hooper, D.C., Spitsin, S.V., Kean, R.B., Champion, J.M., Dickson, G.M., Chaudhry, I. (1998). Uric acid, a natural scavenger of peroxynitrite, in experimental allergic encephalomyelitis and multiple sclerosis. Proc. Natl. Acad. Sci. 95: 675-680

62. Hussain, S.P. and Harris C.C. 2007. Inflammation and cancer: an ancient link with novel potentials. Int. J. Cancer 121: 2373-2380 
63. Ichida, K., Matsumara, T., Sakuma, R., Hosoya, T., Nishino, T. (2001). Mutation of human molybdenum cofactor sulfurase gene responsible for classical xanthinuria type II. Biochem Biophys Res Commun 282: 1194-1200

64. Ichikawa, M., Nishino, T., Nishino, T., Ichikawa, A. (1992). Subcellular localization of xanthine oxidase in rat hepatocytes. High resolution immunoelectron microscopic study combined with biochemical analysis. Journal of Histochemistry and Cytochemistry 40: 10971103

65. Iqbal, M., Cawthon, D., Wideman, R.F., Bottje, W.G. 2001. Lung mitochondrial dysfunction in pulmonary hypertension syndrome I site-specific defects in the electron transport chain. Poultry Science 80: 485-495

66. Jarasch, E.D., Grund, C., Bruder, D., Heid, H.W., Keenan, T.W., Franke, W.W. (1981). Localization of xanthine oxidase in mammary gland epithelium and capillary endothelium. Cell 25: 67-82

67. Jarasch, E.D., Bruder, D., Heid, H.W. (1984). Significance of xanthine oxidase in capillary endothelial cells. Acta Physiologica Scandinavica 126: 39-46

68. Kagan, VE and Packer, L. (1994) Light-induced generation of vitamin E radicals: assessing vitamin E regeneration. Methods Enzymol. 234: 316-320

69. Klandorf, H., Rathore, D.S., Iqbal, M., Shi, X., VanDyke, K. (2001). Accelerated tissue aging and increased oxidative stress in broiler chickens fed allopurinol. Comp. Biochem. and Physiol. Pt. C 129 (2): 93-104

70. Kim, T.S, Pae, C., Yoon, S. et al. (2006). Decreased plasma antioxidants in patients with alzheimer's disease. International Journal of Geriatric Psychiatry. 21: 344-348

71. Kooij, A., Frederiks, W.M., Gossrau, R., Van Noorden, C.J.F. (1991). Localization of xanthine oxidoreductase activity using the tissue protectant polyvinyl alcohol and final electron acceptor tetranitro. Journal of Histochemistry: Cytochemistry 39:87-93 
72. Lane, N. (2005). Power, sex, suicide: mitochondria and the meaning of life. Oxford University Press, New York, pp-306-311

73. Laverty, G. and Dantzler, W.H. (1983). Micropuncture study of urate transport by superficial nephrons in avian (Sturnus vulgaris) kidney. Pflugers Arch. 397: 232-236

74. Lovell, M.A., Ehmann, W.D., Butler, S.M., Markesbery, W.R. (1995). Elevated thiobarbituric acid reactive substances and antioxidant enzyme activity in the brain in Alzheimer's disease. Neurology 45:1594-1601

75. Ling, G.V., Ruby, A.L., Harrold, D.R., Johnson, D.L. (1991). Xanthine-containing calculi in dogs given allopurinol. Journal of the American Veterinary Association. 198:1935-1940

76. Lumeij, J.T. and Redig, P.T. (1992). Hyperuriceamia and visceral gout induced by allopurinol in red-tailed hawks (Buto jamaicensis). Proceedings VIII Tagung der Fachgruppe Geflugelkrankheiten pp. 265-269

77. Lumeij, J.T., Sprang, E.P.M., Redig, P.T. (1998). Further studies on allopurinol induced hyperuriceamia and visceral gout in red-tailed hawks (Buto jamaicensis). Avian Pathology 27:390-393

78. Lyon E.S. and Garret, R.H. (1978). Regulation, purification, and properties of xanthine dehydrogenase in Neurospora crassa. J. Biol. Chem. 1978 253:2604-2614

79. Machin, M., Simoyi, M., Blemings, K., Klandorf, H. (2004). Increased dietary protein elevates plasma uric acid and is associated with decreased oxidative stress in rapidly-growing broilers. Comparative Biochemistry and Physiology Part B. 137: 383-390

80. Martin, G.M., Austad, S.N., Johnson, T.E. (1996) Genetic analysis of ageing: role of oxidative damage and environmental stresses. Nature Genetics $13: 25-34$

81. Monnier,V.M., Sell, D.R., Ramanakoppa, H.N., Miyata, S. (1991). Mechanisms of damage mediated by the Maillard reaction in aging. Gerontology 37:152-165 
82. Moriwaki,Y., Yamamoto, T., Yamakita, J., Takahashi, S., Higashino, K. (1998). Comparitive localization of aldehyde oxidase and xanthine oxidoreductase activity in rat tissues. Histochemical Journal 30: 69-74

83. Munshi-South, J. and Wilkinson, G. (2009). Bats and birds: exceptional longevity despite high metabolic rates. Ageing Research Reviews 237: 1-8

84. Murray, K.N., Watson, J.G., Chaykin, S. (1966). Catalysis of the direct transfer of oxygen from nicotinamide $\mathrm{N}$-oxide to xanthine by xanthine oxidase. Journal of Biological Chemistry 241: 4798-4801

85. Nishino,T., Nishino, T., Schopfer, L., Massey, V. (1989). The reactivity of chicken liver xanthine dehydrogenase with molecular oxygen. Journal of Biological Chemistry 264(5): 2518-2527

86. Oaks, J. L., Gilbert, M., Virani, M.Z., Watson, R.T., Meteyer, C.U., Rideout, B.A., Shivaprasad, H.L., Ahmed, S., Chaudry, M.J.I., Arshad, M., Mahmood, S., All, A., Khan, A.A. (2004). Diclofenac residues as the cause of vulture population decline in Pakistan. Nature 427:630-633

87. Oda, M., Satta, Y., Takenaka, O., Takahata, N. (2002). Loss of urate oxidase activity in hominoids and its evolutionary implications. Mol. Biol. Evol. 19 (5): 640-653

88. Olson, J.S., Ballou, D.P., Palmer, G., Massey, V. (1974). The mechanism of action of xanthine oxidase. J.Biol.Chem. 249: 4363-4382

89. Pacher, P., Nivorozhkin, A., Szabo, C. (2006). Therapeutic effects of xanthine oxidase inhibitors: renaissance half a century after the discovery of allopurinol. Pharmacological Reviews 58 (87): 87-114.

90. Pamplona, R., Portero-Otin, M., Sanz, A., Ayala, V., Vasileva, E., Barja, G. (2005). Protein and lipid oxidative damage and complex I content are lower in the brain of budgerigar and canaries than in mice. Relation to aging rate. Age. 27:267-280 
91. Pappolla M.A., Chyan Y.J., Omar R.A. et al. (1998) Evidence of oxidative stress and in vivo neurotoxicity of beta-amyloid in a transgenic mouse model of Alzheimer's disease: a chronic oxidative paradigm for testing antioxidant therapies in vivo. Am. J. Pathol. 152, 871-877.

92. Pappolla M.A., Omar R.A., Kim K.S., Robakis N.K. (1992) Immunohistochemical evidence of oxidative stress in Alzheimer's disease. Am. J. Pathol. 140, 621-628.

93. Parks, D.A., Granger, D.N. (1986). Xanthine oxidase: biochemistry, distribution, and physiology. Acta Physiol. Scanda. 548 (supplement): 87-99

94. Pea, F. (2005). Pharmacology of drugs for hyperuricemia: mechanisms, kinetics, and interactions. Ronco,C. and Rodegheiro, F., editors. Hyperuricemic syndromes: pathophysiology and therapy (Contributions to Nephrology). 147: 35-46. S. Karger Publications

95. Peterson, D. W.., Hamilton, W. H. Lilyblade, A. L. (1971). Hereditary susceptibility to dietary induction of gout in selected lines of chickens. J. Nutrtion 101:347-354

96. Poffers, J., Lumeij, J.T., Timmermans-Sprang, E.P.M., Redig, P.T. (2002). Further studies on the use of allopurinol to reduce plasma uric acid concentrations in red-tailed hawks (Buto jamaicensis)hyperuraceamic model. Avian Pathology. 31:567-572

97. Remy, C. and Westerfeld, W.W. (1951). The effect of diet on xanthine dehydrogenase in chicken tissues. J. Biol. Chem. 193(2): 659-667

98. Reuter, S., Gupta, S.C., Chaturvedi, M.M., Aggarwai, B.B. 2010. Oxidative stress, inflammation, and cancer: how are they linked? Free Radical Biology and Medicine. 40: 1603-1616

99. Rome, L. and Lindstedt, S. (1998). The quest for speed: muscles built for high-frequency contractions. News Physiol. Sci. 13:261-268

100. Rouquette, M., Page, S., Bryant, R., Benboubetra, M., Stevens, C.R., Blake, D.R., Whish, W.J.D., Harrison, R., Tosh, D. (1998). Xanthine oxidoreductase is asymmetrically localized on outer surface of human endothelial and epithelial cells in culture. FEBS Letters. 426: $397-$ 401 
101. Rowe, P., and Wyngaarden, J. (1966). The mechanism of dietary alterations in rat hepatic xanthine oxidase levels. J. Biol. Chem. 241(23): 5571-5576

102. Saito, T. and Nishino, T. (1989). Differences in redox and kinetic properties between $\mathrm{NAD}$-dependent and $\mathrm{O}_{2}$-dependent types of rat liver xanthine dehydrogenase. Journal of Biological Chemistry 264: 10015-10022

103. Sakamoto, N., Yamamoto, T., Moriwaki,Y., Teranishi, T., Toyoda, M., Onishi,Y., Kuroda, S., Sakaguchi, K., Fujisawa, T., Maeda, M., Hada, T. (2001). Identification of a new point mutation in the human xanthine dehydrogenase gene responsible for a case of classical type I xanthinuria. Human Genetics 108: 279-283

104. Scholz, R.W. and Featherston, W.R. (1967). Effect of alterations in protein intake on liver xanthine dehydrogenase in the chick. Journal of Nutrition 95: 271-277

105. Shannon, J. A. (1983). The excretion of uric acid by the chicken. J. Cell. Comp. Physiol. $11: 135-148$

106. Seaman, C., Moritz, J., Falkenstein, E., VanDyke, K., Casotti, G., Klandorf, H. (2008). Inosine ameliorates the effects of hemin-induced oxidative stress in broilers. Comparitive Biochemistry and Physiology, Part A 151:670-675

107. Settle, T., Carro, M.D., Klandorf, H. 2012a. The Role of Uric Acid in the Avian Species. Uric Acid Biology, Functions, and Diseases. Nova Science Publishers. pp. 1-30

108. Settle, T., Carro, M, Falkenstein, E., Radke, W., Klandorf, H. (2012). Effect of allopurinol and uric acid supplementation on uric acid concentrations and xanthine oxidoreductase activity in broiler tissues. Poultry Science. 90(11): 895-903

109. Simoyi, M., VanDyke, K., Klandorf, H. (2002). Manipulation of plasma uric acid in broiler chicks and its effect on leukocyte oxidative activity. Am. J. Physiol. Regulatory Integrative Comp Phsyiol. 282:791-796 
110. Skinner KA, White CR, Patel R, Tan S, Barnes S, Kirk M, Darley-Usmar V, Parks DA. (1998). Nitrosation of uric acid by peroxynitrite. Formation of a vasoactive nitric oxide donor. Journal of Biological Chemistry, 273(38): 24491-24497.

111. Skinner KA, Tan, S., Parks, D.A. (2001). Uric Acid Metabolism. Encyclopedia of Life Sciences. Nature Publishing Group / www.els.net. pp. 1-8.

112. Slautterback, D. (1965). Mitochondria in cardiac muscle cells of the canary and some other birds. The Journal of Cell Biology 24:1-22

113. Sotgiu S, Pugliatti M, Sanna A, Sotgiu A, Fois ML, Arru G, Rosati G (2002) Serum uric acid and multiple sclerosis. Neurol Sci 23:183-188

114. Stewart, D.J., Holmes, W.N., Fletcher, G. (1969). The renal excretion of nitrogenous compounds by the duck (Anas platyrhynchos) maintained on freshwater and on hypertonic saline. J. Exp Biol 50:527-539

115. Stinefelt,B., S.S. Leonard, K.P. Blemings, X.Shi, H. Klandorf. (2005). Free Radical Scavenging, DNA protection, and inhibition of lipid peroxidation mediated by uric acid. Ann.Clin.Lab.Sci. 35:37-45

116. Strittmatter, C.F. (1965). Studies on avian xanthine dehydrogenases: properties and patterns of appearance during development. J. Biol. Chem. 240(6): 2557-2564

117. Suarez, R.K., Lighton, J.R.B, Brown, G. S., Mathieu-Costello, O. (1991). Mitochondrial respiration in hummingbird flight muscles. Proc. Natl. Acad. Sci. 88:4870-4873

118. Takeshita, K., Graham, D.L., Silverman, S. (1986). Hypervitaminosis D in baby macaws. Proc Assoc Avian Vet Miami pp341-345

119. Tang, z., Iqbal, M., Cawthon, D., Bottje, W.G. 2002. Heart and breast mitochondrial function in pulmonary hypertension syndrome in broilers (gallus domesticus). Comparative Biochemistry and Physiology Part A 132: 527-540 
120. Terada, L., Leff, J., Repine, J. (1990). Measurement of xanthine oxidase in biological tissues. Methods in Enzymology 186: 651-656

121. Terao, M., Kurosaki, M., Zanotta, S., Garattini, E. (1997) The xanthine oxidoreductase gene : structure and regulation. Biochemical Society Transactions 25: 14170-14175

122. Terzioglu, M. and Larson, N.G. (2007). Mitochondrial dysfunction in mammalian aging. Mitochondrial Biology:New Perspectives. Novartis Foundation. John Wiley and Sons, LTD. pp 197-213

123. Thomas ,C., Mackey, M.M., Diaz, A.A., Cox, D.P. (2009). Hydroxyl radical is produced via the Fenton reaction in submitochondrial particles under oxidative stress: implications for diseases associated with iron accumulation. Redox Report 14(3): 102-108.

124. Traber, M.G., Atkinson, J. (2007) Vitamin E, antioxidant nothing more. Free Radical Biol. and Medicine 43(1): 4-15

125. Turrens, J. (2003). Mitochondrial formation of reactive oxygen species. J. Physiol. 552(2): 335-344

126. VanDyke, K., VanDyke, C., Woodfork, K. (2002). Luminescence Biotechnology Instruments and Applications. CRC Press LLC

127. Waugh, W. (2008). Inhibition of iron-catalyzed oxidations by attainable uric acid and ascorbic acid levels; therapeutic implications for Alzheimer's disease and late cognitive impairment. Gerontology 54: 238-243

128. Weisskopf, M.G., O’Reilly, E., Chen, H., Schwarzschild, M.A., Ascherio, A. (2007). Plasma urate and the risk of Parkinson's disease. American Journal of Epidemiology 166(5): $561-567$

129. Westerfeld, W.W., Richert, D.A., Hermans, A.C. (1962). Growth and liver xanthine dehydrogenase in chicks and poults fed casein or soy protein diet. The Journal of Nutrition 76: $475-482$ 
130. Xia, M., Dempski,R., Hille, R. (1999). The reductive half-reaction of xanthine oxidasethe reaction with aldehyde substrates and identification of the catalytically labile oxygen. J. Biol. Chem. 274: 3323-3330

131. Xu, P., Lavalee, P., Hoidal, J. R. (2000). Repressed expression of the human xanthine oxidoreductase gene. J. Biol. Chem. 275: 5918-5926

132. Xu, P., Zhu, X.L., Huecksteadt, T.P., Brothman, A.R., Hoidal, J.R. (1995). Assignment of human xanthine dehydrogenase to chromosome 2p22. Genomics 23: 289-291

133. Xu, P., Hueksteadt, T.P., Hoidal, J.R. (1996). Molecular cloning and characterization of the human xanthine dehydrogenase gene. Genomics 34: 173-180

134. Yu, Z.F., Annadora, J., Bruce-Keller, Y., Goodman., Matteson, M.P. (1998). Uric acid protects neurons against excitotoxic and metabolic insults in cell cultura, and against focal ischemic brain injury in vivo. Journal of Neuroscience Research 53: 613-625

135. Zemlan, F.P., Thienshaus, O.J., Bosmann, H.B. (1988). Superoxide dismutase activity in Alzheimer's disease: a posible mechanism for paired helical filament formation. Brain Research 476(1): 160-162

136. Zmuda, M.J. and Quebbemann, A.J. (1975). Localization of renal tubular uric acid transport defect in gouty chickens. Am.J. Physiol. 229(3):820-825 

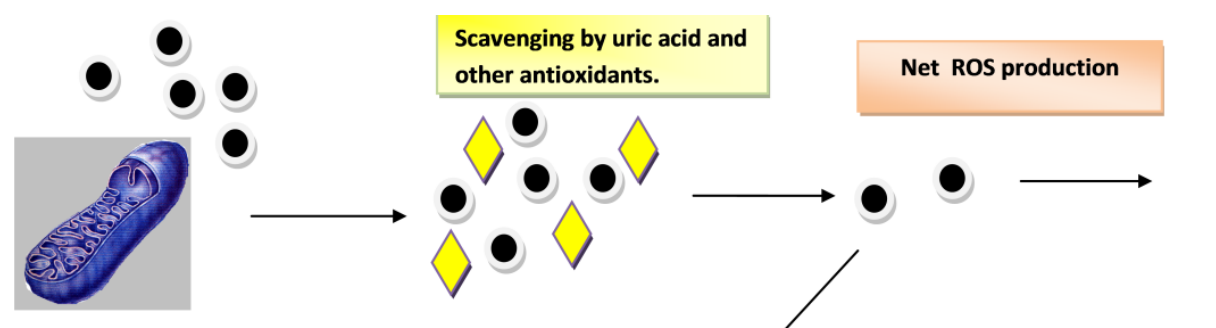

Essential Physiological Function: Immune response and apoptosis.

Mitochondrial ROS Production: Birds have a double-packed cristae structure
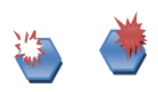<smiles>C1=CC2=[N+]3C=CC(=C1)C23</smiles>
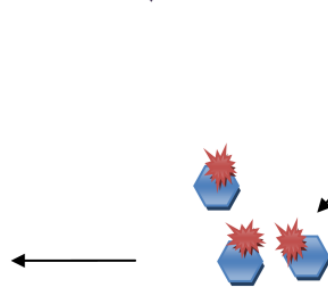

Oxidative Damage: proteins,

Clearance of oxidative damage by endogenous and exogenous antioxidants- repair of degradation nrndurts

material, cellular, etc. due to oxidative stress.

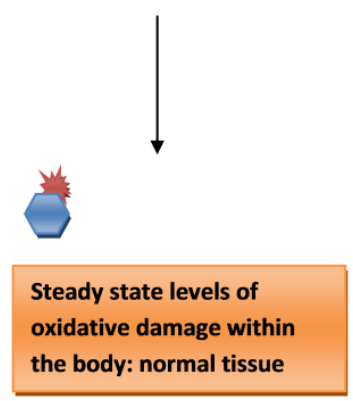

Figure 1. Schematic of mitochondrial ROS production, antioxidant defense, and oxidative stress. As adapted from Settle et al.(2012). 
<smiles>Nc1ncnc2c1ncn2-c1ccccc1</smiles>

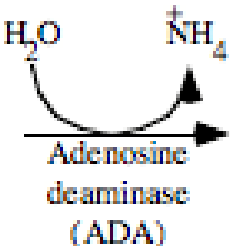

Adenosine<smiles>Cn1cnc2c(=O)[nH]cnc21</smiles>

Inosine

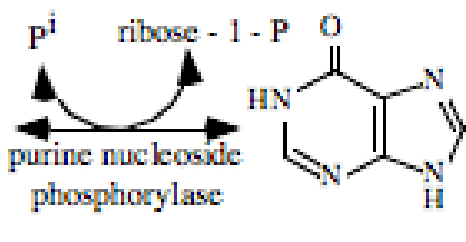

Hypoxanthine<smiles>CCCCn1cnc2c(=O)[nH]c(N)nc21</smiles>

Guanosine

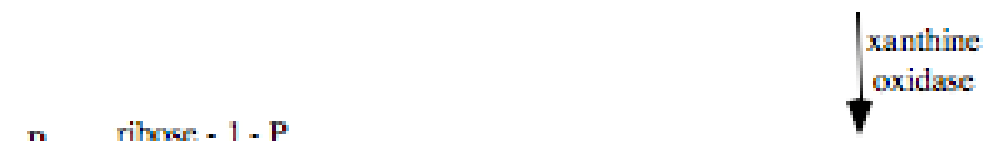

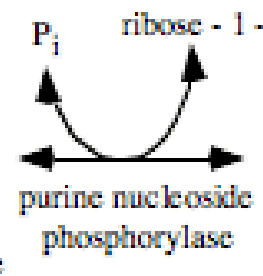<smiles>Nc1nc2[nH]cnc2c(=O)[nH]1</smiles>

Guanine

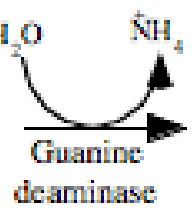<smiles>O=c1[nH]c(=O)c2nc[nH]c2[nH]1</smiles>

Xanthine

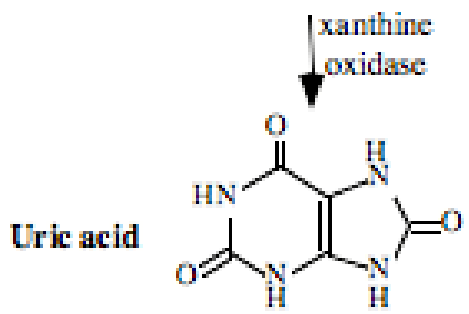

Figure 2. Purine Degradation Pathway. Uric is produced in the terminal reactions of purine degradation by xanthine oxidoreductase (XOR). Adapted from http://seqcore.bref.med.imich.edu/mcb500 
Chapter 1: The effect of Allopurinol and Inosine Administration on Xanthine Oxidoreductase Gene Expression in selected tissues of Broiler Chickens 


\begin{abstract}
Uric acid is considered the most significant factor in amelioration of oxidative burden in birds. Uric acid is formed in the terminal reactions of purine degradation by the enzyme xanthine oxidoreductase (XOR). In this study, inosine, a purine precursor, was fed to 3 groups of 5 birds: Group 1 was fed 0 (control), Group 2, 0.6 mols inosine/kg feed (INO) and Group 3, INO treatment plus $50 \mathrm{mg}$ allopurinol/kg BM (INOAL). Allopurinol is a known inhibitor of XOR and thereby reduces uric acid (UA). INOAL birds showed lower total liver XOR activity $(\mathrm{p}=0.005)$ but kidney XOR activity was not affected. Both INO and INOAL treated birds had higher plasma and kidney UA concentrations than controls. Liver uric acid (LUA) was significantly reduced in INOAL birds when compared to other treatments. XOR gene expression was increased $(\mathrm{p}=0.007)$ in the liver tissue of INOAL birds when compared to CON and INO birds. However, there were no significant changes in XOR gene expression in the kidney tissue. To our knowledge, this is the first report of XOR gene expression measured under these conditions. These results suggest that regulation of UA production is tissue dependent. The results also indicate a compensatory effect of allopurinol on XOR gene expression which can be linked to a decrease in antioxidant protection from UA.
\end{abstract}

Key Words: Uric acid, xanthine oxidoreductase gene expression, oxidative stress 


\section{Introduction}

Xanthine oxidoreductase (XOR) catalyzes the terminal reactions in purine degradation to uric acid (UA), a potent antioxidant for birds and humans. Specifically, XOR catalyzes the formation of UA from hypoxanthine and xanthine. XOR exists in two interconvertible forms: xanthine oxidase $(\mathrm{XO})$ and xanthine dehydrogenase (XD). In mammals, XOR is predominantly found in the XD form, which can be converted to XO either irreversibly via proteolysis or reversibly by oxidation of the sulfhydryl residues (Hille and Massey, 1981). In the avian, a low, but detectable activity of XO has been measured in the liver and kidney (Remy and Westerfeld, 1951; Nishino et al., 1989; Harrison, 2002; Carro et al., 2009a). Despite this discovery, the majority of previous research in birds has focused on activity of XD.

XOR reaction products include UA and reactive oxygen species (ROS), specifically the generation of peroxide and superoxide radicals. Both radical types are implicated in exacerbating oxidative damage to various tissues (Galbusera et al., 2006). In contrast UA is a potent antioxidant in birds (Simoyi et al., 2002; Stinefelt et al., 2005). In most mammals, uricase converts UA to allantoin before excretion. In birds, humans, reptiles, and some higher primates, uricase is absent due to the evolutionary loss of the UOX gene encoding for uricase and therefore UA concentrations in the plasma remain elevated (Oda et al., 2002). Increased UA concentrations have been shown to reduce oxidative stress (Simoyi et al., 2002), while a reduction in UA dramatically increases oxidative stress (Klandorf et al., 2001; Carro et al., 2009b). The gene structure of XOR has been determined in several species including humans, mice, chickens, and insects. However, it should be noted that to our knowledge the gene sequences for either XD or XO specifically have not been determined for chickens and only xanthine oxidoreductase has been sequenced. 
Previous studies have investigated the effects of diet on chicken XD activity (Scholz and Featherson, 1968; Itoh et al., 1978), developmental patterns of XD in the embryo and the posthatching period (Lee and Fisher, 1972), and tissue XOR distribution in broilers (Carro et al., 2009a, Settle et al., 2012), but to our knowledge little is known about the regulation of XOR gene expression in birds.

The gene loci that code for human and mouse XOR have been idntified and the associated genes have been assigned to chromosomes 2p22 and 17 (Harrison, 2002 and Cazzaniga et. al., 1994). Drosophila genes tend to be more compact with only four or five exons (Terao et.al.,1997). In mammals the exon-intron structure is highly conserved and contains $>60 \mathrm{~kb}$ and approximately 36 exons (Xu et.al.,1996). Mammalian and avian cDNA sequences have also been reported. Avians, specifically chickens, have a sequence that corresponds to 1358 amino acids whereas mammalian enzymes have a range from 1330-1335 with approximately $90 \%$ homology between themselves (Harrison, 2002). The Mo-Co binding site is the most conserved of the amino acid sequences and has a 94\% homology between human, rat, and mouse XOR (Xu et. al., 1995). Mutations in the XOR gene in humans, more specifically concerning the XD form, have been linked to inheritable xanthinuria.

Inhibition of the XOR enzyme results from feeding allopurinol or oxypurinol, as well as from feeding molybdenum-deficient diets that are high in tungsten (Harrison, 2002). Allopurinol is used to treat gout and hyperuricemia in humans. In birds, allopurinol decreases plasma uric acid (PUA) levels (Klandorf et al. 2001; Simoyi et al., 2002; Carro et al., 2009b), but information on its effects on XOR activity is scarce, and the effects may be tissue dependent (Woodward et al., 1972; Carro et al., 2009b). Previous studies in our lab have demonstrated inosine fed with allopurinol can lead to a residual toxic effect in the liver tissue of broilers due to reduction of UA 
concentrations within the tissue (Settle et al., 2012). In order to better understand factors that regulate XOR activity, UA levels were increased by exogenous administration of inosine to broilers. While there was no effect on activity of XOR, it was hypothesized that allopurinol would have a down-regulating effect on UA production; however this could potentially have a compensatory effect such that XOR gene expression would increase in response to the reduced antioxidant defense provided by UA.

\section{Methods}

Animals and Experimental Diets Twenty Cobb x Cobb mixed sex chicks at one day of age were donated from Pilgrim's Pride Hatchery (Moorefield, WV) and fed a commercial starter diet until three weeks of age before being offered a commercial grower diet. At 5 weeks of age, 15 birds were selected and divided into 3 homogeneous groups according to their body mass (BM) and PUA concentrations. Each group was randomly assigned to one of 3 treatments CON (control), INO (inosine), and INOAL (inosine with allopurinol). Birds in the control group were fed a commercial broiler diet free of antibiotic additives. Birds in the INO group were provided the control diet supplemented with inosine at a rate of 0.6 mols inosine per $\mathrm{kg}$ of feed. Birds in the INOAL group received the control diet containing inosine and allopurinol at $50 \mathrm{mg}$ per $\mathrm{kg}$ BM over a short period of time to assess the effect of decreased uric acid on XOR gene expression and activity. This dose of inosine had been previously shown to raise PUA levels in broilers (Simoyi et al., 2002). Body weight and feed intake were monitored over the experimental period. At the end of the experimental period, birds in each group were euthanized by cervical fracture and tissues were collected. The right kidney was removed as well as the liver. Tissues were snap frozen in liquid nitrogen and stored in $-80^{\circ} \mathrm{C}$ until analysis. 
cDNA synthesis. Total mRNA from $1 \mathrm{mg}$ of either kidney or liver tissue was extracted using RNA-Bee isolation medium (Tel-Test, TX) and quantified using a Genequant spectrophotometer. Quality was assessed using a denaturing formaldehyde-agarose gel. First strand cDNA was synthesized by using Life Technologies' Superscript II Indirect cDNA Labeling System Life, Carlsbad, CA ) according to the manufacturer's protocol. Each reaction mixture contained $2.5 \mu \mathrm{L}$ of $2.5 \mathrm{mM}$ dNTP mixture, $5.0 \mu \mathrm{L}$ of $5 \mathrm{x}$ reverse transcriptase buffer, $2.0 \mu \mathrm{L}$ of $0.1 \mathrm{M}$ Dithiothreitol (DTT), $0.5 \mu \mathrm{L}$ RNasin (Promega), and $2.0 \mu \mathrm{L}$ random hexamer primers (Roche Scientific). The final cDNA concentration was $1.8 \mu \mathrm{g} / \mu \mathrm{L}$. Each sample was heated to $70^{\circ} \mathrm{C}$ for five minutes and then $4^{\circ} \mathrm{C}$ for five minutes in a MJ Research PTC-200 DNA Engine ( MJ Research Inc.

Watertown, MA, USA). At this time, $1 \mu \mathrm{L}$ reverse transcriptase (Super Script II, Life Technologies, USA) was added to each sample and cycled at $37^{\circ} \mathrm{C}$ for sixty minutes, $90^{\circ} \mathrm{C}$ for five minutes, and $4{ }^{\circ} \mathrm{C}$ for five minutes. Samples were stored at $-80^{\circ} \mathrm{C}$ until analysis with realtime RT-PCR less than 48 hours after synthesis.

Real-Time RT-PCR. Primers for XOR (Forward: 5'CTGCAGGATGCCTGCCGCTT3'; Reverse: 5'GCATGGGCTTGGGTGCTGGT3') and Glyceraldehyde 3-phosphate dehydrogenase (GAPDH) were designed using Primer3 software (Howard Hughes Institute). Each sample was assayed in triplicate for the XOR and GAPDH primers on a 96-well plate. GAPDH (forward: 5'GACGTGCAGGAACACTA3'; reverse: 5'CTTGGACTTTGCCAGAGAGG3') was selected as a normalizer for this experiment as there were no differences in expression patterns due to treatment. A pooled sample, that contained cDNA samples from all treatments, was used for both analyses of both primer efficiencies. Primers were diluted to $5 \mu \mathrm{M} / \mu \mathrm{L}$ concentration in nuclease free water. A serial dilution was used to obtain a standard curve for each primer and efficiency was calculated. Primer efficiencies were determined from the slope of the regression 
line calculating the log of the cDNA concentrations versus the $\mathrm{Ct}$ value using the equation: $\mathrm{E}=10^{(-1 / \text { Slope })}$. The efficiencies were used to calculate the relative mRNA abundance using the “efficiency corrected relative expression” equation (Equation 3; Pfaffl, 2001). Real time RTPCR was performed using IQ Sybr Green Supermix (Bio Rad Inc., USA) on a Bio Rad CFX 96 Real-Time System (Bio Rad Inc., USA). Each PCR reaction mixture contained 10 $\mu$ IQ Sybr Green Supermix, $3 \mu \mathrm{L}$ diluted cDNA (1:10), $1 \mu \mathrm{L}$ each of the forward and reverse primer (diluted to $5 \mu / \mu \mathrm{L}$ ), and $5 \mu \mathrm{L}$ of nuclease-free water. Each sample was run in triplicate on a 96 well plate. The PCR reaction cycle was as follows: $95^{\circ} \mathrm{C}$ for $3 \mathrm{~min}, 95^{\circ} \mathrm{C}$ for $15 \mathrm{sec}, 62^{\circ} \mathrm{C}$ for $30 \mathrm{sec}, 70^{\circ} \mathrm{C}$ for $30 \mathrm{sec}$. (repeated for 40 cycles). Then intervals of $95^{\circ} \mathrm{C}$ and $60^{\circ} \mathrm{C}$ for 5 min. Relative expression was determined using the efficiency corrected relative expression method (Pfaffl, 2001).

Xanthine oxidase and xanthine dehydrogenase activities. Previously, tissue preparation and enzyme activity determination have been described in detail by Settle et al. (2012). Briefly, frozen tissue samples $(0.5 \mathrm{~g})$ were homogenized in $4 \mathrm{~mL}$ of ice-cold $0.1 \mathrm{M}$ TRIS buffer $(\mathrm{pH}=$ 7.8) using a Polytron PT 2100 (Kinematika AG, Littau, Switzerland) for $20 \mathrm{~s}$ at 19,000 rpm. The homogenate was centrifuged $\left(14000 \times \mathrm{g}, 4^{\circ} \mathrm{C}, 30 \mathrm{~min}\right)$ and $1 \mathrm{~mL}$ of the supernatant fraction was immediately chromatographed on Sephadex G-25 (PD-10 desalting colums; GE Healthcare, Piscataway, NJ, USA ) and equilibrated with $1.5 \mathrm{~mL}$ of $0.1 \mathrm{M}$ TRIS buffer $\left(4^{\circ} \mathrm{C}\right)$. The eluates were stored on ice and assayed for XO and XD activities within 1-2 $\mathrm{h}$ after homogenizing the tissue.

$\mathrm{XO}$ and $\mathrm{XD}$ activities were assayed by measuring the formation of UA when xanthine was incubated with the eluates. Each eluate was incubated with $100 \mu \mathrm{M}$ xanthine in the presence of ambient oxygen (XO activity) or with $100 \mu \mathrm{M}$ xanthine and $0.67 \mathrm{mM} \mathrm{NAD}^{+}(\mathrm{XO}+\mathrm{XD}$ activity). 
The reaction mixture contained $200 \mu \mathrm{L}$ of eluate and $2.8 \mathrm{~mL}$ of $0.1 \mathrm{M}$ TRIS buffer $(\mathrm{pH}=7.8)$ with $100 \mu \mathrm{M}$ xanthine. The tubes containing the reaction mixtures were incubated at $41^{\circ} \mathrm{C}$ for 30 min, and absorbance was measured at $294 \mathrm{~nm}$ in a Beckman Spectrophotometer DU 640 (Beckman Instruments, Fullerton, CA). The amount of UA produced was determined from the difference between the absorbance values at 30 and $0 \mathrm{~min}$, as compared to external standards of known UA concentration. Blanks containing xanthine and xanthine plus NAD ${ }^{+}$were incubated along with the sample tubes to correct for nonenzymatic oxidation of xanthine. Each assay was performed in duplicate.

One unit of activity was defined as the production of 1 nanomol of UA per min at $41^{\circ} \mathrm{C}$ and pH 7.8 using $100 \mu \mathrm{M}$ xanthine as substrate in the presence ( $\mathrm{XO}+\mathrm{XD}$ activity) or absence of $0.67 \mathrm{mM} \mathrm{NAD}^{+}$(XO activity). XD activity was calculated as the difference between total $(\mathrm{XO}+$ $\mathrm{XD}$ ) and $\mathrm{XO}$ activity. $\mathrm{XO}$ and $\mathrm{XD}$ activities are expressed as units per mg of protein, but $\mathrm{XO}$ and $\mathrm{XD}$ activity in total liver was calculated as units per $\mathrm{g}$ of liver multiplied by liver weight. Specific activities were expressed in terms of units per mg of protein in the eluate. The protein content in the eluate was assessed by Bio Rad Protein Assay (Bio-Rad Chemical Division, USA) on a spectrophotometer according to the method of Bradford (1976) using serum albumin as standard.

Uric acid analysis. As described by Settle et al. (2012), the UA concentration in plasma was measured in the supernatant fraction by using a commercially available cholorometric diagnostic kit (Sigma Diagnostic kit procedure 685; Sigma Diagnostics, St. Louis, MO). This method employs uricase to generate $\mathrm{H}_{2} \mathrm{O}_{2}$ which reacts with 4-aminoantipyrine (4-AAP) and TBHB in the presence of peroxidise to form a quinoneimine dye measured on a 
spectrophotometer. The resulting change in absorbance at $520 \mathrm{~nm}$ is proportional to UA concentration in the sample.

Concentration of UA in liver and kidney samples was measured using the technique described for PUA analysis using $40 \mu \mathrm{L}$ of the supernatant fraction from the homogenization of tissues for XOR analysis. Briefly, tissues were homogenized in $2 \mathrm{~mL}$ of ice-cold 0.1 M TRIS buffer $(\mathrm{pH}=7.8)$ and centrifuged at $14000 \times g$ at $4^{\circ} \mathrm{C}$ for 30 minutes. Concentrations of UA were analyzed in $40 \mu \mathrm{L}$ of the supernatant fraction by the method described previously.

\section{Statistical Analyses}

Tukey's multiple comparison test was used to assess differences among means. All analyses were conducted using the PROC GLM of SAS (SAS institute, 2002) for both studies. Correlations between UA concentration in liver and kidney were determined by Pearson correlation analysis using the PROC CORR of SAS software. Significance was as $\mathrm{P} \leq 0.05$. Statistical significance for gene expression was assessed using the analysis of variance (ANOVA) procedure of the $\mathrm{R}$ i386 software. When significant differences occur $(\mathrm{P}<0.05)$, means were separated by the least squares mean procedure, and then adjusted for multiple comparisons using the Tukey's multiple comparison test.

\section{Results}

\section{Body Weights, PUA, Tissue Uric Acid, and XOR activity}

Results for body mass, PUA, tissue uric acid, and XOR activity have been reported by Settle et al. (2012). Briefly, there were no differences $(P=0.853)$ in initial BM between the experimental groups (Table 1), after 1 week of treatment BM of the control birds was higher 
$(P<0.001)$ than that of the INO and INOAL birds. No differences $(P>0.05)$ were detected between INO and INOAL groups

As shown in Table 1, PUA concentrations were similar $(P=0.847)$ in all groups at the onset of the study. After 3 days of treatment, INO birds had higher $(P<0.001)$ PUA levels than controls and INOAL birds. The INOAL birds had significantly higher PUA levels than control birds. After 6 days of treatment, PUA concentrations remained elevated $(P<0.001)$ in INO and INOAL birds as compared to control birds, but there were no differences $(P>0.05)$ between INO and INOAL groups.

The effects of experimental treatments on $\mathrm{XO}$ and $\mathrm{XD}$ activities and UA concentrations in the liver and kidney are shown in Tables 2 and 3, respectively. After 6 days of treatment, INOAL birds had lower $(P=0.001)$ liver weights than birds in $\mathrm{CON}$ and INO groups, whereas no differences $(P>0.05)$ between $\mathrm{CON}$ and INO groups were detected. In addition, there were no differences $(P=0.673$ to 0.875$)$ between treatments in $\mathrm{XO}, \mathrm{XD}$, or $\mathrm{XO}+\mathrm{XD}$ activity at the end of the study. However, control birds had higher $(\mathrm{P}<0.05)$ total enzyme activity in the liver (units/liver) than INOAL birds, with no differences $(P>0.05)$ measured between control and INO groups. Concentrations of UA in the liver of INOAL birds, expressed both in $\mathrm{mg}$ per $\mathrm{g}$ of tissue and as total $\mathrm{mg}$ in the liver, were lower $(P<0.001)$ than those in the liver of control and INO birds, while there were no differences $(\mathrm{P}>0.05)$ between INO and CON birds. 
No differences ( $\mathrm{P}=0.510$ to 0.573$)$ in UA existed between any of the groups in enzyme activity of the kidney were detected (Table 3).

Kidney UA concentrations in CON birds were lower $(\mathrm{P}<0.05)$ than those found in the INO treatment, but no difference $(\mathrm{P}>0.05)$ was detected between CON and INOAL groups.

\section{XOR Gene Expression}

There was an upregulation of XOR gene expression in liver tissue (Figure 1) of the INOAL group when compared to both the CON $(\mathrm{p}=0.007)$ and INO $(\mathrm{p}=0.008)$ groups. There was no difference $(\mathrm{p}=0.996)$ in XOR gene expression in the liver between CON and INO groups. There was no significant difference in kidney XOR (Figure 2) gene expression between CON, INO, and INOAL groups $(\mathrm{p}=0.462, \mathrm{p}=0.906, \mathrm{p}=0.264$ respectively).

\section{Discussion}

The liver and kidney have been documented as sources of XOR activity in avian species (Harrison, 2002; Strittmatter, 1965; Carro et al., 2009b). The most studied form of XOR is XD, which is the more readily available form in the tissues. Little attention has been paid to $\mathrm{XO}$ in birds, although it has been identified in several tissues including the liver, kidney, intestine, and pancreas of broilers (Remy and Westerfield, 1951; Strittmatter, 1965; Carro et al., 2009a).

In this study, inosine, a precursor known to increase UA concentrations in birds (Simoyi et al., 2001), was administered separately and in combination with allopurinol (Settle et al., 2012). To our knowledge, this is the first study to investigate the effect of combining allopurinol and inosine on XOR activity, UA concentrations, and XOR gene expression. As previously reported, the administration of inosine did not affect birds BM, but the INOAL birds showed a decreased 
final BM at the end of the study as compared with control and INO birds. This is in accordance with previous observations in birds fed the same allopurinol dose (Carro et al., 2009b).

As in previous studies (Della Corte and Stirpe, 1967; Simoyi et al., 2002, 2003), birds in the INO group had significantly higher PUA than controls after 3 and 6 days of treatment, with INOAL birds having intermediate PUA concentrations but higher than in controls. This suggests that allopurinol was unable to completely inhibit XOR activity. Unexpectedly, liver UA concentrations were not affected by the administration of inosine, despite the higher UA concentrations observed in plasma and kidney of INO birds compared with the controls (3.2 and 7.1 times higher, respectively). These results suggest a different regulating mechanism of UA concentrations in liver and kidney.

Although it was reported that there were no differences in the XOR activity in the liver between groups, when total $\mathrm{XO}+\mathrm{XD}$ activity in the liver was calculated, the INOAL birds showed significantly lower total enzyme activity, indicating that allopurinol was inhibiting enzyme activity as compared to control birds, which confirms the results observed in Settle et al. (2012) when birds fed diets containing allopurinol (25mg/kg BW) were supplemented with uric acid exhibited no change in XO or XD activity, but demonstrated a reduction in total enzyme activity. In accordance with that observation, the birds in the INOAL group exhibited significantly lower UA concentrations in the liver as compared with control and INO birds. This observation suggests a pronounced residual effect of allopurinol or oxypurinol, regardless of the presence of inosine which is converted into UA. The lack of differences in liver UA concentrations and XOR activity between control and INO birds indicates that inosine had no effect on UA concentrations or enzyme activity in the liver. 
To our knowledge, this is the first report of XOR gene expression in birds. The chicken XD gene was first cloned by Sato et al. (1995) and was found to contain 1358 nucleotides. In this study, there was a significant induction of XOR gene expression in liver tissue of INOAL birds. Given that the liver UA content was significantly decreased it can be hypothesized that the liver may be vulnerable to oxidative damage due to a reduction in antioxidant defense. Simoyi et al. (2001) showed that a decrease in uric acid of the plasma can be linked to an increase in leukocyte oxidative activity, which suggests that the increase in XOR gene expression represents a compensatory mechanism to reduce oxidative damage to this tissue. A study by Dupont et al. (1992) reported that there was an increase in XD/XO gene expression at the transcriptional level in rat endothelial cells under treatment with IFN- $\gamma$, linking an increase in this gene with an increase in pro-inflammatory cytokines. Furthermore, there is evidence that uric acid, a scavenger of peroxynitrite, exhibits protective properties in the inhibition of CNS inflammation as well as the blood-CNS barrier that has been compromised by peroxynitrite damage (Hooper et al., 2000). It is suggested that there is an increase in oxidative damage and inflammation in INOAL birds which may be directly related to the reduction in uric acid in the liver thereby causing a concomitant increase in the XOR gene expression.

There was not a significant difference in the kidney tissue with respect to XOR gene expression, indicating that there are tissue-specific differences in regulation of UA. A study by Suzuki et al. (1984) using a rat model, suggested that liver and kidney tissue may show differences in sensitivity to allopurinol doses such that a range of $10-100 \mathrm{mg} / \mathrm{kg} \mathrm{BW} /$ day can be toxic resulting in hepatic necrosis and renal damage in some cases. In the case of the kidney, it was found that relative kidney weight, creatinine, and BUN increased at doses above $10 \mathrm{mg} / \mathrm{kg}$ BW, indicative of renal damage and it was concluded that the kidney may be more sensitive to 
allopurinol, but the mechanism was not determined (Suzuki et al., 1984). In birds uric acid is packaged in protein vesicles in the kidney before secretion (Braun and Dantzler, 1997) and the insoluble uric acid crystals are excreted along with fecal material from the cloaca (Skinner et al., 2001). Uric acid is actively transported by MRP4 from the proximal tube epithelium (Bataille et al., 2008). The mechanism of transport from the avian liver is, to our knowledge, unknown. These results also indicate that the regulation of uric acid differs between tissues.

In conclusion, these studies show that allopurinol had a residual toxic effect in the liver and kidney, as indicated by chronically depressed UA concentrations in both tissues. The low UA tissue concentrations reported by Settle et al. (2012) are an indication of increased susceptibility to oxidative stress, due to the inverse relationship that UA has with oxidative stress. There was a significant increase in XOR gene expression in liver tissue, indicative that a reduction in concentrations of uric acid may initiate a compensatory up-regulation of the XOR gene to restore antioxidant protection to the tissue. However, this was not demonstrated in kidney tissue, which indicates that the mechanisms regulating UA production in liver and kidney may differ. Future work with the allopurinol model of inflammation will further increase our understanding of the role that XOR has within the avian and the importance in the regulation of uric acid in the antioxidant defense system.

\section{References}

1. Bradford, M.M., (1976). A rapid and sensitive method for quantitation of microgram quantities of protein utilizing the principle of protein-dye-binding. Anal Biochem 72, 248-54.

2. Bataille, AM., Goldmeyer, J., Renfro, J. L. (2008). Avian renal proximal tubule epithelium urate secretion is mediated by Mrp4. Am J Physiol Integr Comp Physiol 295:2024-2033 
3. Braun, E. and W. Dantzler. (1997). Vertebrate renal system. In: Handbook of Physiology.Comparative Physiology. Bethesda, MD: American Physiological Society, sect.13, vol I, chapt. 8, pp 481-576.

4. Carro, M.D, E. Falkenstein, K.P. Blemings, H. Klandorf.(2009a). Determination of xanthine oxidoreductase activity in broilers: effect of $\mathrm{pH}$ and temperature of the assay and distribution in tissues. Poult Sci 88, 2406-2414.

5. Carro, M.D., E. Falkenstein, W.J. Radke, H. Klandorf. (2009b). Effects of allopurinol on uric acid concentrations, xanthine oxidoreductase activity, and oxidative stress in broiler chickens. Comp Biochem Physiol C 151, 12-17.

6. Cazzaniga, G., Terao, M., Lo Schiavo, P., Galbiati, F., Segalla, F., Seldin, M.F., Garattino, E. (1994). Chromosomal mapping, isolation, and characterization of the mouse xanthine dehydrogenase gene. Genomics 23: 390-402

7. Della Corte, E., F. Stirpe.(1967). Regulation of xanthine dehydrogenase in chick liver: further experiments on the effects of inosine, actinomycin D, and other factors. Biochem J 102, 520-524.

8. Dupont, G.P., Hueksteadt, T.P., Marshall, B.C., Ryan, U.S., Michael, J.R., Hoidal, J.R. (1992). Regulation of xanthine dehydrogenase and xanthine oxidase activity and gene expression in cultured rat pulmonary endothelial cells. Journal of Clinical Investigation 89:197-202

9. Galbusera, C., P. Orth, D. Fedida, T. Spector. (2006). Superoxide radical production by allopurinol and xanthine oxidase. Biochem Pharmacol 71, 1747-1752.

10. Harrison, R. (2002). Structure and function of xanthine oxidoreductase: where are we now? Free Radic Biol Med 33, 774-797.

11. Hooper, D.C., Scott, G.S., Zborek, A., Miksheeva, T., Kean, R.B., Koprowski, H., Spitsin, S.V. (2000). Uric acid, a peroxynitrite scavenger, inhibits CNS inflammation, blood-CNS barrier permeability changes, and tissue damage in a mouse model of multiple sclerosis. FASEB Journal. 14: 691-698

12. Hille, R. and V. Massey (1981). Studies on the oxidative half-reaction of xanthine oxidase. J Biol Chem 256, 9090-9095. 
13. Itoh, R., T. Nishino, C. Usami, K.Tsushima, (1978). An immunochemical study of the changes in chicken liver xanthine dehydrogenase activity during dietary adaptation. $\mathrm{J}$ Biochem 84, 19-26.

14. Klandorf, H., D.S. Rathore, M. Iqbal, X. Shi, K. VanDyke. (2001). Accelerated tissue aging and increased oxidative stress in broiler chickens fed allopurinol. Comp Biochem Physiol C 129, 93-104.

15. Lee, P.C., J.R. Fisher. (1972). Effect of allopurinol on the accumulation of xanthine dehydrogenase in liver and pancreas of chicks after hatching. Arch Biochem Biophys 148, 277-281.

16. Nishino,T., T. Nishino. L. Schopfer, V. Massey. (1989). The reactivity of chicken liver xanthine dehydrogenase with molecular oxygen. J Biol Chem 264, 2518-2527.

17. Oda, M., Satta, Y., Takenaka, O., Takahata, N. (2002). Loss of urate oxidase activity in hominoids and its evolutionary implications. Mol. Biol. Evol. 19 (5): 640-653

18. Pfaffl, M. W. (2001). A new mathematical model for relative quantification in real-time RT-PCR. Nucleic acids research, 29(9), e45-e45.

19. Remy, C., W.W. Westerfeld. (1951). The effect of diet on xanthine dehydrogenase in chicken tissues. J Biol Chem 193, 659-667.

20. Sato, A., Nishino, T., Noda, K. (1995). The structure of chicken liver xanthine dehydrogenase: cDNA cloning and the domain structure. Journal of Biological Chemistry 270: $2818-2826$

21. Scholz, R.W., W.R. Featherston. (1967). Effect of alterations in protein intake on liver xanthine dehydrogenase in the chick. J Nutr 95, 271-277.

22. Settle,T.,Carro, M.d., Falkenstein, E., Radke, W., Klandorf, H. (2012). The effects of allopurinol, uric acid, and inosine administration on xanthine oxidoreductase activity and uric acid concentrations in broilers. Poultry Science 91:2895-2903.

23. Simoyi, M., K. VanDyke, H. Klandorf. (2002). Manipulation of plasma uric acid in broiler chicks and its effect on leukocyte oxidative activity. Am J Physiol Regulatory Integrative Comp Phsyiol 282: 791-796.

24. Skinner KA, Tan, S., Parks, D.A. (2001). Uric Acid Metabolism. Encyclopedia of Life Sciences. Nature Publishing Group / www.els.net. pp. 1-8. 
25. Stinefelt, B., S.S. Leonard, K.P. Blemings, X.Shi, H. Klandorf. (2005). Free Radical Scavenging, DNA protection, and inhibition of lipid peroxidation mediated by uric acid. Ann Clin Lab Sci 35, 37-45.

26. Stirpe, F., E.Della Corte. (1965). Regulation of xanthine dehydrogenase in chick liver. Effect of starvation and of administration of purines and purine nucleosides. Biochem. J. 94, 309-313.

27. Strittmatter, C.F., (1965). Studies on avian xanthine dehydrogenases: properties and patterns of appearance during development. J Biol Chem 240, 2557-2564.

28. Suzuki, Y., Sudo ,J. TanAbe, T. (1984). Allopurinol toxicity: its toxic organ specificity between the liver and kidney in the rat. The Journal of toxicological sciences 9:343-351

29. Terao, M., Kurosaki, M., Zanotta, S., Garattini, E. (1997) The xanthine oxidoreductase gene : structure and regulation. Biochemical Society Transactions 25: 14170-14175

30. Xu, P., Zhu, X.L., Huecksteadt, T.P., Brothman, A.R., Hoidal, J.R. (1995). Assignment of human xanthine dehydrogenase to chromosome 2p22. Genomics 23: 289-291

31. Xu, P., Hueksteadt, T.P., Hoidal, J.R. (1996). Molecular cloning and characterization of the human xanthine dehydrogenase gene. Genomics 34: 173-180

32. Woodward, W.D., P.C. Lee, N.W. DeLapp, J.R. Fisher. (1972). Induction of chick liver xanthine dehydrogenase by purines. Arch Biochem Biophys 153, 537-542. 


\section{XOR Gene Expression in Liver Tissue}

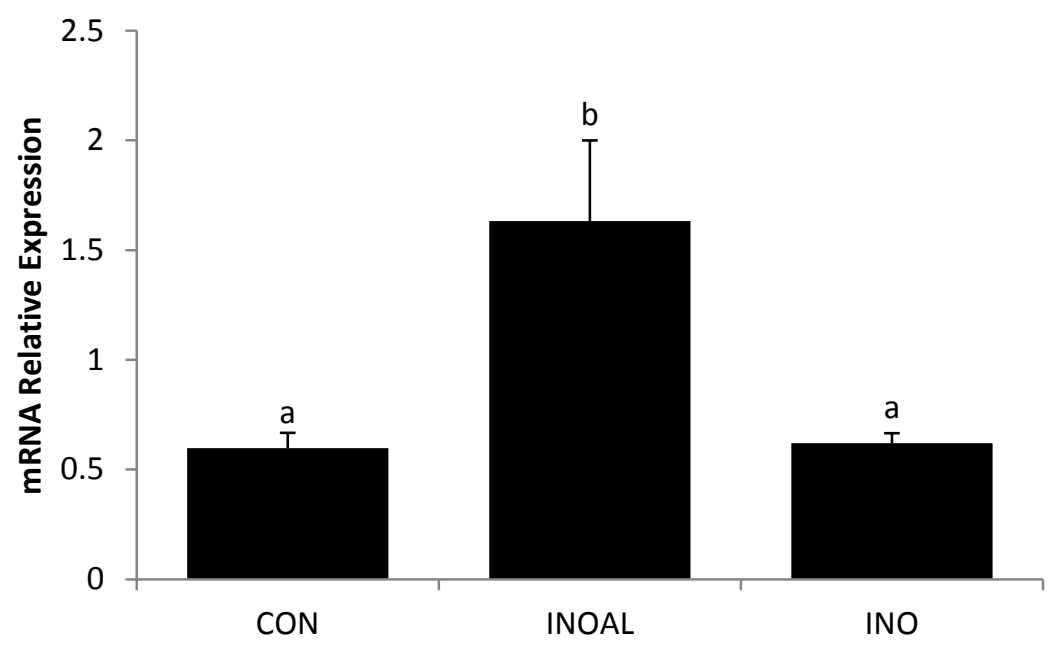

Figure 1. Effects of experimental treatments (CON: 0; INO: $161 \mathrm{~g}$ of inosine $/ \mathrm{kg}$ feed; INOAL: $161 \mathrm{~g}$ of inosine plus $0.5 \mathrm{~g}$ of allopurinol $/ \mathrm{kg}$ feed) XOR gene expression in the liver tissue of broilers $(\mathrm{n}=5)$. ${ }^{\mathrm{a}, \mathrm{b}}$ For each variable, means a bar lacking a common superscript differ $(P<0.05)$. Error bars represent SEM for each treatment. 


\section{XOR Gene Expression in Kidney Tissue}

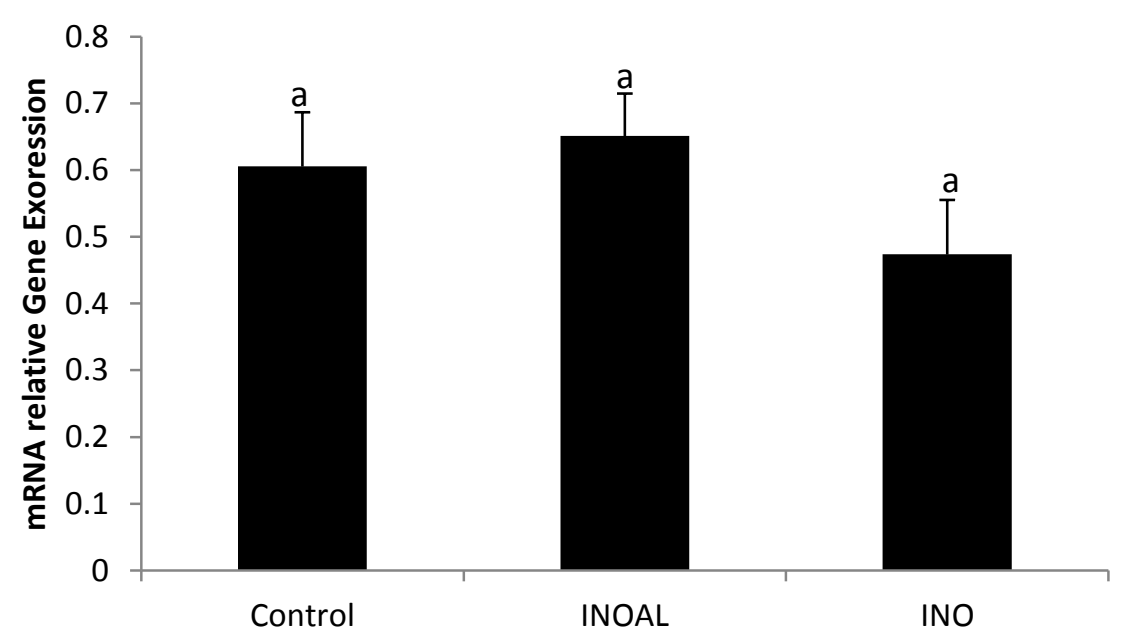

Figure 2. Effects of experimental treatments (CON: 0; INO: $161 \mathrm{~g}$ of inosine/kg feed; INOAL: $161 \mathrm{~g}$ of inosine plus $0.5 \mathrm{~g}$ of allopurinol $/ \mathrm{kg}$ feed) XOR gene expression in the kidney tissue of broilers $(\mathrm{n}=5)$. ${ }^{\mathrm{a}, \mathrm{b}}$ For each variable, means a bar lacking a common superscript differ $(P<0.05)$. Error bars represent SEM for each treatment. 


\section{Table 1}

Effects of experimental treatments (CON: 0; INO: $161 \mathrm{~g}$ of inosine/kg feed; INOAL: $161 \mathrm{~g}$ of inosine plus $0.5 \mathrm{~g}$ of allopurinol $/ \mathrm{kg}$ feed) on plasma uric acid concentrations and body mass $(\mathrm{BM})$ and in broilers $(\mathrm{n}=5)$

\begin{tabular}{lcccccc}
\hline & & & & \multicolumn{2}{c}{ Plasma uric acid (mg/dL) } \\
\cline { 5 - 6 } \cline { 5 - 6 } Treatment & $\begin{array}{c}\text { Initial BM } \\
(\mathrm{kg})\end{array}$ & $\begin{array}{c}\text { Final BM } \\
(\mathrm{kg})\end{array}$ & & Day 0 & Day 3 & Day 6 \\
\hline CON & 2.26 & $2.87^{\mathrm{b}}$ & & 5.12 & $4.41^{\mathrm{a}}$ & $4.46^{\mathrm{a}}$ \\
INO & 2.19 & $2.65^{\mathrm{b}}$ & & 4.93 & $18.6^{\mathrm{c}}$ & $14.3^{\mathrm{b}}$ \\
INOAL & 2.23 & $2.07^{\mathrm{a}}$ & & 4.96 & $13.9^{\mathrm{b}}$ & $12.0^{\mathrm{b}}$ \\
SEM & 0.080 & 0.110 & & 0.530 & 1.070 & 1.133 \\
$P=$ & 0.853 & $<0.001$ & & 0.847 & $<0.001$ & $<0.001$ \\
\hline
\end{tabular}

${ }^{\mathrm{a}, \mathrm{b}, \mathrm{c}}$ For each variable, means within a column lacking a common superscript differ $(P<0.05)$.

SEM: standard error of the mean. 


\section{Table 2}

Effects of experimental treatments (CON: 0; INO: $161 \mathrm{~g}$ of inosine/kg feed; INOAL: $161 \mathrm{~g}$ of inosine plus $0.5 \mathrm{~g}$ of allopurinol $/ \mathrm{kg}$ feed) on liver weight, activities of xanthine oxidase (XO) and xanthine dehydrogenase (XD) and uric acid concentration in the liver of broilers $(n=5)$.

\begin{tabular}{|c|c|c|c|c|c|c|c|}
\hline \multirow[b]{2}{*}{ Treatment } & \multirow[b]{2}{*}{$\begin{array}{l}\text { Liver weight } \\
\text { (g) }\end{array}$} & \multicolumn{3}{|c|}{$\begin{array}{c}\text { Activity } \\
\text { (units/mg protein) }\end{array}$} & \multirow[b]{2}{*}{$\begin{array}{c}\text { Total XO + XD } \\
\text { activity } \\
\text { (units/liver) }\end{array}$} & \multicolumn{2}{|c|}{ Uric acid } \\
\hline & & XO & XD & $\underset{\mathrm{XD}}{\mathrm{XO}+}$ & & $\begin{array}{l}\mathrm{mg} / \mathrm{g} \text { wet } \\
\text { tissue }\end{array}$ & $\begin{array}{l}\text { total } \mathrm{mg} \text { in } \\
\text { the liver }\end{array}$ \\
\hline $\mathrm{CON}$ & $60.8^{b}$ & 7.92 & 37.9 & 45.9 & $24.7^{b}$ & $0.262^{b}$ & $15.5^{b}$ \\
\hline INO & $53.6^{b}$ & 7.97 & 37.2 & 44.6 & $20.9^{a b}$ & $0.266^{b}$ & $14.3^{b}$ \\
\hline INOAL & $41.2^{\mathrm{a}}$ & 7.33 & 35.7 & 43.7 & $16.2^{\mathrm{a}}$ & $0.093^{\mathrm{a}}$ & $3.76^{\mathrm{a}}$ \\
\hline SEM & 2.82 & 0.559 & 2.50 & 3.00 & 1.49 & 0.0333 & 1.582 \\
\hline$P=$ & 0.001 & 0.673 & 0.812 & 0.875 & 0.005 & 0.005 & $<0.001$ \\
\hline
\end{tabular}

${ }^{\mathrm{a}, \mathrm{b}}$ For each variable, means within a column lacking a common superscript differ $(P<0.05)$.

SEM: standard error of the mean. 


\section{Table 3}

Effects of experimental treatments (CON: 0; INO: $161 \mathrm{~g}$ of inosine /kg feed; INOAL: $161 \mathrm{~g}$ of inosine plus $0.5 \mathrm{~g}$ of allopurinol $/ \mathrm{kg}$ feed) on activities of xanthine oxidase (XO) and xanthine dehydrogenase (XD) and uric acid concentration in the kidney of broilers $(n=5)$.

\begin{tabular}{lcccc}
\hline & \multicolumn{3}{c}{ Activity (units/mg protein) } & \\
\cline { 2 - 4 } Treatment & XO & XD & XO + XD & $\begin{array}{c}\text { Uric acid (mg/g wet } \\
\text { tissue) }\end{array}$ \\
\hline CON & 5.80 & 34.2 & 40.0 & $0.084^{\mathrm{a}}$ \\
INO & 5.49 & 31.5 & 37.0 & $0.596^{\mathrm{b}}$ \\
INOAL & 5.22 & 31.0 & 36.2 & $0.139^{\mathrm{a}}$ \\
SEM & 0.341 & 2.28 & 2.56 & 0.1193 \\
$P=$ & 0.510 & 0.573 & 0.554 & 0.006 \\
\hline
\end{tabular}

${ }^{\mathrm{a}, \mathrm{b}}$ For each variable, means within a column lacking a common superscript differ $(P<0.05)$.

SEM: standard error of the mean. 
Chapter 2. The Effect of Allopurinol Administration on Mitochondrial Respiration and Gene Expression of Xanthine Oxidoreductase, iNOS, and Inflammatory Cytokines in selected Tissues of Broiler Chickens

T.Settle, E.Falkenstein, and H.Klandorf 


\section{Abstract}

Birds have a remarkable longevity for their body size despite an increased body temperature, higher metabolic rate, and increased blood glucose concentrations compared to most mammals. Theoretically, birds should sustain a much higher degree of oxidative damage yet do not, in part due to the powerful antioxidant, uric acid. As the end-product of purine degradation, uric acid is generated in the xanthine/hypoxanthine reactions catalyzed by xanthine oxiodreductase (XOR). In the first study, Cobb x Cobb broilers $(n=12 ; 4$ weeks old $)$ were separated into two treatments $(n=6)$; control $(\mathrm{CON})$ and AL (allopurinol 35mg/kg BW). The purpose of this study was to assess mitochondrial function in broiler chickens in response to potential oxidative stress generated from the administration of allopurinol. Mitochondria were freshly isolated from liver tissue and assessed for State III and State IV respiration using polarography. There was a significant reduction in State III respiration $(\mathrm{p}=0.01)$ and State IV respiration $(\mathrm{p}=0.007)$ in allopurinol-treated birds compared to the controls. The purpose of the second study was to assess the effect of allopurinol on gene expression of inflammatory cytokines IFN- $\gamma$, IL-1 $\beta$, IL-6 and IL-12p35 as well as iNOS and XOR in liver tissue. Cobb x Cobb broilers were separated into two groups at 4 weeks of age $(n=10)$; control $(\mathrm{CON})$ and ALLO (allopurinol 35mg/kg BW). After one week of allopurinol treatment, half of the birds in each group (CON 1 and ALLO 1) were euthanized while the remaining birds continued on allopurinol treatment for an additional week (CON 2 and ALLO 2). A significant increase in gene expression of XOR, IFN- $\gamma$, IL-1 $\beta$, and IL-12p35 in ALLO 2 birds as compared to birds in CON 2 was detected. iNOS was numerically increased in ALLO 2 birds though this was not significant $(\mathrm{p}=0.076)$. Liver uric acid content was significantly 
decreased in both ALLO 1 $(\mathrm{p}=0.003)$ and ALLO $2(\mathrm{p}=0.012)$ birds when compared to CON1 and CON 2 respectively. No differences in body weight (BW) were measured from 0-7 days of treatment in any of the groups. However, there was a significant decrease in BW of ALLO 2 birds when compared to CON 2 birds at $10(\mathrm{p}=0.011)$ and 14 days $(\mathrm{p}=0.012)$ of treatment. The reduced uric acid concentration in the liver suggests that allopurinol treatment leads to a lowered antioxidant activity leading to increased oxidative stress and inflammation in this tissue which results in mitochondrial dysfunction.

Key Words: Uric Acid, Allopurinol, Mitochondrial Respiration, and Inflammation 


\section{Introduction}

Birds have a remarkable longevity for their body size despite an increased body temperature, higher metabolic rate, and increased blood glucose concentration compared with mammals (Holmes and Austad, 1995). Theoretically, birds should sustain a much higher degree of oxidative damage (Monnier et al., 1991). Despite comparatively low mitochondrial reactive oxygen species (ROS) production, there is cumulative oxidative damage by ROS as evidenced by the accumulation of pentosidine throughout the bird's lifespan (Barja, 1998; Chaney et al., 2003). To cope with this production of ROS over time, birds must utilize a more efficient antioxidant defense system.

Oxidative stress can contribute to inflammation by activating select transcription factors including NF- $\mathrm{BB}$, PPAR $\gamma$, and AP-1 which are associated with the pathogenesis of disease processes (Reuter et al., 2010). In turn, activation of these transcription factors can lead to the expression of genes coding for inflammatory cytokines and chemokines amongst other regulatory molecules. ROS are involved in a broad spectrum of diseases associated with chronic inflammation, neurodegenerative diseases, and some cancer mechanisms (Reuter et al., 2010). Induction of these chemokines and cytokines as well as nitric oxide synthase (NOS), the enzyme family responsible for the conversion of L-arginine and NADPH to nitric oxide (NO) and Lcitrulline, have been reported to have a role in oxidative stress induced inflammation (Hussain and Harris, 2007). Furthermore, inducible nitric oxide synthase (iNOS) can be activated by IFN$\gamma$ (Guzik et al., 2003). Inflammation, an increase in oxidative stress, and a decrease in NO production have been linked to pulmonary hypertension syndrome and mitochondrial 
dysfunction in the liver and heart of broiler chickens (Chapmen and Wideman, 2006).

Dysfunction of cardiac, liver and lung mitochondria resulting in an increase in ROS production have been linked with inflammation and can be considered a possible underlying factor in pulmonary hypertension syndrome in broilers (Tang et al., 2002; Cawthon et al., 2000; Iqbal et al., 2000).

Birds, comparable to other species, rely on exogenous and endogenous antioxidant defense systems. Uric acid is a potent antioxidant and it is arguably, the dominant antioxidant defense mechanism for birds (Seaman et al., 2008, Stinefelt et al., 2005, Machin et al., 2004, Simoyi et al., 2002, Klandorf et al., 2001). Due to the evolutionary lack of urate oxidase expression, also known as uricase, birds (comparable to reptiles, higher primates, and humans) do not convert uric acid to allantoin and so uric acid is the end product of purine degradation in birds. In models of multiple sclerosis, urate is known to scavenge peroxynitrite radicals (Hooper et al., 2000).

The enzyme xanthine oxidoreductase (XOR) catalyzes the reaction between hypoxanthine and xanthine to form uric acid. This enzyme is present in two forms: xanthine dehydrogenase (XD) and xanthine oxidase (XO). In birds, XD is the predominant form in the liver, kidney, pancreas, intestine, and other tissues (Harrison, 2002). Recently, however, XO activity has been measured in chicken liver, kidney, pancreas, and intestine (Carro et al., 2009a). Settle et al. (2012) reported that allopurinol, an inhibitor of XOR, reduced tissue uric acid concentrations in the liver of broiler chickens, so creating a residual toxic effect in the liver, which potentially leads to an increase in oxidative damage. Furthermore, a combination of the purine precursor to uric acid, inosine, when combined with allopurinol failed to maintain either liver or kidney uric acid concentrations while XOR activity remained unchanged in the kidney 
but was lowered in the liver of allopurinol-fed birds which suggested a tissue dependent regulation of this enzyme (Settle et al., 2012). Lee and Fisher (1972) reported that chicks fed allopurinol at a dose of $75 \mathrm{mg} / \mathrm{g}$ feed from 1-28 days of age showed an increase in XOR activity in the liver concomitant with a decrease in uric acid content. The authors suggested that these data provided evidence for a feedback mechanism via the purine precursors to restore tissue uric acid concentrations.

This study was designed to better understand the factors that regulate XOR gene expression and the role of uric acid as an antioxidant in the liver tissue. We hypothesized that XOR inhibition with allopurinol would decrease uric acid, which would result in an increase in XOR gene expression in response to the reduced UA levels. Secondly, lowered protection by UA in the liver is hypothesized to induce mitochondrial dysfunction and inflammation leading to an increase in oxidative damage and ultimately, a decline in bird health. To our knowledge, this is the first time that mitochondrial function and markers of inflammation will be measured in the liver tissue of broilers under these experimental conditions.

\section{Materials and Methods}

All experimental protocols were approved by the West Virginia University Animal Care and Use Committee.

\section{Experiment 1}

The purpose of this study was to determine the preliminary effects of administering allopurinol (AL) on mitochondrial respiration and respiratory control ratio, in order to identify sources of oxidative stress in selected tissues. To our knowledge, a link between reduced UA in the tissue and indices of mitochondrial function has not been established in broiler chickens. 
Broilers and Experimental Procedures. Twenty mixed sex Cobb 500 (Cobb xCobb ) broilers (one day of age) were donated from a local hatchery (Pilgrim's Pride, Moorefield, WV) and maintained under standard husbandry practices. At 4 weeks of age, twelve birds were separated into two groups CON (control, no allopurinol) and AL (allopurinol). AL birds were administered allopurinol in the feed at a dose of $35 \mathrm{mg} / \mathrm{kg} \mathrm{BW}$. Previously, Carro et al (2009a) and Settle et al. (2012) demonstrated that a dose range of $25-50 \mathrm{mg} / \mathrm{kg} \mathrm{BW}$ successfully lowered plasma and tissue uric acid, so for this study an intermediary dose of $35 \mathrm{mg} / \mathrm{kg}$ BW was selected. BW was measured at the beginning and the end of the study. Birds in the AL group were administered allopurinol for one week. At this time, control and AL birds were euthanized by cervical fracture. Heart (left ventricle) and liver tissue were excised, weighed, and immediately placed in ice cold phosphate buffered saline (PBS) pH 7.0 for mitochondrial extraction and analysis. Remaining tissue was stored at $-80^{\circ} \mathrm{C}$. Relative liver and heart weights were calculated as the ratio of tissue weight to body weight multiplied by 100 . Heart tissue was used as a control for the measurement of respiration.

Mitochondrial Isolation. Mitochondrial and cytosolic fractions were freshly isolated using the Mitochondria/Cytosolic Fractionation kit (BioVision Inc. San Francisco, CA, USA) according the manufacture's protocol. Briefly, tissues were rinsed in PBS, blotted dry, and then weighed. Approximately $1 \mathrm{~g}$ of tissue was minced and homogenized. Homegenates were centrifuged at centrifuge at $700 \times \mathrm{xg}(3000 \mathrm{rpm})$ for 10 minutes at $4^{\circ} \mathrm{C}$ and supernatant was transferred to $1.5 \mathrm{~mL}$ microcentrifuge tube and spun at $10,000 \mathrm{xg}(13000 \mathrm{rpm})$ for 30 minutes at $4^{\circ} \mathrm{C}$. The supernatant was collected (cytosolic fraction) and stored at $-80^{\circ} \mathrm{C}$ until analyzed. The resulting pellet was resuspended (mitochondrial fraction) in $0.5 \mathrm{~mL}$ mitochondria suspension buffer $(70 \mathrm{mM}$ sucrose, 
220mM mannitol, 2mM HEPES at $\mathrm{pH} 7.4$, and $1 \mathrm{mM}$ EDTA). Protein was measured using the Coomassie Bradford Protein Assay Kit (Bio Rad, USA).

Measurement of State 3 and State 4 Respiration and Respiratory Control Ratio. State 3 (active) and State 4 (resting) respiration were measured and analyzed for each tissue type using the OX1LP Dissolved Oxygen Package (Qubit Systems, Canada) polarography software. $1.5 \mathrm{~mL}$ of respiration buffer was added to each chamber along with $1 \mathrm{mg} / \mathrm{mL}$ BSA (bovine serum albumen) to calibrate each chamber. $40 \mu \mathrm{L}$ of each individual sample was added to the chamber at 0 minutes, $15 \mu \mathrm{L}$ of a $1: 1$ ratio of glutamate $(5 \mathrm{nM})$ and malate $(5 \mathrm{mM})$ was added at 3 minutes to initiate the electron transport chain, and $6 \mu \mathrm{L}$ of $250 \mathrm{mM}$ ADP was added at 5 minutes to the reaction. Oxygen consumption was read for approximately 40 minutes per sample. Respiration is reported as mmol of oxygen consumed per minute per milligram of protein. The first slope of the resulting respiration graph corresponds to State 3 respiration while the second slope corresponds to State 4 respiration. Means for each treatment were analyzed and graphed. Respiratory control ratio (RCR) is calculated by the division of State 3 by State 4 slopes.

Measurement of cytosolic uric acid. Cytosolic UA content was measured using a modification of the protocols for plasma uric acid from Settle et al. (2012). Briefly, the UA concentration in $40 \mu \mathrm{L}$ samples of cytosol from liver and heart tissue was measured by using a commercially available colorometric diagnostic kit (Sigma Diagnostic kit procedure 685; Sigma Diagnostics, St. Louis, MO). This method employs uricase to generate $\mathrm{H}_{2} \mathrm{O}_{2}$ which reacts with 4aminoantipyrine (4-AAP) and TBHB (tribromo-3 hydroxy benzoic acid) in the presence of peroxidise to form a quinoneimine dye. The resulting change in absorbance at $520 \mathrm{~nm}$ is proportional to UA concentration in the sample. 


\section{Experiment 2}

The purpose of this study is to establish whether a reduction in uric acid can lead to an increase in inflammation in the liver tissue and whether XOR gene expression is upregulated in a compensatory response to re-establish antioxidant defense mechanisms. To our knowledge this has not been established for broiler chickens.

Birds and Experimental Procedures. Thirty mixed sex Cobb 500 (Cobb x Cobb) broilers (one day of age) were generously donated from a local hatchery (Pilgrim's Pride, Moorefield, WV) and maintained under standard husbandry practices. At 4 weeks of age, 20 birds were separated and placed into two groups ( $\mathrm{n}=10$ per group): CON (control) and ALLO (allopurinol). CON birds were given a commercial diet with no allopurinol inclusion. ALLO birds were administered allopurinol at a dose of $35 \mathrm{mg} / \mathrm{kg} \mathrm{BW}$ as in experiment 1 . After one week of allopurinol administration half of the birds in each group (CON 1 and ALLO 1) were euthanized by cervical fracture. The liver of each bird was removed, placed in a sterile bag, and immediately frozen in liquid nitrogen. Samples were stored in a $-80^{\circ} \mathrm{C}$ freezer until analysis. Remaining birds (CON 2 and ALLO 2) were maintained on treatment for an additional week before euthanasia and tissue removal. Relative liver weight was calculated as described for experiment 1 . Birds in each group were weighed at 0,3,6, and 7 days. Additionally, CON 2 and ALLO 2 birds were weighed at 10 and 14 days. Feed intake was monitored at these time intervals as well and doses of allopurinol were adjusted accordingly throughout the experimental period.

cDNA synthesis. Total mRNA from $1 \mathrm{mg}$ of liver tissue was extracted using RNA-Bee isolation medium (Tel-Test, TX) and quantified using a Genequant spectrophotometer. First strand cDNA was synthesized by using Life Technologies' Superscript II Indirect cDNA Labeling System 
(Life, Carlsbad, CA ) according to the manufacturer's instructions. Briefly, each reaction mixture contained $2.5 \mu \mathrm{L}$ of $2.5 \mathrm{mM}$ dNTP mixture, $5.0 \mu \mathrm{L}$ of $5 \mathrm{x}$ reverse transcriptase buffer, $2.0 \mu \mathrm{L}$ of 0.1M Dithiothreitol (DTT), $0.5 \mu \mathrm{L}$ RNasin (Promega), and $2.0 \mu \mathrm{L}$ random hexamer primers (Roche Scientific). The final cDNA concentration was $1.8 \mu \mathrm{g} / \mu \mathrm{L}$. Each sample was heated to $70^{\circ} \mathrm{C}$ for five minutes and then $4^{\circ} \mathrm{C}$ for five minutes in a MJ Research PTC-200 DNA Engine (MJ Research Inc. Watertown, MA, USA). At this time reverse transcriptase was added to each sample and cycled at $37^{\circ} \mathrm{C}$ for sixty minutes, $90^{\circ} \mathrm{C}$ for five minutes, and $4^{\circ} \mathrm{C}$ for five minutes. Samples were stored at $-80^{\circ} \mathrm{C}$ until assayed with real-time RT-PCR.

Real-Time RT-PCR. Primers XOR, IL-1 $\beta$, IFN- $\gamma$, IL-6, IL-12p35, iNOS and Glyceraldehyde 3phosphate dehydrogenase (GAPDH) were designed (Table 1) using Primer3 software (Howard Hughes Institute). Each sample was run in triplicate for the XOR and GAPDH primers on a 96well plate. GAPDH was selected as a housekeeping gene as no differences in expression patterns were expected due to treatment. A pooled sample, that contains cDNA samples from all treatments, was used for both analyses of primer efficiencies. Primers were diluted to $5 \mu \mathrm{M} / \mu \mathrm{L}$ concentration in nuclease free water. A serial dilution was used to obtain a standard curve for each primer and the efficiency of each primer was calculated. Primer efficiencies were determined from the slope of the regression line of the log of the cDNA concentrations versus the $\mathrm{Ct}$ value by the equation $\mathrm{E}=10^{(-1 / \mathrm{Slope})}$. The efficiencies were used to calculate the relative mRNA abundance using the "efficiency corrected relative expression" equation (Equation 3; Pfaffl, 2001). Real time RT-PCR was performed using IQ Sybr Green Supermix (Bio Rad Inc., USA) on a Bio Rad CFX 96 Real-Time System (Bio Rad Inc. USA). Each PCR reaction mixture contained $10 \mu \mathrm{L}$ IQ Sybr Green Supermix, $3 \mu \mathrm{L}$ diluted cDNA, $1 \mu \mathrm{L}$ each of the forward and reverse primer (diluted to $5 \mu \mathrm{g} / \mu \mathrm{L}$ ), and $5 \mu \mathrm{L}$ of nuclease-free water. Each sample was run in 
triplicate on a 96 well plate. The PCR reaction cycle was as follows: $95^{\circ} \mathrm{C}$ for $3 \mathrm{~min}, 95^{\circ} \mathrm{C}$ for 15 sec, $60^{\circ} \mathrm{C}$ for $30 \mathrm{sec}, 70^{\circ} \mathrm{C}$ for $30 \mathrm{sec}$. (repeated for 40 cycles) then intervals of $95^{\circ} \mathrm{C}$ and $60^{\circ} \mathrm{C}$ for $5 \mathrm{~min}$.

Liver uric acid content. Concentration of UA in liver samples was measured using the technique described for cytosolic UA as modified by Settle et al. (2012). Briefly, 0.5g of liver tissue was weighed and homogenized in $2 \mathrm{~mL}$ of ice-cold $0.1 \mathrm{M}$ TRIS buffer $(\mathrm{pH}=7.8)$ and centrifuged at $14,000 \times \mathrm{g}$ at $4^{\circ} \mathrm{C}$ for 30 minutes. Concentrations of UA were analyzed in $40 \mu \mathrm{L}$ aliquots of the supernatant fraction.

Statistical Analysis. In Experiment 1, the mitochondrial respiration states were analyzed using the t-test function of the GraphPad Prism 6 Software (GraphPad Software Inc, CA, USA). Data was analyzed as the difference between groups for State 3 respiration and the difference between groups for State 4 respiration. State 3 was not compared to State 4 . Body weight data, relative liver weight, relative heart weight, RCR, and cytosolic uric acid content were analyzed by using the t-test function of JMP Software (SAS institute, USA).

In Experiment 2, the body weights were analyzed as a repeated measures for time by treatment effects from 0-7 days for $\mathrm{n}=10$ birds using the MIXED PROC procedure of SAS (SAS Institute) to obtain the least-squared means. Tukey's HSD was used to determine differences between each group. Body weights were also analyzed for CON 2 and ALLO 2 birds from 10-14 days as using the t-test function and the Wilcoxon/Kruskal-Wallis test of JMP Statistical Software (SAS Institute) to determine differences between means. Liver uric acid content was analyzed using the t-test function of JMP Software (SAS Institute). For both studies, significance was defined as $\mathrm{p} \leq 0.05$. Statistical significance for gene expression was assessed for each treatment using the $\mathrm{t}-$ 
test procedure of the JMP software (SAS institute). Significance was defined as $\mathrm{p} \leq 0.05$ as compared to the control group of each week.

\section{Results}

\section{Experiment 1}

There was no difference in the initial $(\mathrm{p}=0.8588)$ or final body weight $(\mathrm{p}=0.1865)$ of the AL bird when compared to birds in the CON group (Table 1). Relative liver weight of the AL group did not differ significantly ( $\mathrm{p}=0.688$ ) from the CON group (Table 1). Similarly, there was no difference $(\mathrm{p}=0.289)$ between AL birds and CON birds in terms of relative heart weight (Table 1).

Cytosolic uric acid concentrations measured in heart tissue were significantly increased $(\mathrm{p}=$ 0.004) in AL birds as compared to the control (Table 3). However, no differences $(p=0.302)$ were detected in liver cytosolic uric acid concentrations of AL birds when compared to the control group (Table 2).

Mitochondrial respiration was measured for heart and liver tissue. There were no significant differences between treatment groups in State $3(p=0.829)$ or State $4(p=0.282)$ in the heart as shown in Figure 1A. There was a significant $(\mathrm{p}=0.015)$ decrease in State 3 respiration in mitochondria isolated from the liver tissue of Treated (AL) birds as compared to control (Figure 1B). There was also a significant decrease $(\mathrm{p}=0.007)$ in State 4 respiration of Treated (AL) birds as compared to the control (Figure 2$)$. RCR was also significantly decreased $(p=0.035)$ in liver 
mitochondria of AL birds when compared to the controls (Table 2). This difference was not measured in heart tissue of AL birds $(\mathrm{p}=0.375)$ as compared to the control group.

\section{Experiment 2}

Body weight (Figure 2) did not differ between CON $(n=10)$ or ALLO $(n=10)$ birds at days $0,3,6$, or $7(\mathrm{P}=0.249 ; \mathrm{P}=1.00 ; \mathrm{P}=0.676, \mathrm{P}=0.402$ respectively $)$. There was a significant decrease in body weight of ALLO 2 birds at day $10(\mathrm{p}=0.011)$ and day $14(\mathrm{p}=0.012)$ of treatment (Table 4). Feed intake, measured by weighing back feeders in each pen, did not differ during the 0-7 day period between ALLO 1 birds and CON 1 (193 and $195 \mathrm{~g} / \mathrm{bird} /$ day respectively). By day 10 and 14 birds in the ALLO 2 group had a reduced feed intake as compared to birds in CON 2 (215 and $230 \mathrm{~g} /$ day/bird respectively).

Liver uric acid content was reduced $(\mathrm{p}=0.002)$ in ALLO 1 birds as compared to CON 1 after one week of treatment (Table 5). Liver uric acid was also decreased $(\mathrm{p}=0.011)$ in ALLO 2 when compared to CON 2 birds (Table 5). Relative liver weight did not differ ( $\mathrm{p}=0.524)$ between CON 1 and ALLO 1 groups after one week or between CON 2 and ALLO 2 groups $(\mathrm{p}=0.946)$ after two weeks (Table 5).

After one week of treatment, there were no differences $(\mathrm{p}=0.649)$ between CON 1 and ALLO 1 birds in IFN- $\gamma$ gene expression in liver tissue (Fig. 2A). However, there was a numerical increase $(\mathrm{p}=0.071)$ in IL-1 $\beta$ gene expression in the liver of ALLO 1 birds when compared to CON 1 (Fig. 3A). No differences in liver gene expression of IL-12p35 ( $p=0.340)$ were observed in ALLO 1 birds as compared to CON1 (Fig. 5A). Similarly, there were no differences in iNOS ( $\mathrm{p}=0.612$ ) between the groups (Figure 6A). No significant changes in IL-6 $(\mathrm{p}=0.752)$ expression in the liver of ALLO 1 birds were measured after one week of treatment 
(Fig. 4A). There was no change in expression of XOR $(\mathrm{p}=0.118)$ in ALLO 1 birds as compared to $\mathrm{CON} 1$ (Fig. 7A).

After two weeks of treatment, however, there was a significant increase $(p=0.0355)$ in gene expression of IFN- $\gamma$ in the liver tissue of ALLO 2 birds as compared to the control group (Fig. 2B). There was also a significant increase in expression of IL-1 $\beta(p=0.013)$, and IL-12p35 $(\mathrm{p}=0.028)$ in ALLO 2 birds as compared to CON 2 birds (Fig 3B and 5B respectively). However, there was no change $(\mathrm{p}=0.677)$ in IL-6 expression in the liver tissue between CON 2 and ALLO 2 birds (Fig. 4B). There was a numerical trend $(\mathrm{p}=0.076)$ in the expression of iNOS in ALLO 2 birds when compared to CON 2 (Fig. 6B). XOR gene expression was increased $(\mathrm{p}=$ 0.051) in the liver tissue of ALLO 2 birds as compared to the CON 2 group (Fig. 7B).

\section{Discussion}

\section{Experiment 1}

In agreement with previous studies (Settle et al, 2012; Carro et al, 2009), there was no adverse effect after one week of allopurinol treatment on body weight as compared to control. These results also confirm a study by Lee and Fisher (1972), in which chicks were administered allopurinol (750mg/kg feed) from hatch to 28 days and noted no adverse effects on body weight. Relative liver weight was not different between CON and AL groups, consistent with Carro et al. (2009).

Interestingly, mitochondrial State 3 and State 4 respiration was significantly reduced in the liver of AL birds. Broilers with pulmonary hypertension syndrome have been shown to have a decrease in State 3 and State 4 respiration in heart, liver, and breast tissue, indicative of reduced mitochondrial function (Tang et al, 2002, Cawthon et al., 2000). As anticipated, heart 
mitochondria did not exhibit differences between treatments in State 3 or State 4. Heart tissue acted as a control for the assay as it is not a known target tissue of allopurinol (Pacher et al., 2006).

Respiratory control ratio (RCR), another indicator of mitochondrial function in tissues, measures the coupling of the electron transport chain (Estabrook, 1967). RCR in the liver was significantly reduced in the liver of AL birds (Table 2) which further indicates that allopurinol negatively impacts mitochondrial function in young broilers. However, there was no difference in RCR of the heart, which indicates that there was no effect of treatment on mitochondrial function of the heart. Settle et al. (2012) found that there was a residual toxic effect of allopurinol-fed birds in the liver tissue even after removal of allopurinol from the diet for one week which contributes to an increase in oxidative damage. Mitochondrial complexes I and III are the primary sources of endogenous ROS and proton leak is greater during disease pathogenesis (Chen et al, 2003). The results suggest that the mitochondrial dysfunction in the liver tissue of allopurinol-fed birds and that this is a contributing factor to oxidative damage in this tissue.

Allopurinol at doses of $10-50 \mathrm{mg} / \mathrm{kg}$ BW inhibits the enzyme XOR thereby inhibiting uric acid production, which reduces plasma and tissue uric acid concentrations in broiler chickens (Settle et al., 2012;Carro et al., 2009, Simoyi et al., 2002; Klandorf et al., 2001). Uric acid is higher in the cytosol of human cells and concentrations increase when injured cells undergo degradation of their RNA and DNA (Shi et al, 2003). Interestingly, there was a significant increase in cytosolic UA in the heart tissue of AL birds as compared to the control birds. Uric acid is known to be a potent antioxidant for birds (Simoyi et al, 2002, Stinefelt et al, 2005) and ameliorates mitochondrial dysfunction when administered in a combination with Anti-TNF 
antibody to ob/ob mice (Garcia-Ruiz et al., 2006). It is possible that the increase in cytosolic uric acid results in an enhanced antioxidant protection of the heart tissue, for a reduction in uric acid results in an increase in oxidative stress (Klandorf et al., 2001). Interestingly, there was a tissuespecific response as this effect was evidenced by the increase in UA in the heart but not in the liver.

\section{Experiment 2}

In the second study, allopurinol (35mg/kg BW) was administered to broiler chicks over a two week period. During the first week of treatment, there were no differences in body weight between control and allopurinol-fed birds, consistent with the results found in experiment 1 . However, by days 10 and 14, there was a significant reduction in body weight of ALLO 2 birds compared with CON 2 consistent with previous studies in which a decrease in body weight signifies a decline in bird health concomitant with an increase in oxidative stress (Settle et al., 2012., Carro et al., 2009, Simoyi et al., 2002, Klandorf et al., 2001).

Liver uric acid concentrations were markedly reduced in ALLO 1 and ALLO 2 birds as compared with CON 1 and CON 2 birds respectively. The rapid response of liver tissue to allopurinol is consistent with previous studies where birds fed allopurinol in combination with inosine demonstrated a reduction in liver uric acid content (Settle et al., 2012). Interestingly, birds that were fed allopurinol for two weeks showed that uric acid remained lower in the liver tissue even after terminating allopurinol treatment which suggests that there was a residual toxic effect on the liver (Settle et al, 2012).

$\mathrm{XOR}$ is the enzyme responsible for the production of uric acid in the purine degradation pathway. Carro et al. (2009) reported that XOR activity was increased in liver tissue of birds fed allopurinol at a dose of $50 \mathrm{mg} / \mathrm{kg} / \mathrm{BW}$ and suggested that this response is a compensatory 
mechanism to maintain UA levels in this tissue. In agreement with this finding, XOR gene expression was significantly increased in ALLO 2 birds in a response to the reduced uric acid. It has also been reported that allopurinol can act as both a substrate and an inhibitor of xanthine oxidase which indicates a substrate-induced regulation of XOR in the liver (Massey et al., 1970). As suggested in previous studies, the increase in xanthine and hypoxanthine concentrations in the liver may be responsible for the increase in XOR activity (Lee and Fisher, 1972; Woodward et al., 1972; Della-Corte, 1965). In contrast, there was no difference in XOR gene expression between CON 1 and ALLO 1 birds despite the decrease in UA concentrations in the liver, which suggests that gene expression of XOR is not affected by acute treatment with allopurinol. Clearly, there are many factors regulating gene expression of XOR and so future studies need to address the dose and duration of treatment in order to ascertain the regulatory mechanisms governing this gene.

It has been previously reported that there is a negative relationship between plasma uric acid concentrations and oxidative stress in broiler chickens such that a decrease in plasma uric acid is associated with an increase in oxidative stress (Simoyi et al, 2002; Klandorf et al, 2001). Oxidative stress has been associated with inflammation due to activation of inflammatory cytokines and transcription factors in a plethora of pathways (Reuter et al., 2010). In this study, IL-1 $\beta$ was numerically up-regulated in ALLO 1 birds, although this was not significant after one week of treatment with allopurinol. There were no differences observed in expression of IFN- $\gamma$, IL-12p35, IL-6, or iNOS in ALLO 1 birds as compared to CON 1. However, after two weeks of treatment with allopurinol, ALLO 2 birds showed a marked increase in gene expression of the pro-inflammatory cytokine IFN- $\gamma$ as compared to CON 2. Additionally, IL-1 $\beta$ and IL-12p35 gene expression were also up-regulated in ALLO 2 birds. Notably, there was a numerical 
increase in iNOS gene expression in ALLO 2 birds, however, this was not significant. Activation of iNOS by IFN- $\gamma$ results in the production of nitric oxide which can be directly linked to inflammation (Guzik et al, 2003). It is possible that a study of longer duration would reveal an increase iNOS production. As in birds fed allopurinol for one week, there was no change in IL6 gene expression after two weeks of treatment with allopurinol. IL- 6 has been reported to function as both a pro-inflammatory cytokine as well as an anti-inflammatory myokine, remains unchanged in some primary infection responses (Hong et al., 2006). After one week of treatment, IL- $1 \beta$ is numerically increased, suggesting that the inflammation process has been initiated at this time as birds in ALLO 2 demonstrated a further increase after two weeks. Collectively, the increase in expression of the IFN- $\gamma$, IL-1 $1 \beta$, and IL-12p35 inflammatory cytokines in the liver after two weeks of treatment with allopurinol can be interpreted as an increase in inflammation of this tissue. In previous studies it has been suggested that allopurinol exerts a toxic effect on hawks exhibiting hyperuricemia which was attributed to the increase in oxypurinol, the nephrotoxic endproduct of allopurinol (Lumeij et al., 1998). In a second study in rats demonstrated that doses ranging from 3-100 mg/kg BW are toxic in liver tissue (Suzuki et al., 1984). Although, allopurinol has been reported as "safe" for long-term treatment in humans (Rundles, 1985), the dose used in our study demonstrates a pronounced adverse effect with the result that inflammation is up-regulated over time and treatment. Further, the decrease in protection by uric acid in this tissue potentially increases the susceptibility of the liver to oxidative damage and inflammation ultimately leading to a decline in health of the bird. Based on these data, it can be inferred that a reduction in uric acid concentrations in the liver can generate a pro-inflammatory response in liver tissue indicating the importance of antioxidant defense by uric acid. 
In conclusion, these studies show that a reduction in uric acid after one week of treatment with allopurinol results in mitochondrial dysfunction in the liver tissue as indicated by the reduction in mitochondrial respiration states. After two weeks of treatment with allopurinol, liver tissue UA is chronically depressed which increases susceptibility to oxidative stress due to the inverse relationship that UA has with oxidative stress. Furthermore, in response to the reduction of uric acid concentrations in the liver, there is a compensatory up regulation of XOR gene expression, which is suggested to maintain antioxidant protection by UA. Further studies are required to investigate how XOR is regulated. The chronic reduction of UA in the liver also results in an increase in the expression of selected inflammatory cytokines which leads to the expression of the inflammatory state.

\section{Acknowledgements}

This work was supported by Hatch grant (H393) and in part by the University of Central Oklahoma Research Grant provided by Dr. William Radke. Thanks are given to the Hollander Laboratory and Dr. Yao for the use of equipment for real-time RT-PCR and mitochondrial function. Chicks were generously donated by Pilgrim's Pride Hatchery (Moorefield, West Virginia).

\section{References}

1. Barja, G. (1998). Mitochondrial free radical production and aging in mammals and birds. Annals of New York Academy of Sciences 854(1): 224-238

2. Carro, M.D., Falkenstein, E., Radke, W.J., Klandorf, H. (2009). Effects of allopurinol on uric acid concentrations, xanthine oxidoreductase activity, and oxidative stress in broiler chickens. Comparitive Biochemistry and Physiology, Part C 151: 12-17

3. Cawthon, D., Beers, K., Bottje, W.J. (2001). Electron transport chain defect and inefficient respiration may underlie pulmonary hypertension syndrome (ascites)associated mitochondrial dysfunction in broilers. Poultry Science 80: 474-484 
4. Chaney, R.C. Jr., Blemings, K.P., Bonner, J., Klandorf, H. (2003). Pentosidine as a measure of chronological age in wild birds. The Auk 394-399

5. Chapman, M.E. and Wideman, R.F. (2006). Evaluation of total plasma nitric oxide concentrations in broilers infused intraveneously with sodium nitrite, lipopolysaccharide, aminoguanidine, and sodium nitroprusside. Poultry Science 85: 312-320

6. Chen, Q., Vazquez, E., Mghaddas, S., Hoppel, C., Lesnefsky, E. (2003). Production of reactive oxygen species by mitochondria: central role of complex III. The Journal of Biological Chemistry 278(38): 36027-36031

7. Della Corte, E., F. Stirpe.(1967). Regulation of xanthine dehydrogenase in chick liver: further experiments on the effects of inosine, actinomycin D, and other factors. Biochem J 102, 520-524.

8. Estabrook, R.W. (1967). Mitochondrial respiratory control and polarographic measurement of ADP/O ratios. Methods Enzymol. 10: 41-47

9. Garcia-Ruiz, I., Rodriguez-Juan, C., Diaz-Sanjuan, T. et al. (2006). Uric acid and antiTNF antibody improve mitochondrial dysfunction in ob/ob mice. Hepatology 44: 581591

10. Guzik, T.J., Korbut, R., Guzik, A. 2003. Nitric oxide and superoxide in inflammation and immune regulation. Journal of Physiology and Pharmacology 54 (4): 469- 487

11. Harrison, R. (2002). Structure and function of xanthine oxidoreductase : where are we now? Free Radical Biology and Medicine 33(6): 774-797

12. Holmes,D.J. and Austad, S.N. (1995). The evolution of avian senescence patters; implications for understanding primary aging processes. Am. Zoo. 35:307-317

13. Hooper, D.C., Scott, G.S., Zborek, A., Miksheeva, T., Kean, R.B., Koprowski, H., Spitsin, S.V. (2002). Uric acid, a peroxynitrite scavenger, inhibits CNS inflammation, blood-CNS barrier permeability changes, and tissue damage in a mouse model of multiple sclerosis. FASEB J. 14: 691-698

14. Hong, Y., Lillehoj, H., Lee, S., Dalloul, R., Lillehoj, E. (2006). Analysis of chicken cytokine and chemokine gene expression following Eimeria acervulina and Eimeria tenella infections. Veterinary Immunology and Immunopathology 114: 209-223

15. Hussain, S.P. and Harris C.C. 2007. Inflammation and cancer: an ancient link with novel potentials. Int. J. Cancer 121: 2373-2380

16. Iqbal, M., Cawthon, D., Wideman, R.F., Bottje, W.G. (2001). Lung mitochondrial dysfunction in pulmonary hypertension syndrome I site-specific defects in the electron transport chain. Poultry Science 80: 485-495

17. Klandorf, H., Rathore, D.S., Iqbal, M., Shi, X., VanDyke, K. (2001). Accelerated tissue aging and increased oxidative stress in broiler chickens fed allopurinol. Comp. Biochem. and Physiol. Pt. C 129 (2): 93-104

18. Lee, P.C., J.R. Fisher. (1972). Effect of allopurinol on the accumulation of xanthine dehydrogenase in liver and pancreas of chicks after hatching. Arch. Biochem. Biophys. $148,277-281$. 
19. Lumeij, J.T. and Redig, P.T. (1992). Hyperuriceamia and visceral gout induced by allopurinol in re-tailed hawks (Buto jamaicensis). Proceedings VIII Tagung der Fachgruppe Geflugelkrankheiten pp. 265-269

20. Machin, M., Simoyi, M., Blemings, K., Klandorf, H. (2004). Increased dietary protein elevates plasma uric acid and is associated with decreased oxidative stress in rapidlygrowing broilers. Comparative Biochemistry and Physiology Part B. 137: 383-390

21. Monnier,V.M., Sell, D.R., Ramanakoppa, H.N., Miyata, S. (1991). Mechanisms of damage mediated by the Maillard reaction in aging. Gerontology 37:152-165

22. Pacher, P., Nivorzhkin, A., Szabo, C., (2006). Therapeutic effects of xanthine oxidase inhibitors:renaissance half a century after the discovery of allopurinol. Pharmacological Reviews 58(1):87-113

23. Pfaffl, M. W. (2001). A new mathematical model for relative quantification in real-time RT-PCR. Nucleic acids research, 29(9), e45-e45.

24. Reuter, S., Gupta, S.C., Chaturvedi, M.M., Aggarwai, B.B. (2010). Oxidative stress, inflammation, and cancer: how are they linked? Free Radical Biology and Medicine. 40: 1603-1616

25. Rundles, R.W. (1985). The development of allopurinol. Arch. Internal Med 145: 14921502

26. SAS Institute. (2002). User's Guide Statistics

27. Seaman, C., Moritz, J., Falkenstein, E., VanDyke, K., Casotti, G., Klandorf, H. (2008). Inosine ameliorates the effects of hemin-induced oxidative stress in broilers. Comparitive Biochemistry and Physiology, Part A 151:670-675

28. Settle, T., Carro, M, Falkenstein, E., Radke, W., Klandorf, H. (2012). Effect of allopurinol and uric acid supplementation on uric acid concentrations and xanthine oxidoreductase activity in broiler tissues. Poultry Science. 90(11): 895-903

29. Shi, Y., Evans, J., Rock, K. (2003). Molecular identification of a danger signal that alerts the immune system to dying cells. Letters to Nature 425: 516-521

30. Simoyi, M., VanDyke, K., Klandorf, H. (2002). Manipulation of plasma uric acid in broiler chicks and its effect on leukocyte oxidative activity. Am. J. Physiol. Regulatory Integrative Comp Phsyiol. 282: 791-796

31. Slautterback, D. (1965). Mitochondria in cardiac muscle cells of the canary and some other birds. The Journal of Cell Biology 24:1-22

32. Stinefelt,B., S.S. Leonard, K.P. Blemings, X.Shi, H. Klandorf. (2005). Free Radical Scavenging, DNA protection, and inhibition of lipid peroxidation mediated by uric acid. Ann. Clin. Lab. Sci. 35:37-45

33. Suzuki, Y., Sudo, J., Tanabe, T. (1984). Allopurinol toxicity: its toxic organ-specificity between the liver and the kidney in the rat. The Journal of Toxicological Sciences 9: 343351

34. Tang, z., Iqbal, M., Cawthon, D., Bottje, W.G. (2002). Heart and breast mitochondrial function in pulmonary hypertension syndrome in broilers (gallus domesticus). Comparative Biochemistry and Physiology Part A 132: 527-540 
35. Woodward, W.D., P.C. Lee, N.W. DeLapp, J.R. Fisher. (1972). Induction of chick liver xanthine dehydrogenase by purines. Arch Biochem Biophys 153, 537-542. 
Figure 1 A. State 3 and State 4 Respiration measured in isolated mitochondria from heart or liver tissue of broilers ( $\mathrm{n}=6 /$ group). Treated birds were administered allopurinol at $35 \mathrm{mg} / \mathrm{kg} \mathrm{BW}$ for one week. Data is represented as the comparison of Treated State 3 compared to Control State 3 and the Treated State 4 compared to the Control State 4. Error bars represent the standard error of the mean. 1B. State 3 and State 4 Respiration measured in isolated mitochondria from liver tissue of broilers ( $n=6 /$ group). Data is represented as the comparison of Treated State 3 compared to Control State 3 as denoted by A,B and the Treated State 4 compared to the Control State 4 as denoted by a,b. Error bars represent the standard error of the mean. Significance is defined as $\mathrm{p} \leq 0.05$

Figure 2A . IFN- $\gamma$ gene expression in broiler liver tissue. ALLO 1 birds $(n=5)$ were administered $35 \mathrm{mg} / \mathrm{kg}$ BW allopurinol in feed for one week. CON $1(n=5)$ were maintained on a commercial diet. Gene expression is represented as the mean \pm SEM for each treatment. *denotes a significant difference as compared to CON 1. Significance is defined as $\mathrm{p} \leq 0.05$. Figure $2 B$. IFN- $\gamma$ gene expression in broiler liver tissue. ALLO 2 birds $(\mathrm{n}=5)$ were administered $35 \mathrm{mg} / \mathrm{kg} \mathrm{BW}$ allopurinol in feed for 2 weeks. CON $2(n=5)$ were maintained on a commercial diet. Gene expression is represented as the mean \pm SEM for each treatment. *denotes a significant difference as compared to CON 1. Significance is defined as $\mathrm{p} \leq 0.05$.

Figure 3A. IL 1- $\beta$ gene expression in broiler liver tissue. ALLO 1 birds $(n=5)$ were administered $35 \mathrm{mg} / \mathrm{kg}$ BW allopurinol in feed for one week. CON $1(\mathrm{n}=5)$ were maintained on a commercial diet. Gene expression is represented as the mean \pm SEM for each treatment. *denotes a significant difference as compared to CON 1. Significance is defined as $\mathrm{p} \leq 0.05$. Figure 3B. $\mathrm{IL}-1 \beta$ gene expression in broiler liver tissue. ALLO 2 birds $(\mathrm{n}=5)$ were administered $35 \mathrm{mg} / \mathrm{kg}$ BW allopurinol in feed for 2 weeks. CON $2(n=5)$ were maintained on a commercial diet. Gene expression is represented as the mean \pm SEM for each treatment. *denotes a significant difference as compared to CON 1. Significance is defined as $\mathrm{p} \leq 0.05$.

Figure 4A . IL-6 gene expression in broiler liver tissue. ALLO 1 birds $(n=5)$ were administered $35 \mathrm{mg} / \mathrm{kg}$ BW allopurinol in feed for one week. CON $1(n=5)$ were maintained on a commercial diet. Gene expression is represented as the mean \pm SEM for each treatment. *denotes a significant difference as compared to CON 1 . Significance is defined as $p \leq 0.05$. Figure 4B. IL- 6 gene expression in broiler liver tissue. ALLO 2 birds $(\mathrm{n}=5)$ were administered 35mg/kg BW allopurinol in feed for 2 weeks. CON $2(n=5)$ were maintained on a commercial diet. Gene expression is represented as the mean \pm SEM for each treatment. *denotes a significant difference as compared to CON 1. Significance is defined as $\mathrm{p} \leq 0.05$.

Figure 5A. IL-12p35 gene expression in broiler liver tissue. ALLO 1 birds $(n=5)$ were administered $35 \mathrm{mg} / \mathrm{kg}$ BW allopurinol in feed for one week. CON $1(\mathrm{n}=5)$ were maintained on a commercial diet. Gene expression is represented as the mean \pm SEM for each treatment. *denotes a significant difference as compared to CON 1. Significance is defined as $p \leq 0.05$. Figure 5B. IL-12 p35 gene expression in broiler liver tissue. ALLO 2 birds $(n=5)$ were administered 
$35 \mathrm{mg} / \mathrm{kg}$ BW allopurinol in feed for 2 weeks. CON $2(\mathrm{n}=5)$ were maintained on a commercial diet. Gene expression is represented as the mean.Error bars are SEM for each treatment. *denotes a significant difference as compared to CON 1. Significance is defined as $\mathrm{p} \leq 0.05$.

Figure 6A. iNOS gene expression in broiler liver tissue. ALLO 1 birds $(\mathrm{n}=5)$ were administered $35 \mathrm{mg} / \mathrm{kg}$ BW allopurinol in feed for one week. CON $1(\mathrm{n}=5)$ were maintained on a commercial diet. Gene expression is represented as the mean \pm SEM for each treatment. *denotes a significant difference as compared to CON 1. Significance is defined as $p \leq 0.05$. Figure $6 \mathrm{~B}$. iNOS gene expression in broiler liver tissue. ALLO 2 birds $(\mathrm{n}=5)$ were administered $35 \mathrm{mg} / \mathrm{kg}$ BW allopurinol in feed for 2 weeks. CON $2(n=5)$ were maintained on a commercial diet. Gene expression is represented as the mean \pm SEM for each treatment. *denotes a significant difference as compared to CON 1. Significance is defined as $\mathrm{p} \leq 0.05$.

Figure 7A. XOR gene expression in broiler liver tissue. ALLO 1 birds $(\mathrm{n}=5)$ were administered $35 \mathrm{mg} / \mathrm{kg}$ BW allopurinol in feed for one week. CON $1(\mathrm{n}=5)$ were maintained on a commercial diet. Gene expression is represented as the mean \pm SEM for each treatment. *denotes a significant difference as compared to CON 1 . Significance is defined as $p \leq 0.05$. Figure 7B. XOR gene expression in broiler liver tissue. ALLO 2 birds $(\mathrm{n}=5)$ were administered $35 \mathrm{mg} / \mathrm{kg}$ BW allopurinol in feed for 2 weeks. CON $2(n=5)$ were maintained on a commercial diet. Gene expression is represented as the mean \pm SEM for each treatment. *denotes a significant difference as compared to CON 1. Significance is defined as $\mathrm{p} \leq 0.05$. 
Figure 1

(A).

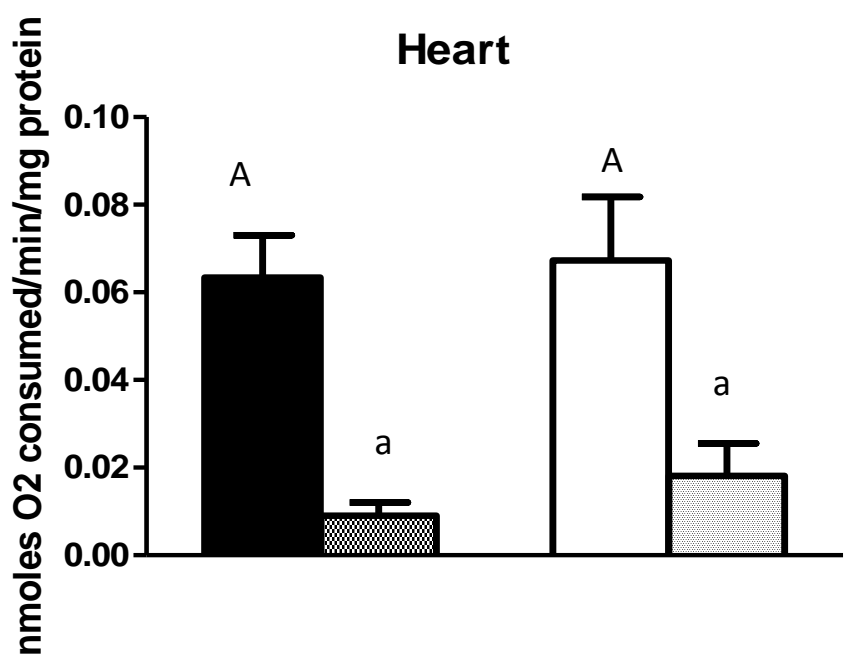

Control State 3

Control State 4

$\square$ Treated State 3

$\square$ Treated State 4

(B)

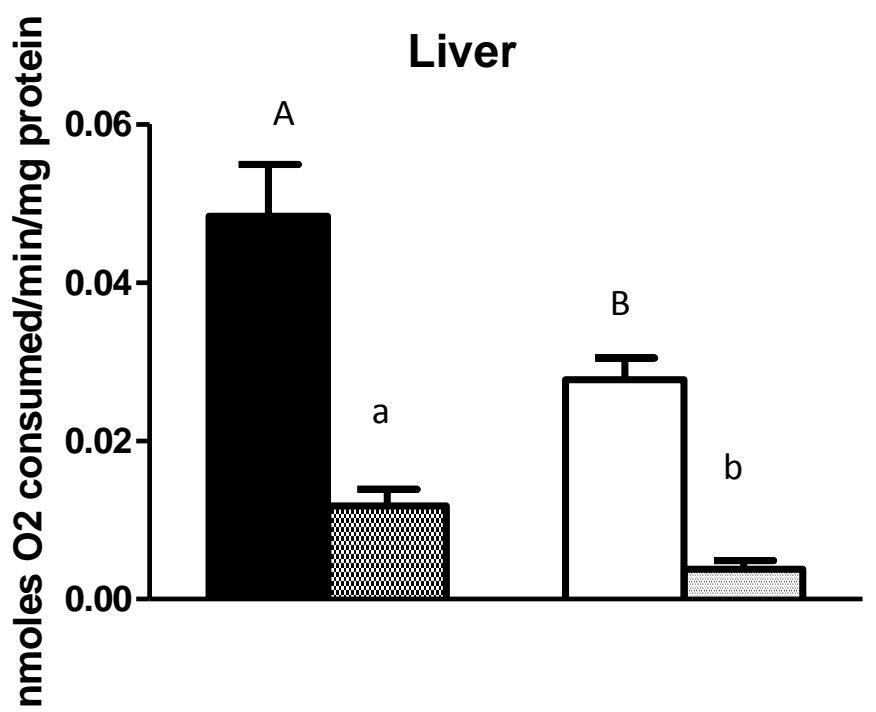

Control State 3

- Control State 4

$\square$ Treated State 3

$\square$ Treated State 4 


\section{Table 1}

Experiment 1. Effects of experimental treatments (CON: 0; AL 35mg/kg BW) and body weight (BW) and relative liver weight, and relative heart weight in broilers $(n=6)$

\begin{tabular}{lccccc}
\hline & & & \multicolumn{2}{c}{ Relative Weight $(\%)$} \\
\cline { 5 - 6 } Treatment & Initial BW $(\mathrm{kg})$ & Final BW $(\mathrm{kg})$ & & Liver & Heart \\
\hline CON (control) & $0.973 \pm 0.060$ & $1.421 \pm 0.219$ & & $2.55 \pm 0.124$ & $0.622 \pm 0.019$ \\
AL (treated) & $0.956 \pm 0.071$ & $1.273 \pm 0.220$ & & $2.44 \pm 0.172$ & $0.637 \pm 0.016$ \\
$P=$ & 0.429 & 0.907 & & 0.688 & 0.289 \\
\hline
\end{tabular}

${ }^{\mathrm{a}, \mathrm{b}}$ For each variable, means within a column lacking a common superscript $\operatorname{differ}(P<0.05)$.

Data are represented as the parameter \pm SEM

SEM: standard error of the mean. 


\section{Table 2}

Experiment 1. Effects of experimental treatments (CON: 0; AL 35mg/kg BW on respiratory control ratio (RCR) measured as the ratio between the slope of State 3 to State 4 and Cytosolic uric acid content in broilers $(n=6)$

\begin{tabular}{lccccc}
\hline & & & & \multicolumn{2}{c}{ Cytosolic Uric Acid (mg/dL) } \\
\cline { 5 - 6 } Treatment & Liver RCR & Heart RCR & & Liver & Heart \\
\hline CON(control) & $10.68 \pm 2.61$ & $6.23 \pm 0.83$ & & $2.772 \pm 0.59$ & $0.553 \pm 0.09$ \\
AL (treated) & $4.65 \pm 0.90^{*}$ & $4.76 \pm 1.32$ & & $3.07 \pm 0.23$ & $0.943 \pm 0.08^{*}$ \\
$P=$ & 0.035 & 0.375 & & 0.298 & 0.004 \\
\hline
\end{tabular}

* For each variable, means within a column lacking a common superscript differ from CON birds $(P<0.05)$.

Data are represented as the parameter \pm SEM

SEM: standard error of the mean. 
Table 3. Primer sets. Primers are arranged 5' to 3' with forward and reverse sequences for each gene used in Experiment 2.

\begin{tabular}{|l|l|l|}
\hline Primer & Forward 5' to 3' & Reverse 5' to 3' \\
\hline XOR & CTGCAGGATGCCTGCCGCTT & GCATGGGCTTGGGTGCTGGT \\
\hline IFN-Gamma & GTGGTGAGCTTCTGGCAGAG & GCTTGCAGGCTGACGGTAA \\
\hline IL1-B & GCATCAAGGGCTACAAGCTC & CAGGCGGTAGAAGATGAAGC \\
\hline IL-6 & CTCCTCGCCAATCTGAAGTC & CCCTCACGGTCTTCTCCATA \\
\hline IL-12p35 & GCCCCGTACTGGAAAGTTCT & GGATGTCAGCACCCTCAGAT \\
\hline iNOS & CCTTTCAACGGCTGGTACAT & CCAGTCCCATTCTTCTTCCA \\
\hline GAPDH & GACGTGCAGGAACACTA & CTTGGACTTTGCCAGAGAGG \\
\hline
\end{tabular}




\section{Table 4}

Experiment 2. Effects of experimental treatments on body weight in CON and ALLO broilers $(n=10)$ for Days 0-7 and CON 2 and ALLO 2 broilers $(n=5)$ on Day 10 and 14

\section{Body weight (kg)}

\begin{tabular}{l|c|c|c|c|c|c}
\cline { 2 - 7 } Item & Day 0 & Day 3 & Day 6 & Day 7 & Day 10 & Day 14 \\
\hline CON 2 & $0.80 \pm 0.01$ & $1.31 \pm 0.03$ & $1.51 \pm 0.04$ & $1.81 \pm 0.05$ & $2.19 \pm 0.08$ & $2.43 \pm 0.05$ \\
ALLO 2 & $0.83 \pm 0.02$ & $1.30 \pm 0.033$ & $1.59 \pm 0.04$ & $1.72 \pm 0.05$ & $1.95 \pm 0.04^{*}$ & $2.12 \pm 0.09^{*}$ \\
P-Value & 0.249 & 1.00 & 0.676 & 0.402 & 0.011 & 0.012 \\
\hline
\end{tabular}

* Within a column, means differ from CON $2(P<0.05)$.

Data is represented as average $\mathrm{BW} \pm \mathrm{SEM}$ : standard error of the mean 


\section{Table 5}

Experiment 2. Effects of experimental treatments on relative liver weight (Liver weight: body weight) and uric acid concentration in the liver of broilers ( $\mathrm{n}=5$ per treatment). CON 1 and ALLO 1 birds ( $\mathrm{n}=5)$ euthanized on Day 7. CON 2 and ALLO 2 birds $(n=5)$ were euthanized on Day 14.

\begin{tabular}{lccc} 
& & \multicolumn{2}{c}{ Uric acid } \\
\cline { 3 - 4 } Item & $\begin{array}{c}\text { Relative Liver } \\
\text { Weight }(\%)\end{array}$ & $\mathrm{mg} / \mathrm{g}$ wet tissue & total mg in the liver \\
\hline CON 1 & 2.281 & $0.113 \pm 0.008$ & $4.72 \pm 1.09$ \\
ALLO 1 & 2.298 & $0.036 \pm 0.012^{*}$ & $1.39 \pm 1.64 *$ \\
P Value & 0.524 & 0.0013 & .0027 \\
\hline CON 2 & 45.6 & $0.131 \pm 0.026$ & $5.90 \pm 1.13$ \\
ALLO 2 & 42.8 & $0.028 \pm 0.008^{*}$ & $1.23 \pm 0.39^{*}$ \\
P Value & 0.946 & 0.0134 & 0.0115 \\
\hline
\end{tabular}

* Within a column, means differ between CON 1 and ALLO 1 or CON 2 and ALLO 2 $(P<0.05)$. Data was analysed using t-test in JMP software (SAS Institute)

Data is represented at \pm SEM: standard error of the mean. 
Figure 2

(A).

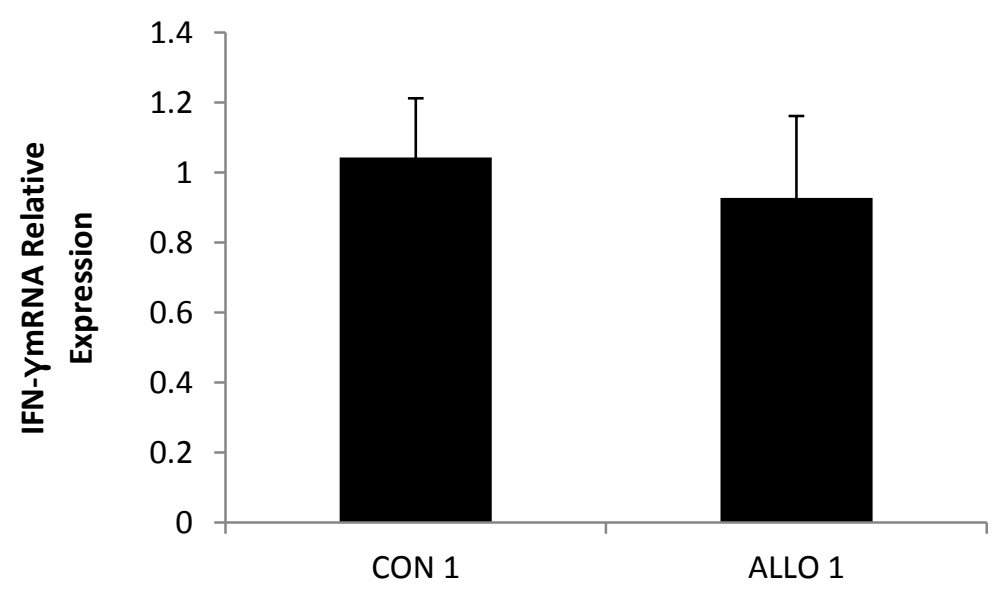

(B).

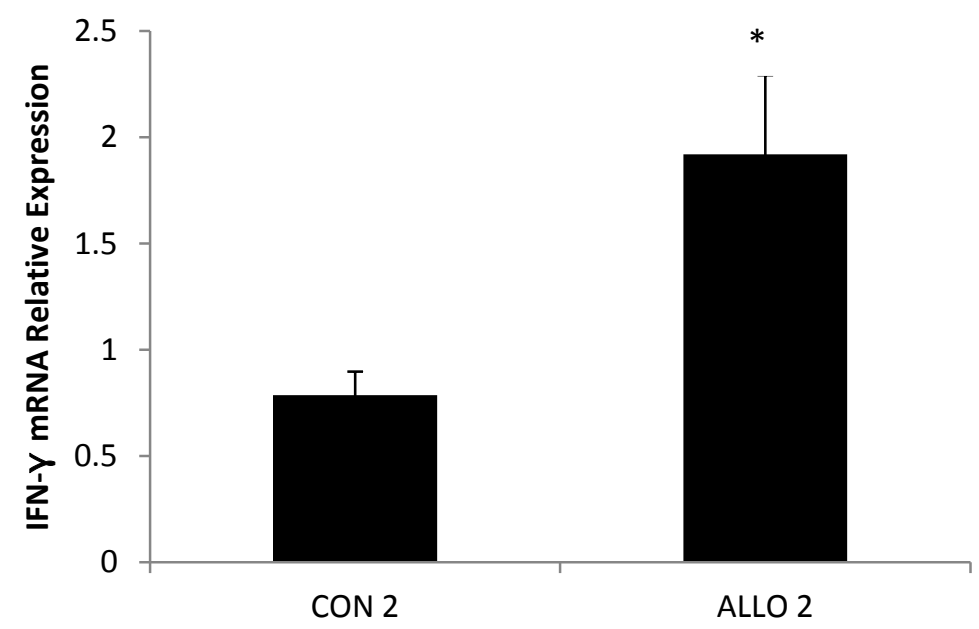


Figure 3

(A)

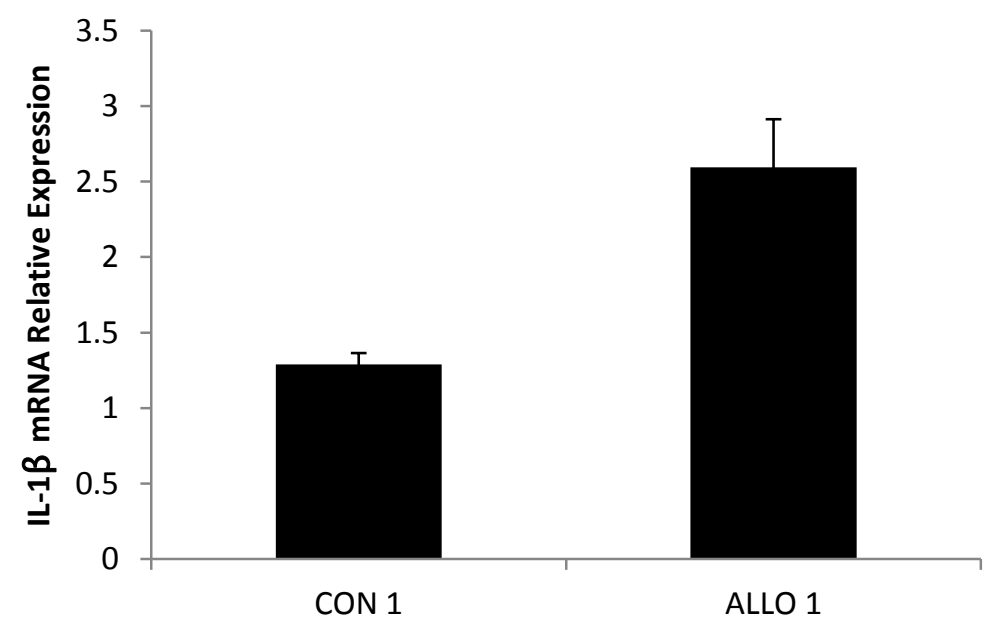

(B)

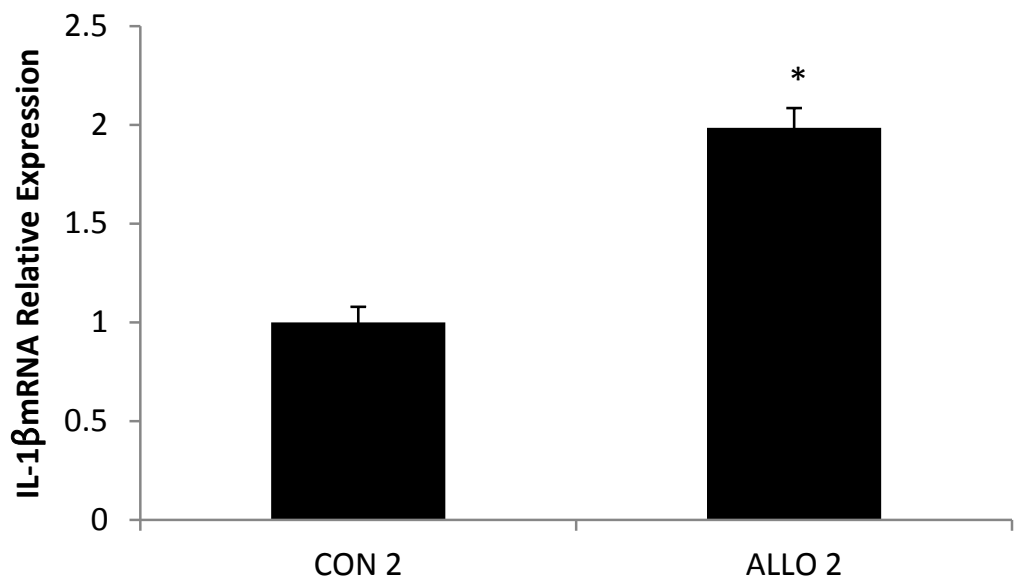


Figure 4

(A)

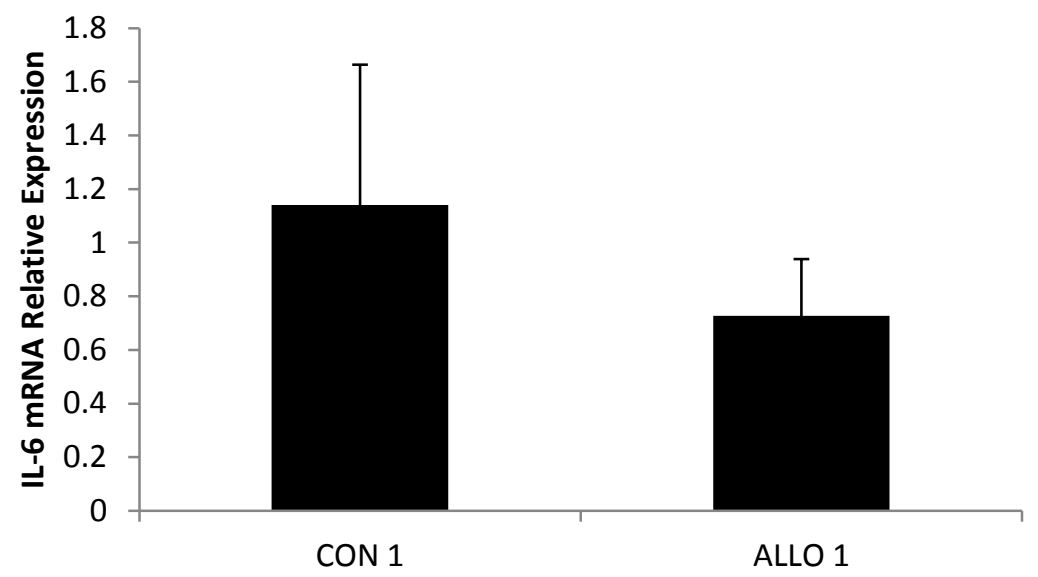

(B)

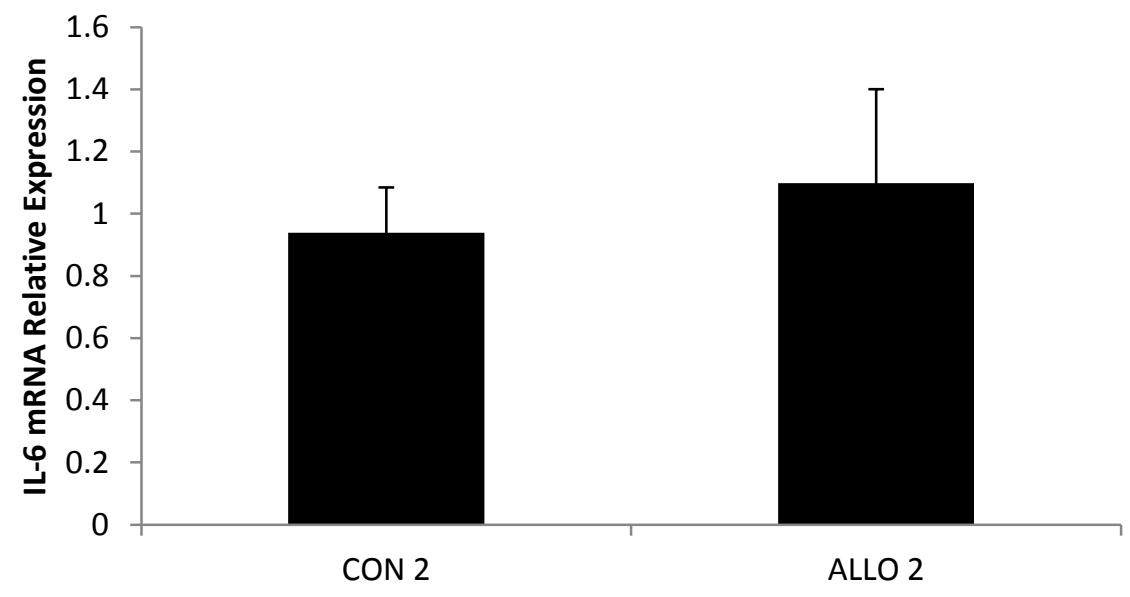


Figure 5

(A)

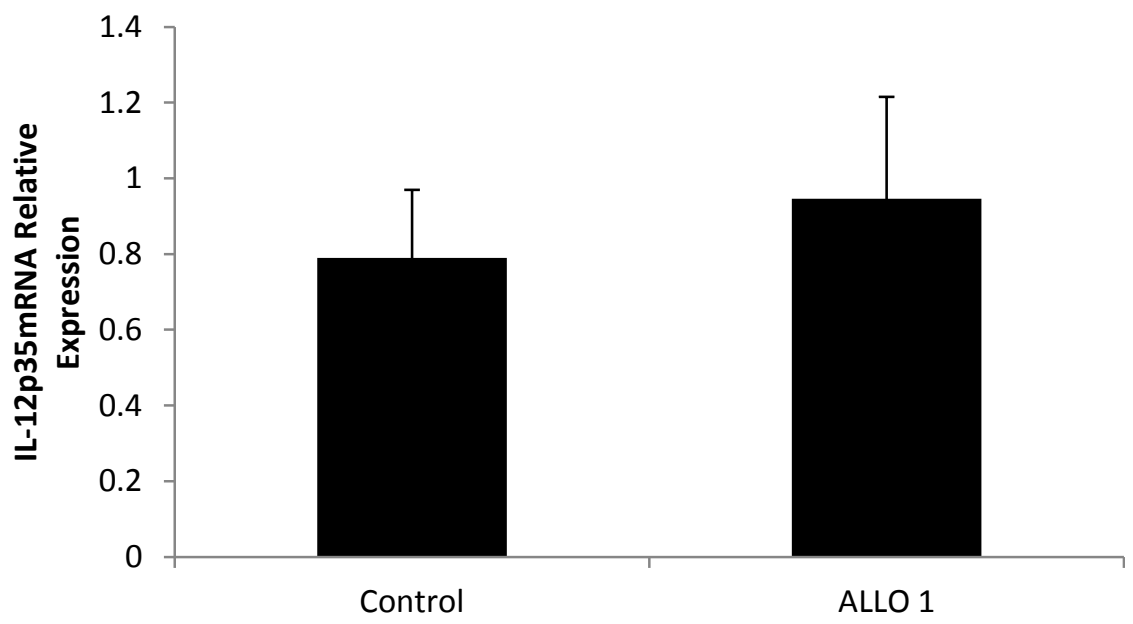

(B)

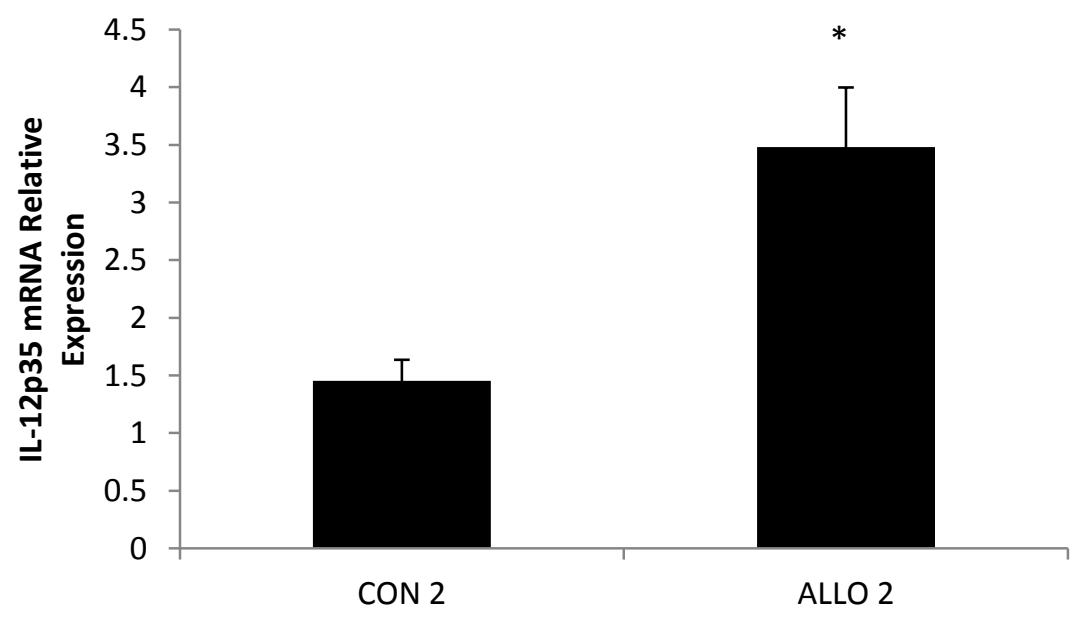


Figure 6

(A).

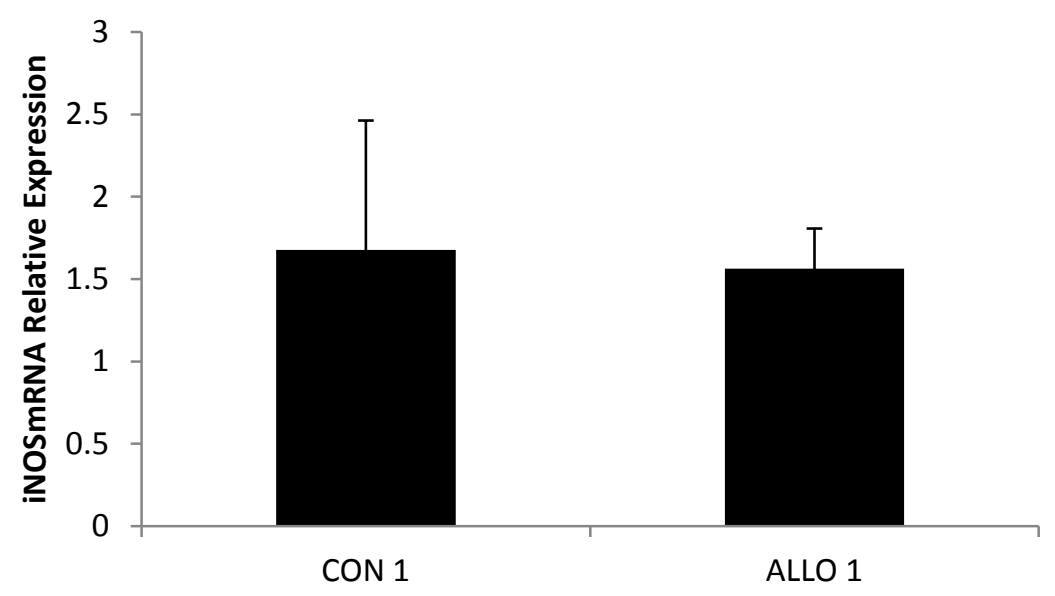

(B)

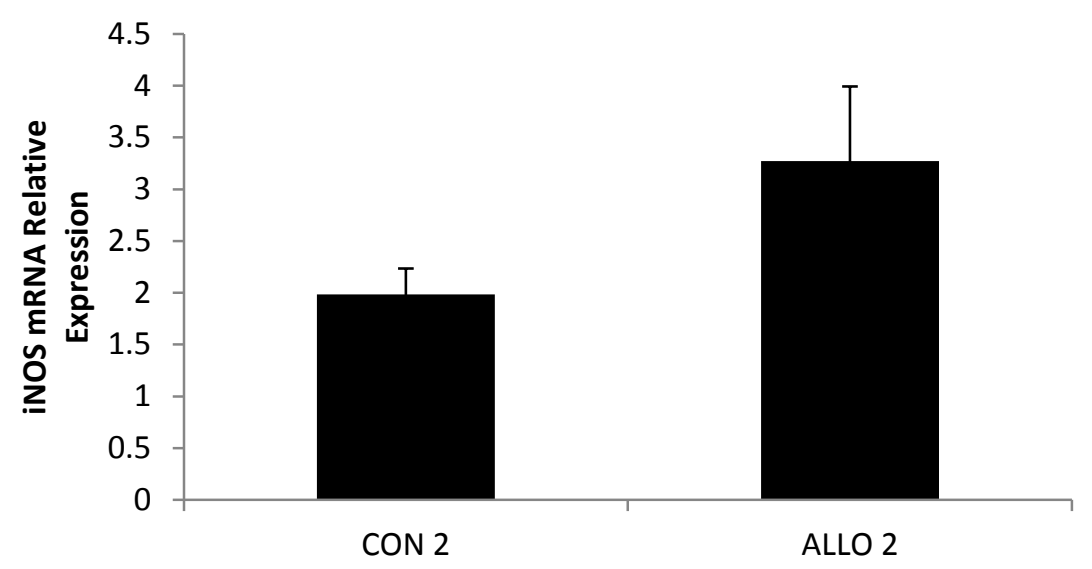


Figure 7

(A)

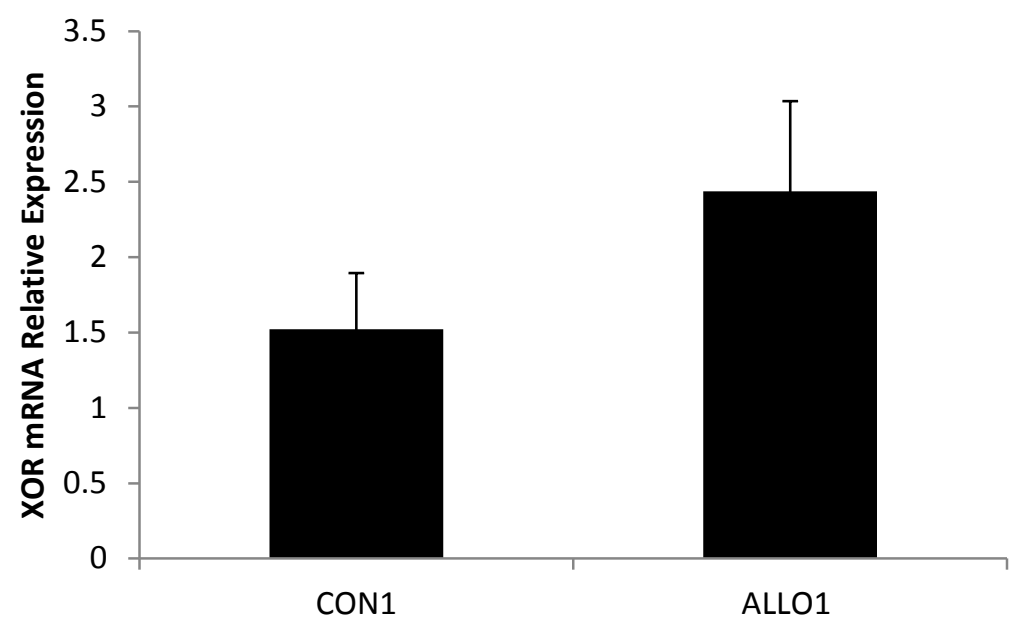

(B)

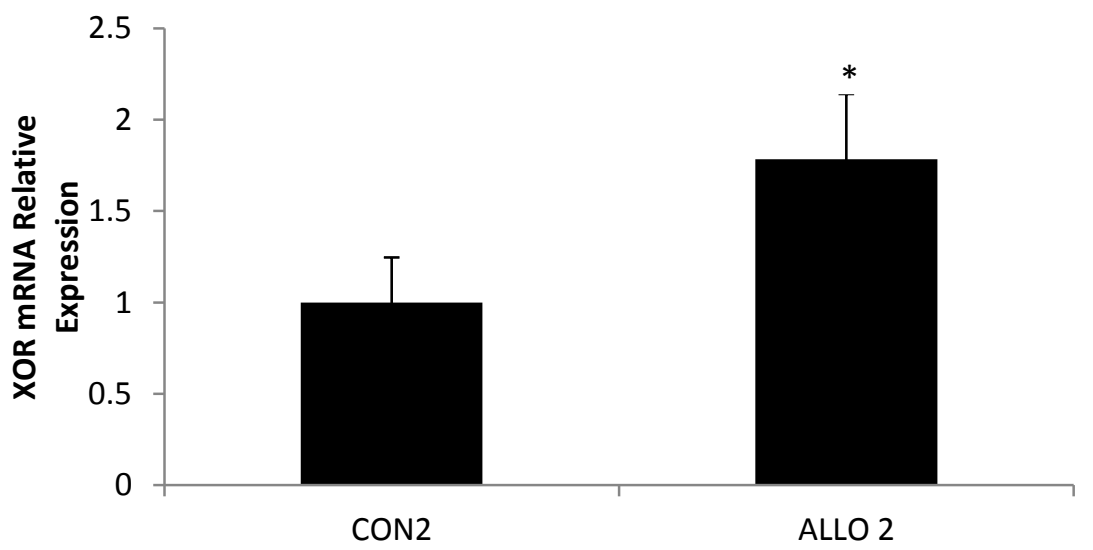




\section{CONCLUSIONS AND FUTURE STUDIES}

Based on the literature a decrease in uric acid concentrations in the plasma resulted in a subsequent increase in oxidative stress in broiler chickens. However, mitochondrial function in select tissues has not been clearly assessed for broilers outside of a pathogenic state. Our research has shown that mitochondrial function in liver tissue may be compromised when antioxidant protection by uric acid is reduced after one week of treatment with allopurinol. However, more research is required in the area to ascertain the mechanisms involved and if there are tissue differences. There may be differences in mitochondrial ROS production and function in tissues of poultry as compared to other avian species. It would be essential to establish respiration, RCR, and other indices of function over the normal production span of poultry species to provide a reference for disease states and other studies in which physiological response may be altered. Our hypothesis was that an allopurinol-induced oxidative stress model will exhibit mitochondrial dysfunction due to an increase in inflammation as well as a compensatory up-regulation of XOR in response to reduced UA. Our lab has established that after two weeks of treatment with allopurinol, there are significant increases in some inflammatory cytokines as well as XOR, however more research will be needed to establish this effect as a causation of mitochondrial dysfunction and ultimately a decline in health of the birds. The model for this research has been the broiler chicken. However, it would be of interest to explore these mechanisms in laying hen populations over time. Literature searches indicate that there are distinct differences in immune response of laying hens and broilers with respect to inflammation. The question remains if there are differences seen when production cycles are considered normal versus when uric acid is altered in laying hens. This will help to establish mechanisms that govern antioxidant protection in comparison studies between different production birds. 
Lastly, subpopulations of mitochondria have been determined for rodent cardiac tissue. It is unknown whether these exist in the avian heart or in other tissues. Subpopulations can be isolated in both broiler and laying hen heart tissue and could function differently dependent upon oxidative stress situations versus a bird not undergoing oxidative stress. Therefore, it would be pertinent to explore this concept in both varieties of production poultry. 


\section{Appendix 1. Schematic of Role of Uric Acid as an Antioxidant.}

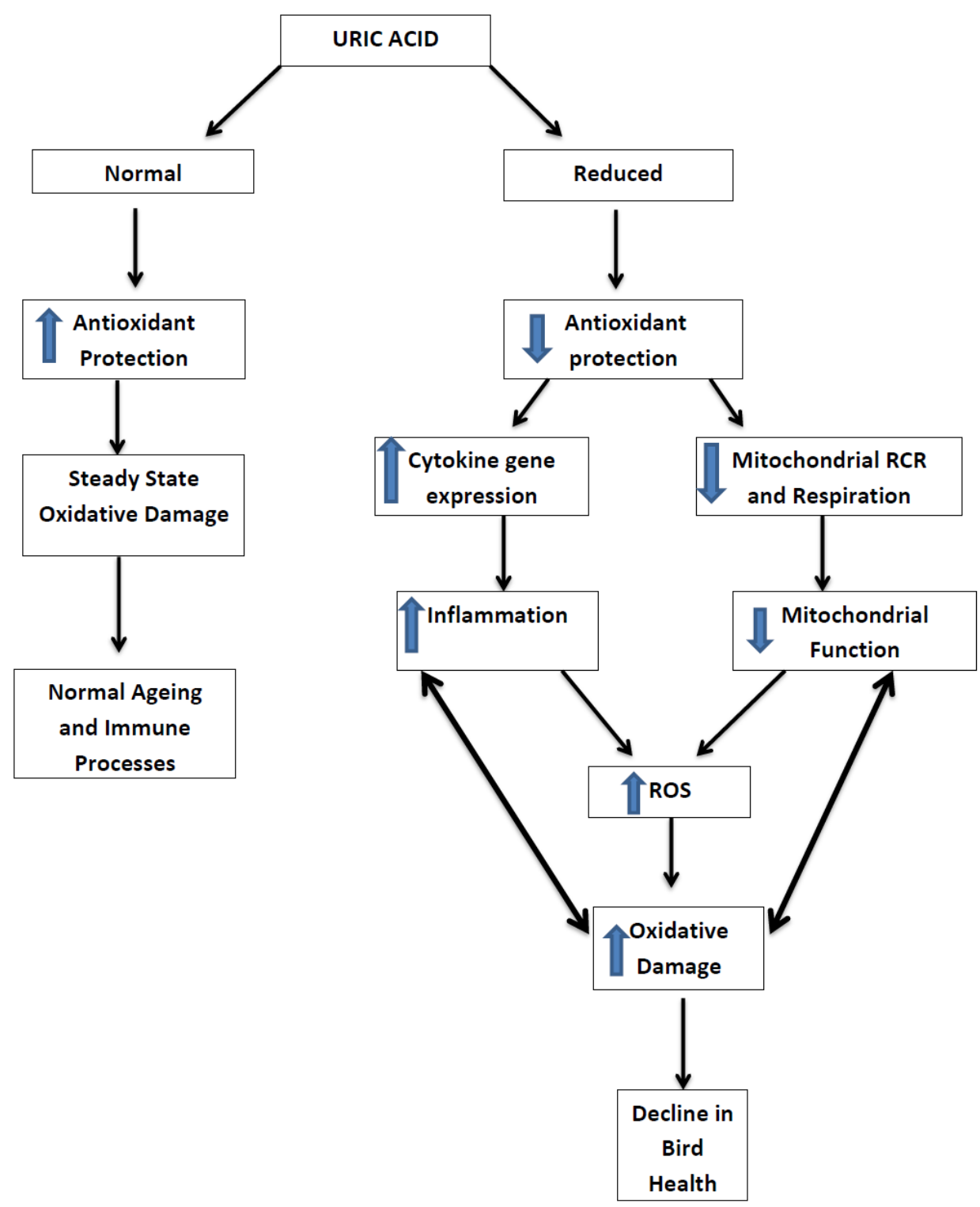

Figure 1. Schematic of the relationship of uric acid to Inflammation, Mitochondrial Function, and Oxidative Damage. When Uric acid is reduced, our studies have demonstrated an increase in inflammation and a propensity toward mitochondrial dysfunction leading to an increase in ROS production and ultimately, oxidative damage. Oxidative damage can initiate further inflammatory processes. 
Appendix 2: Starter diet. Formulated manufactured at West Virginia University Animal and Veterinary Science Farm by Dr. Joseph Moritz. Fed to chicks 0-14 days of age.

\begin{tabular}{|l|l|}
\hline Ingredients & Amount Inclusion (\%) \\
\hline Corn & 62.92 \\
\hline SBM & 32.20 \\
\hline Defl. Phosophorous & 1.53 \\
\hline Meat and Bone Meal & 1.35 \\
\hline SB oil & 0.50 \\
\hline Limestone & 0.50 \\
\hline Methionine & 0.26 \\
\hline NB3000 & 0.25 \\
\hline Salt & 0.24 \\
\hline Lysine & 0.20 \\
\hline Coban & 0.08 \\
\hline Threonine & 0.04 \\
\hline Calculated Values & \\
\hline Crude Protein (\%) & 21.54 \\
\hline Crude Fat (\%) & 3.04 \\
\hline Calcium (\%) & 0.91 \\
\hline Phosphorous (\%) & 0.72 \\
\hline & \\
\hline & \\
\hline
\end{tabular}

${ }^{1}$ Supplied per kg of diet: manganese, $0.02 \%$; zinc, $0.02 \%$; iron, $0.01 \%$; copper, $0.0025 \%$; iodine, $0.0003 \%$; selenium, $0.00003 \%$; folic acid, $0.69 \mathrm{mg}$; choline $386 \mathrm{mg}$; riboflavin, $6.61 \mathrm{mg}$; biotin $0.03 \mathrm{mg}$; vitaminB ${ }_{6}$ $1.38 \mathrm{mg}$; niacin, 27.56; pantothenic acid, $6.61 \mathrm{mg}$; thiamine,2.20mg; manadione, $0.83 \mathrm{mg}$; vitamin $B_{12}$ $0.01 \mathrm{mg}$; Vitamin E, $16.53 \mathrm{IU}$; Vitamin $\mathrm{D}_{3}, 2133 \mathrm{IU}$; Vitamin A, $7716 \mathrm{IU}$

2 Active drug ingredient Monensin Sodium $60 \mathrm{gpb}$ (90 g/ton inclusion)- Elanco Animal Health, Indianapolis, IN. Aids in the prevention of coccidiosis caused by Eimeria $s p$. 


\section{Appendix 3: Grower diet. Formulated manufactured at West Virginia University Animal and Veterinary Science Farm by Dr. Joseph Moritz. Fed to chicks 14-42 days of age .}

\begin{tabular}{|l|l|}
\hline Ingredients & Amount inclusion (\%) \\
\hline Corn & 69.51 \\
\hline SBM & 26.58 \\
\hline Defl. Phosophorous & 1.72 \\
\hline Meat and Bone Meal & 0 \\
\hline SB oil & 0.50 \\
\hline Limestone & 0.55 \\
\hline Methionine & 0.28 \\
\hline NB3000 & 0.20 \\
\hline Salt & 0.16 \\
\hline Lysine & 0.29 \\
\hline Coban & 0.08 \\
\hline Threonine & 0.08 \\
\hline Calculated Values & \\
\hline Crude Protein (\%) & 18.81 \\
\hline Crude Fat (\%) & 3.08 \\
\hline Calcium (\%) & 0.89 \\
\hline Phosphorous (\%) & 0.68 \\
\hline & \\
\hline & \\
\hline
\end{tabular}

${ }^{1}$ Supplied per kg of diet: manganese, $0.02 \%$; zinc, $0.02 \%$; iron, $0.01 \%$; copper, $0.0025 \%$; iodine, $0.0003 \%$; selenium, $0.00003 \%$; folic acid, $0.69 \mathrm{mg}$; choline $386 \mathrm{mg}$; riboflavin, $6.61 \mathrm{mg}$; biotin $0.03 \mathrm{mg}$; vitaminB 6 $1.38 \mathrm{mg}$; niacin, 27.56; pantothenic acid, $6.61 \mathrm{mg}$; thiamine, $2.20 \mathrm{mg}$; manadione, $0.83 \mathrm{mg}$; vitamin $\mathrm{B}_{12}$ $0.01 \mathrm{mg}$; Vitamin E, $16.53 \mathrm{IU}$; Vitamin $\mathrm{D}_{3}, 2133 \mathrm{IU}$; Vitamin A, $7716 \mathrm{IU}$

${ }^{2}$ Active drug ingredient Monensin Sodium $60 \mathrm{gpb}$ (90 g/ton inclusion)- Elanco Animal Health, Indianapolis, IN. Aids in the prevention of coccidiosis caused by Eimeria sp. 